\title{
LUIZ MINUZZO
}

RELAÇÃO ENTRE INIBIÇÃO DA ENZIMA DE CONVERSÃO DA ANGIOTENSINA E ELEVAÇÃO DA TROPONINA I CARDÍACA EM PACIENTES COM SÍNDROME CORONÁRIA AGUDA SEM SUPRADESNIVELAMENTO DO SEGMENTO ST

Tese apresentada ao Instituto Dante Pazzanese de Cardiologia, Entidade associada à Universidade de São Paulo para a obtenção do título em Doutor em Ciências.

Área de concentração: Medicina, Tecnologia e Intervenção em Cardiologia.

Orientador: Prof. Dr. Ari Timerman 


\section{Dados Internacionais de Catalogação na Publicação (CIP)}

Preparada pela Biblioteca do Instituto Dante Pazzanese de Cardiologia ${ }^{\odot}$ reprodução autorizada pelo autor

\section{Minuzzo, Luiz}

Relação entre inibição da enzima de conversão da angiotensina e elevação da Troponina I cardíaca em pacientes com síndrome coronária aguda sem supradesnivelamento do segmento ST / Luiz Minuzzo._São Paulo, 2013.

Tese(doutorado)--Instituto Dante Pazzanese de Cardiologia, Universidade de São Paulo.

Área de Concentração: Medicina, Tecnologia e Intervenção em Cardiologia.

Orientador: Dr. Ari Timerman

Descritores: 1. SÍNDROME CORONARIANA AGUDA. 2. INIBIDORES DE ENZIMA CONVERSORA DA ANGIOTENSINA. 3. TROPONINA I. 4. ANGINA INSTÁVEL. 
“Há um tempo em que é preciso abandonar as roupas usadas, que já têm a forma do nosso corpo, e esquecer os nossos caminhos, que nos levam sempre aos mesmos lugares. É o tempo da travessia: e, se não ousarmos fazê-la, teremos ficado, para sempre, à margem de nós mesmos"

Fernando Pessoa

"A ciência e a verdade podem residir em nós sem juízo, e este pode habitar-nos desacompanhado delas: o reconhecimento da própria ignorância é um dos mais belos e seguros testemunhos de juízo que conheço... Não procuro nos livros senão alcançar prazer mediante um divertimento honesto, ou, se estudo, não busco senão a ciência que trata do conhecimento de nós próprios, e que me ensina a morrer e a viver bem."

Michel de Montaigne 


\section{DEDICATÓRIA}

A união maravilhosa de amor de meus pais Pio e Vitalina, que me possibilitaram em um lindo dia de primavera nascer, viver, amar e conhecer este mundo.

A minha filha Carolina, cujo florescimento na primavera rejuvenesceu minha alma para a eternidade.

A minha esposa Elisângela que, com lealdade e perseverança, esteve a meu lado nas alegrias e dificuldades do dia a dia... e concebeu minha filha.

A todos meus irmãos-amigos: Pedro, Luiza, Lourdes, Vera, Antonio, Teca, Izilda, Isabel e Madalena. Poucos são aqueles que têm a proteção e a convivência com uma verdadeira fraternidade...

A todos os sobrinhos e seus filhos dessa tão grande família.

Ao amigo-irmão Marcos Paulo Pereira, pela grande amizade nos longos anos na emergência, e que hoje ora por nós em seu cantinho no Éden.

(in memoriam)

"Através da sabedoria o Senhor deitou os fundamentos da terra, através do entendimento, estabeleceu os céus no lugar, e através de seu conhecimento as profundezas foram divididas".

Provérbios 3:19-20 


\section{AGRADECIMENTOS}

A Deus, que me iluminou desde o nascimento, dando-me um lar de amor, fraternidade e esperança.

A todos os amigos que me acompanharam durante toda minha jornada, desde a infância...

A meu orientador Prof. Dr. Ari Timerman que, com paciência, sempre esteve presente para fazer as devidas observações, que por meio de sua larga experiência enriqueceu meu trabalho.

A todos os amigos do Pronto-Socorro, que estão comigo há tantos anos, em especial, à Dra. Elizabete Silva dos Santos (companheira do dia a dia); toda a equipe de enfermagem, às enfermeiras Maria Selma Pacheco Peixoto, Márcia Viana de Oliveira Klassen e Ana Paula Dias de Oliveira e a todos os auxiliares de enfermagem.

À minha secretária e amiga Therezinha de Araújo, pela dedicação e ajuda em todos esses anos de intenso trabalho na emergência.

Às secretárias do Pronto-Socorro: Márcia Lillian Figueira Pereira, Rosimeire Alves da Silva e Guilherme da Silva Ribeiro, pelo empenho e profissionalismo.

Aos funcionários do SAME do Instituto, sempre disponíveis e prestativos na aquisição de prontuários.

Aos funcionários do laboratório Maria de Lourdes Nunes Kono (bióloga chefe), Andréa Lemos de Azevedo (Técnica de Laboratório) e Roberto Enzo Nigro (Farmacêutico), na aquisição dos resultados dos exames. 
À estatística Roberta de Souza, cujo empenho e experiência delinearam minha pesquisa com acurácia.

A meu irmão Antonio que, em um momento decisivo, prestou sua consultoria técnica na elaboração do banco de dados, além dos gráficos e tabelas, e outras sugestões que engrandeceram em muito minha pesquisa.

À equipe da biblioteca: Anna Simene de Souza Leite (bibliotecária) e Claudiana Gois e Perla Aparecida dos Santos Silva (assistentes), na aquisição de periódicos e na revisão das referências bibliográficas.

Finalmente, a todos os pacientes, verdadeiros amigos, que não são apenas números nesta pesquisa, mas, a razão de nossa profissão. 


\section{SUMÁRIO}

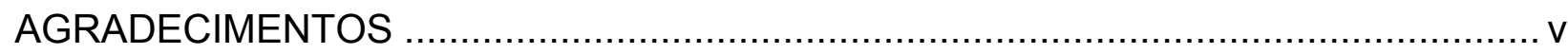

LISTA DE ABREVIATURAS, SIGLAS E ACRÔNIMOS .............................................. ix

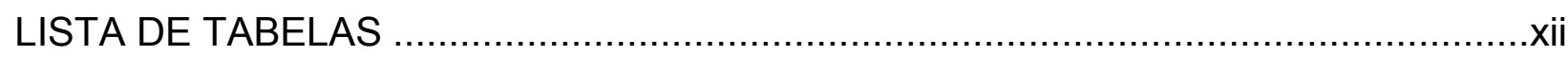

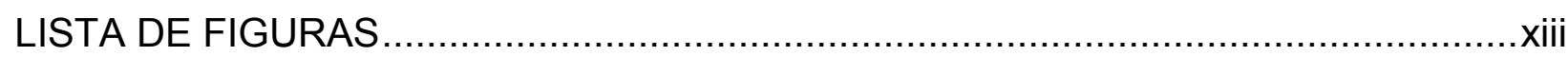

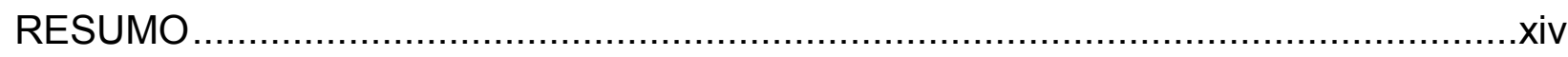

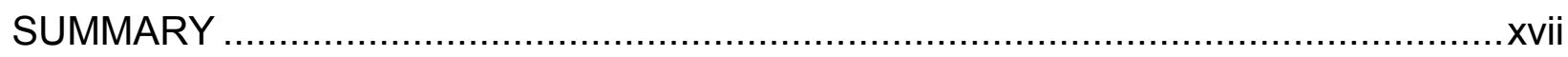

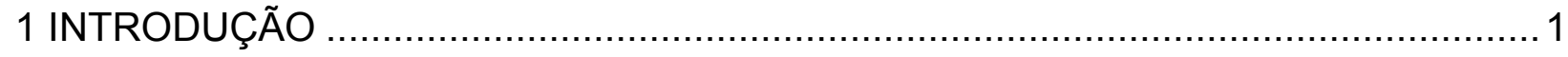

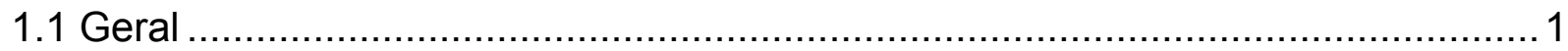

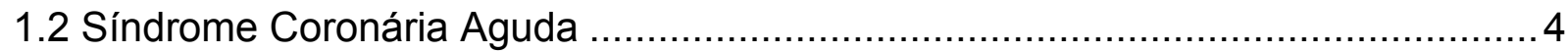

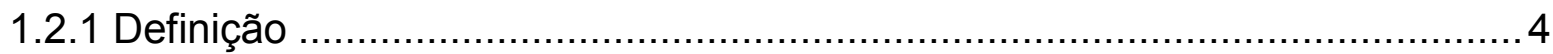

1.2.2 Implicações propositivas para este estudo .............................................. 5

1.2.3 Fisiopatologia da Síndrome Coronária Aguda ...........................................

1.3 Sistema Renina-Angiotensina-Aldosterona (SRAA) ………......................... 9

1.3.1 Funções do Sistema Renina-Angiotensina-Aldosterona ............................13

1.3.2 Importância das alterações patológicas nas estruturas cardiovasculares e sua

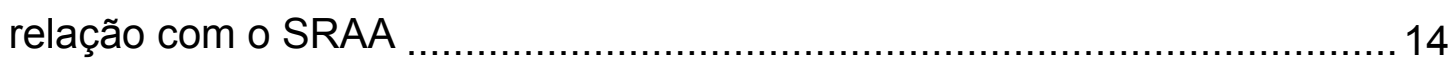

1.3.3 Inibidores da enzima de conversão da angiotensina..................................15

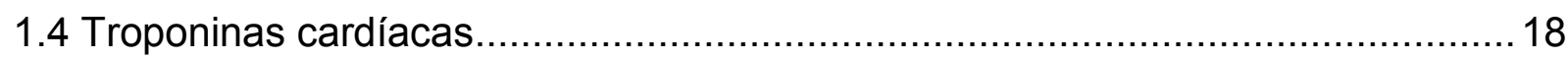

1.4.1 Estrutura e funções das troponinas ...................................................... 18

1.4.2 Troponinas - injúria miocárdica e prognóstico ......................................... 20

1.4.3 Troponina versus CK-MB atividade como marcadores prognósticos .............26

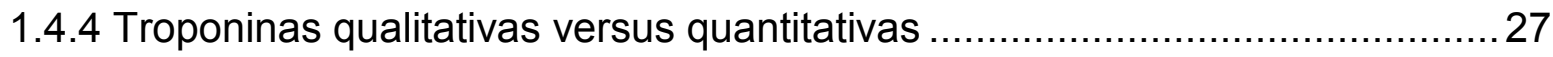

1.4.5 Atuais recomendações das troponinas para o diagnóstico de IAM ................ 35

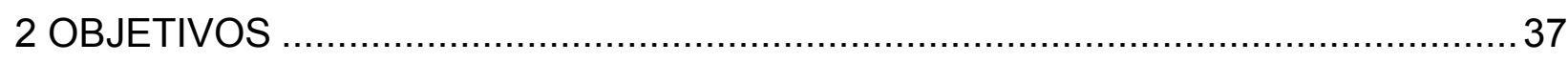

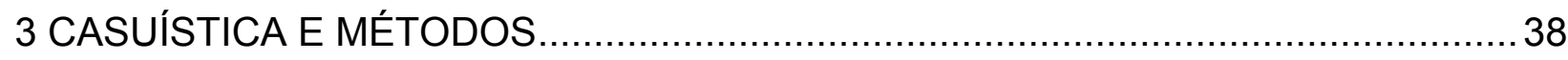

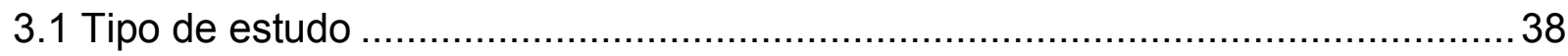


3.2 Local do estudo.

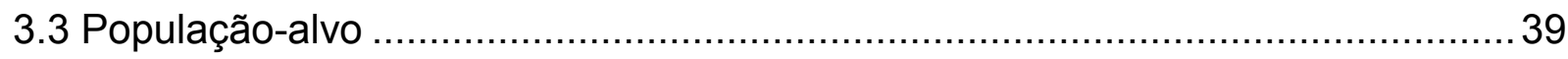

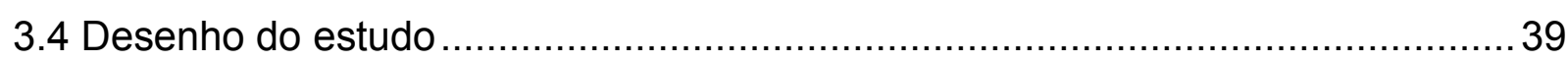

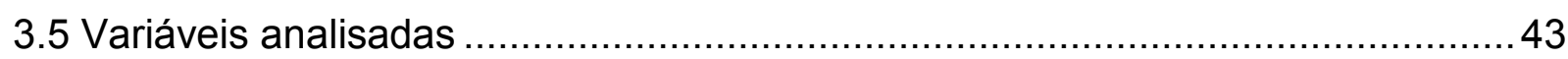

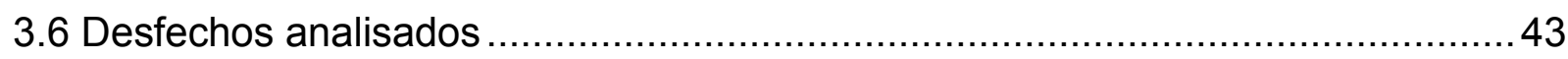

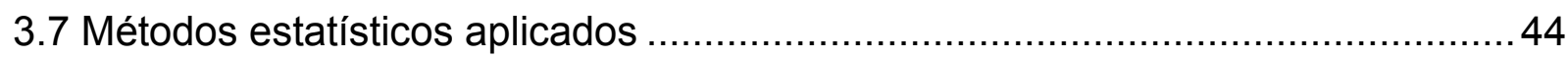

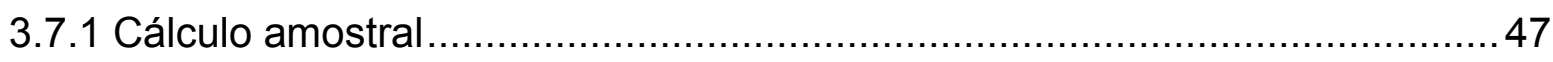

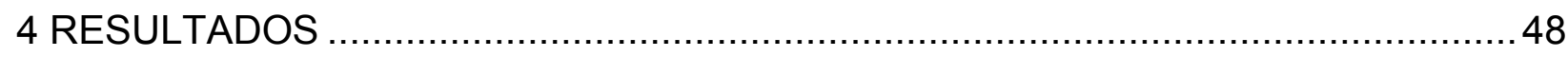

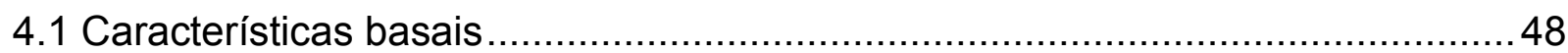

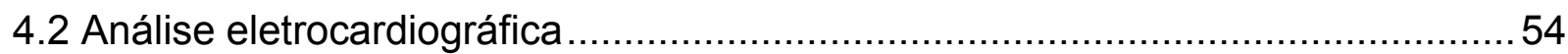

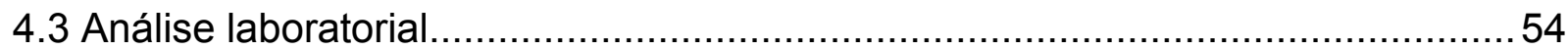

4.4 Tratamento durante a internação ........................................................... 55

4.5 Evolução no período hospitalar ..................................................... 58

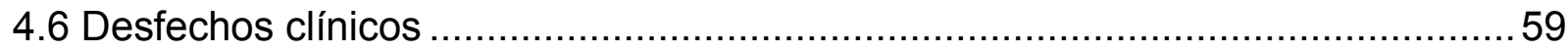

4.7 Análise estatística das variáveis selecionadas ....................................... 60

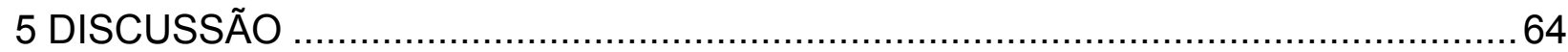

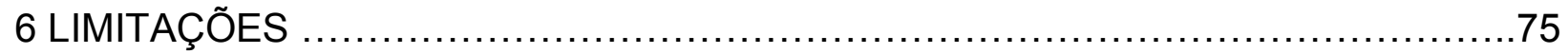

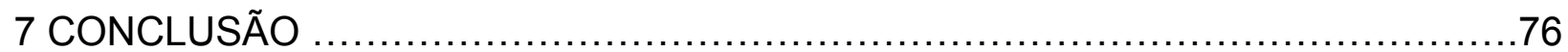

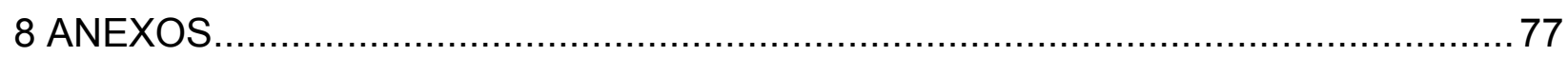

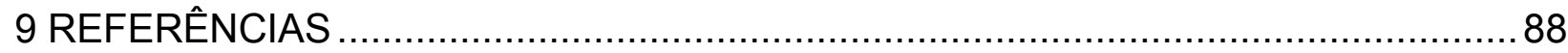




\section{LISTA DE ABREVIATURAS, SIGLAS E ACRÔNIMOS}

AAS........... Ácido acetilsalicílico

ACC.......... American College of Cardiology

AHA.......... American Heart Association

Ang I......... Angiotensina I

Ang II........ Angiotensina II

Ang IV........ Angiotensina IV

Al............. Angina instável

AT1 ........... Receptor de angiotensina I

AT2 .......... Receptor de angiotensina II

ATP........... Adenosina trifosfato

AVE.......... Acidente vascular encefálico

BRA.......... Bloqueador do receptor de angiotensina II

Cage ......... Enzima geradora de quimostatina sensível à angiotensina II

Cine........... Cineangiocoronariografia

CK-MB....... Fração MB da creatinafosfoquinase

CPK.......... Creatinafosfoquinase

CSST ........ Com supradesnivelamento do segmento ST

CRUSADE... Can Rapid Risk Stratification of Unstable Angina Patients Suppress Adverse Outcomes with Early Implementation of the ACC/AHA Guidelines (CRUSADE)

DAC ........... Doença arterial coronária

DCV........... Doenças cardiovasculares

DNC........... Doenças não-comunicáveis

DP............ Desvio-padrão

EC............ Células endoteliais 
ECA ............ Enzima de conversão da angiotensina

ECG........... Eletrocardiograma

EDTA......... Ácido etileno-diamino-tetracético

ELISA.......... Enzyme-linked immunosorbent assay

EMMACE..... Evaluation of the Methods and Management of Acute Coronary Events

EP

Erro-padrão

ESC

European Society of Cardiology

ET-1

Endotelina 1

FRISC

FRagmin during Instability in Coronary artery disease

GRACE. Global Registry of Acute Coronary Events

GUSTO Global Utilization of Streptokinase and TPA for Occluded Coronary Arteries

HAS Hipertensão arterial sistêmica

IAM Infarto Agudo do Miocárdio

IC Intervalo de confiança

ICC Insuficiência cardíaca congestiva

ICP. Intervenção coronária percutânea

IECA Inibidor da enzima de conversão da angiotensina

$\| \mathrm{Q}$ Intervalo interquartílico

MCP-1 Proteína quimioatrativa de macrófagos-1

MERLIN. Metabolic Efficiency With Ranolazine for Less Ischemia in Non-ST Elevation Acute Coronary Syndromes

NACB National Academy of Clinical Biochemistry

NO Óxido nítrico

NYHA New York Heart Association

OR Odds ratio (razão de chances)

PAI-1 Inibidor do ativador do plasminogênio-1 
PURSUIT...... Platelet glycoprotein Ilb/llla in Unstable angina: Receptor Suppression Using Integrilin (epitifibatide)

RM............. Revascularização do miocárdio

RR............. Risco relativo

SCA........... Síndrome Coronária Aguda

SPSS.......... Statistical Package for the Social Sciences

SRAA ........... Sistema renina-angiotensina-aldosterona

SST ............ Supradesnivelamento do segmento ST

SSST ........... Sem supradesnivelamento do segmento ST

TACTICS...... Treat Angina with Aggrastat and Determine Cost of Therapy with an Invasive or Conservative Strategy

TIMI............ Thrombolisis in Myocardial Infarction

TnC............ Troponina C

Tnl............. Troponina I

TnT .............. Troponina T

t-PA ............ Ativador do plasminogênio tecidual

VPN............ Valor preditivo negativo

VSMC .......... Células musculares lisas vasculares

WHF........... World Health Federation 


\section{LISTA DE TABELAS}

Tabela 1 Risco de morte ou de IAM associados com um teste de troponina positiva em pacientes com Angina Instável 24

Tabela 2 Características basais da população do estudo 49

Tabela 3 Medicamentos prévios à admissão hospitalar 50

Tabela 4 Características basais de acordo com o valor da troponina ..... 51

Tabela 5 Características basais de acordo com uso ou não uso prévio de IECA ......52

Tabela 6 Variáveis eletrocardiográficas qualitativas 54

Tabela 7 Alterações laboratoriais da população do estudo 55

Tabela 8 Medicamentos utilizados durante a internação hospitalar 56

Tabela 9 Cine na internação e tratamento realizado 57

Tabela 10 Tratamento realizado de acordo com o valor da troponina. 57

Tabela 11 Complicações durante a internação hospitalar 59

Tabela 12 Causas de óbito em até 180 dias 60

Tabela 13 Modelo inicial de troponina $>0,5 \mathrm{ng} / \mathrm{mL}$ 61

Tabela 14 Modelo final de troponina $>0,5 \mathrm{ng} / \mathrm{mL}$ 61

Tabela 15 Modelo inicial de óbito em 180 dias. 62

Tabela 16 Modelo final de óbito em 180 dias 63 


\section{LISTA DE FIGURAS}

Figura 1. Taxa de incidência de IAM ajustada para idade e gênero: 1999-2008 - EUA .2

Figura 2. Uso prévio de medicação em pacientes com SCASSST: 1999-2008 - EUA ...2

Figura 3. Tendências recentes na mortalidade por doenças não-comunicáveis: 1996, 2000 e 2007- Brasil 3

Figura 4. Razão de chance ajustada para mortalidade em 30 dias: 2000-2008 - EUA ..3

Figura 5. Representação esquemática da fisiopatologia da SCASSST 6

Figura 6. Trombose por erosão 7

Figura 7. Trombose por ruptura 7

Figura 8. Vias clássica e alternativa da formação de angiotensina II 12

Figura 9. Angiotensina II e sua relação com o processo aterosclerótico 12

Figura 10. Principais efeitos da angiotensina II e dos mecanismos mediadores não hemodinâmicos 14

Figura 11. Esquema do sistema contrátil das troponinas .20

Figura 12. Liberação temporal de mioglobina, CK-MB e Troponinas, após IAM 22

Figura 13. Eventos clínicos até 14 dias estratificados pela mensuração da Troponina I

Figura 14. Taxa de mortalidade aos 42 dias de acordo com os níveis de Troponina I..24

Figura 15. Troponinas cardíacas são preditoras em angina instável. .25

Figura 16. Curva de Kaplan-Meier: estimativa de sobrevida durante o primeiro ano para pacientes com dosagem de Troponina $\mathrm{T}$ .25

Figura 17. Depressão do segmento ST e troponinas são preditoras em SCASSST .....25

Figura 18. Fluxograma do desenho da pesquisa. .42 


\section{RESUMO}

Minuzzo L. Relação entre inibição da enzima de conversão da angiotensina e elevação da troponina I cardíaca em pacientes com Síndrome Coronária Aguda sem supradesnivelamento do segmento ST [tese]. São Paulo. Instituto Dante Pazzanese de Cardiologia, Universidade de São Paulo; 2013. 101p.

INTRODUÇÃO: O tratamento da Síndrome Coronária Aguda (SCA) sem supradesnivelamento do segmento ST (SSST) sofreu grandes avanços nos últimos 20 anos, com a introdução de novos medicamentos e intervenções invasivas, que reduziram significativamente os eventos clínicos graves como morte e re(infarto), em curto, médio e longo prazos, a despeito dessa entidade ainda representar uma alta taxa de mortalidade no mundo ocidental. Entre os medicamentos, os inibidores da enzima conversora da angiotensina (IECA) tiveram um papel fundamental, demonstrando redução desses eventos em pacientes com alto risco cardiovascular. Nesse período, as troponinas cardíacas consolidaram-se como os biomarcadores de necrose miocárdica de escolha para o diagnóstico e avaliação prognóstica nesses pacientes, devido às suas altas sensibilidade e especificidade. OBJETIVO: Determinar o papel da inibição da enzima de conversão da angiotensina na elevação da troponina I cardíaca em pacientes com SCASSST, e avaliar os desfechos clínicos em até 180 dias. CASUÍSTICA e MÉTODOS: Estudo prospectivo, observacional, em um único centro de cardiologia, realizado entre 8 de setembro de 2009 e 10 de outubro de 2010, com 457 pacientes, consecutivamente internados no Pronto-Socorro com SCASSST. Os pacientes deveriam apresentar sintomas isquêmicos agudos, nas últimas 48 horas. Foram excluídos os que demonstrassem elevação do segmento ST, ou qualquer alteração confundidora ao ECG, como ritmo de marca-passo, bloqueio de ramo 
esquerdo ou fibrilação atrial. Foram selecionados para análise exploratória, dados de história clínica, exame físico, eletrocardiográficos e laboratoriais, com ênfase à troponina I cardíaca. As variáveis com nível de significância menor que 10\% nesta análise, foram submetidas a um modelo de regressão logística múltipla. RESULTADOS: Na população estudada, observou-se que a idade média era de 62,1 anos $(\mathrm{DP}=11,04)$ e 291 pacientes $(63,7 \%)$ do gênero masculino. Fatores de risco como hipertensão arterial sistêmica $(85,3 \%)$ e dislipidemia $(75,9 \%)$ foram os mais prevalentes, além da presença de SCA prévia em 275 (60,2\%) pacientes; com 49,5\% dos pacientes já submetidos a alguma revascularização prévia (Intervenção Coronária Percutânea(ICP) ou Revascularização do Miocárdio(RM)), além de 35,0\% de diabéticos. $\mathrm{Na}$ avaliação de eventos em 180 dias, ocorreram 28 óbitos (6,1\%): 11 por choque cardiogênico, 8 por infarto agudo do miocárdio, 3 por choque séptico, além de outras causas. Foi elaborado um modelo de análise estatística, onde foram analisadas as variáveis que interferiam com a liberação de troponina. Por esse modelo, observouse que os antecedentes pessoais de diabete melito e angina estável reduziam as chances da troponina ser maior que $0,5 \mathrm{ng} / \mathrm{mL}$ em $50,2 \% \quad(p=0,0419)$ e $71,5 \%$ $(p<0,001)$, respectivamente; cada $1 \mathrm{mg} / \mathrm{dL}$ a mais na glicemia de admissão, aumentava a chance da troponina ser maior que $0,5 \mathrm{ng} / \mathrm{mL}$ em $0,8 \%(p=0,0034)$; o uso de IECA previamente à internação reduzia a chance da troponina ser maior que $0,5 \mathrm{ng} / \mathrm{mL}$ em $40,6 \%(p=0,0482)$ e a presença de infradesnivelamento do segmento ST igual ou maior a $0,5 \mathrm{~mm}$, em uma ou mais derivações, aumentava a chance da troponina ser maior que $0,5 \mathrm{ng} / \mathrm{mL}$ em 2,6 vezes ( $p=0,0016)$. A estatística $C$ para este modelo foi de 0,77 .

CONCLUSÃO: Os dados apresentados nesta pesquisa em um centro terciário de cardiologia, demonstraram uma relação inequívoca entre o uso de IECA e a redução do marcador de necrose miocárdica troponina I cardíaca, utilizado como medida 
qualitativa, porém, ainda não há dados disponíveis para se afirmar se esta redução poderia levar a um número menor de eventos clínicos graves como morte e re(infarto), no período de 180 dias.

DESCRITORES: 1. Síndrome coronariana aguda. 2. Inibidores de enzima conversora da angiotensina. 3. Troponina I. 4. Angina instável. 


\section{ABSTRACT}

Minuzzo L. Relationship between angiotensin-converting enzyme inhibition and increased levels of cardiac troponin I in patients with non-ST elevation acute coronary syndrome [thesis]. São Paulo. Instituto Dante Pazzanese de Cardiologia, Universidade de São Paulo; 2013. 101p.

INTRODUCTION: The last 20 years have seen great advances in the management of non-ST elevation acute coronary syndrome (NSTE-ACS). The introduction of novel drugs and invasive interventions significantly reduced major clinical events such as death and (re)infarction in the short, medium and long term. Yet, mortality rates remain high in the Western world. Among these drugs, angiotensin-converting enzyme (ACE) inhibitors have played a critical role in reducing these events in patients at high cardiovascular risk. In the meantime, cardiac troponins became firmly established as the myocardial necrosis biomarkers of choice to make the diagnosis and prognosis of these patients, due to their high sensitivity and specificity. OBJECTIVE: The purpose of this study was two-fold: to determine the role of angiotensin-converting enzyme (ACE) inhibition in cardiac troponin I elevation in patients with NSTE-ACS, and to assess the clinical outcomes up to 180 days. PATIENTS AND METHODS: This was a prospective, observational study conducted at a single tertiary cardiology center from September 8, 2009 to October 10, 2010 with 457 consecutive patients admitted to the emergency department for NSTE-ACS. Only patients with acute ischemic symptoms within the past 48 hours were included in the study. Those with ST-segment elevation or any confounding ECG factor, such as pacemaker rhythm, left bundle branch block, or atrial fibrillation, were excluded. Study population underwent exploratory analysis, clinical history, physical examination, ECG, and laboratory tests, particularly for cardiac 
troponin I. Variables with a significance level less then $10 \%$ were entered into a multiple logistic regression model. RESULTS: The mean age of the study population was 62.1 years $(S D=11.04)$, and 291 patients $(63.7 \%)$ were male. Risk factors such as hypertension (85.3\%) and dyslipidemia (75.9\%) were the most prevalent, followed by previous ACS in 275 (60.2\%) patients; $49.5 \%$ of the patients had already undergone previous revascularization procedures (either percutaneous coronary intervention $[\mathrm{PCl}]$ or coronary artery bypass grafting [CABG]). Diabetes was present in $35 \%$ of the patients. At the 180-day assessment, 28 patients (6.1\%) had died: 11 as a result of cardiogenic shock, 8 of acute myocardial infarction, and 3 of septic shock, among other causes. In this study, a statistical model was developed to determine which variables affected troponin release. This model showed that history of diabetes mellitus and stable angina reduced the likelihood of troponin being higher than $0.5 \mathrm{ng} / \mathrm{mL}$ by $50.2 \%$ $(p=0.0419)$ and $71.5 \%(p<0.001)$, respectively; each $1 \mathrm{mg} / \mathrm{dL}$ increase in admission blood glucose increased the likelihood of troponin being higher than $0.5 \mathrm{ng} / \mathrm{mL}$ by $0.8 \%$ $(p=0.0034)$; the use of ACE inhibitors prior to admission reduced the likelihood of troponin being higher than $0.5 \mathrm{ng} / \mathrm{mL}$ by $40.6 \%(\mathrm{p}=0.0482)$, and the presence of STsegment depression $\geq 0.5 \mathrm{~mm}$ in one or more ECG leads increased 2.6 times the likelihood of troponin being higher than $0.5 \mathrm{ng} / \mathrm{mL}(p=0.0016)$. The C-statistic for this model was 0.77 . CONCLUSION: The data from this study conducted at a tertiary cardiology center show an unequivocal relationship between the use of ACE inhibitors and decreased levels of cardiac troponin I, a biomarker of myocardial necrosis used as a qualitative measure. However, there is no available data to determine whether or not this decrease would result in a lower number of major clinical events, such as death and re(infarction) within 180 days. 
DESCRIPTORS: 1. Acute coronary syndrome. 2. Angiotensin-converting enzyme inhibitors. 3. Troponin I. 4. Unstable angina. 


\section{INTRODUÇÃO}

\subsection{Geral}

No mundo ocidental, as doenças cardiovasculares constituem a principal causa de morte, tanto em países desenvolvidos como naqueles em desenvolvimento ${ }^{1,2}$, atingindo um custo altíssimo, tanto em termos de tratamento como em suas consequências clínicas, como insuficiência cardíaca, arritmias cardíacas e morte súbita, além de causar um impacto social expressivo ${ }^{2,3,4}$.

Registros recentes demonstram que cerca de 1 milhão de pessoas são hospitalizadas nos Estados Unidos da América (EUA) por Síndrome Coronária Aguda (SCA) sem supradesnivelamento do segmento ST (SSST) ${ }^{5,6}$; representando um espectro que inclui pacientes com angina instável e infarto agudo do miocárdio (IAM) sem elevação do segmento ST; notando-se um aumento na prevalência de SCASSST em comparação à SCA com supradesnivelamento do segmento ST (CSST) ${ }^{7}$ (Figura 1); provavelmente pelo aumento da população de idosos, diabéticos e à maior predominância de mulheres $^{8}$, observando-se um aumento considerável no binômio obesidade-diabetes em pacientes mais jovens, inclusive antecipando em 3 anos o primeiro episódio de SCASSST ${ }^{9}$. Isto tudo frente a uma gradativa taxa de redução de tabagistas a cada ano, tanto no Brasil $^{2}$ como nos países desenvolvidos ${ }^{10}$.

É importante destacar outros fatores na maior prevalência de SCASSST, como o aumento no uso de medicamentos utilizados na prevenção de doenças cardiovasculares - betabloqueadores, inibidores da enzima de conversão da 
angiotensina, bloqueadores dos receptores de angiotensina II, tienopiridínicos e estatinas $^{7}$ (Figura 2) - além de um aumento no diagnóstico e admissão hospitalar desses pacientes, realizados pela presença de marcadores de necrose miocárdica, em especial, pelas troponinas de alta sensibilidade ${ }^{11}$.

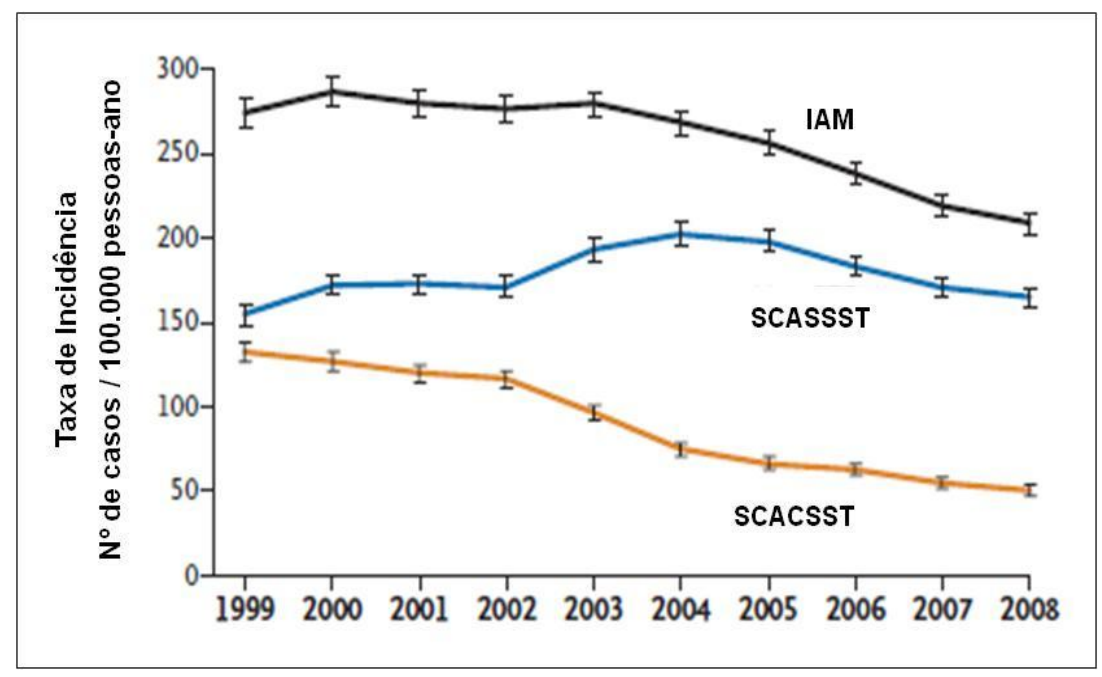

Figura 1. Taxa de incidência de IAM ajustada para idade e gênero: 1999-2008 - EUA ${ }^{7}$ Notas: Barras I representam intervalos de confiança $=95 \%$; IAM=Infarto Agudo do Miocárdio; SCASSST=Síndrome Coronária Aguda sem supradesnivelamento do segmento ST; SCACSST=Síndrome Coronária Aguda com supradesnivelamento do segmento ST.

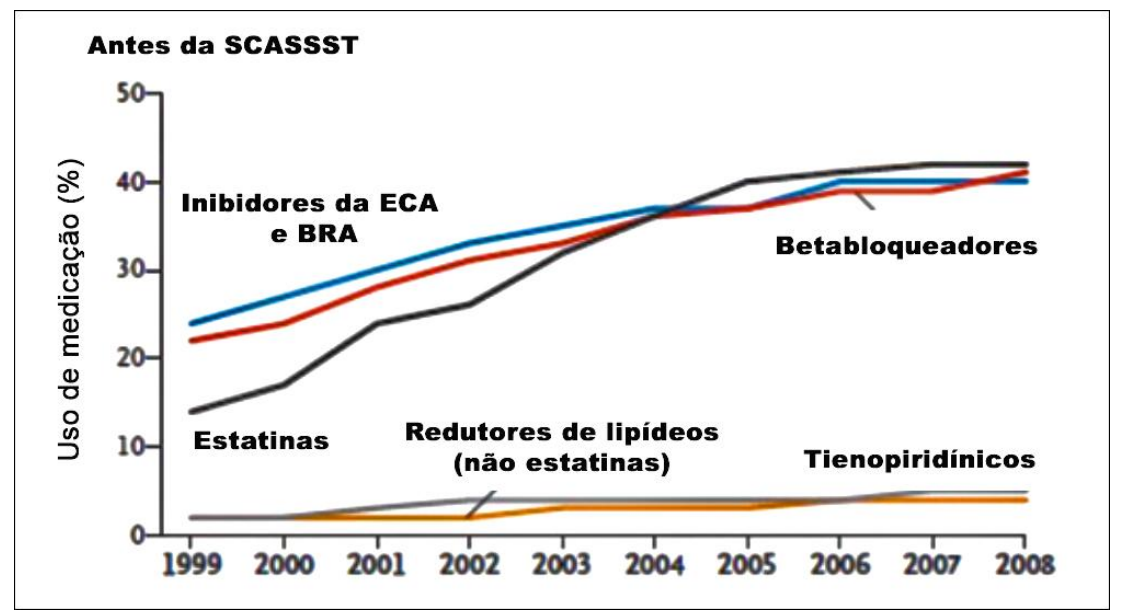

Figura 2. Uso prévio de medicação em pacientes com SCASSST: 1999-2008 - EUA ${ }^{7}$ Notas: ECA=enzima de conversão da angiotensina; BRAs=bloqueadores do receptor de angiotensina II; SCASSST=Síndrome Coronária Aguda sem supradesnivelamento do segmento ST . 
No Brasil, atualmente, cerca de $30 \%$ das mortes são causadas por doenças cardiovasculares ${ }^{2,3}$, com uma redução nos últimos anos, fato esse derivado da melhora de prevenção primária e secundária praticada por profissionais da saúde, resultando em um maior controle de riscos cardiovasculares, verificados em nosso país e EUA ${ }^{2,7,12}$ (Figuras 3 e 4).

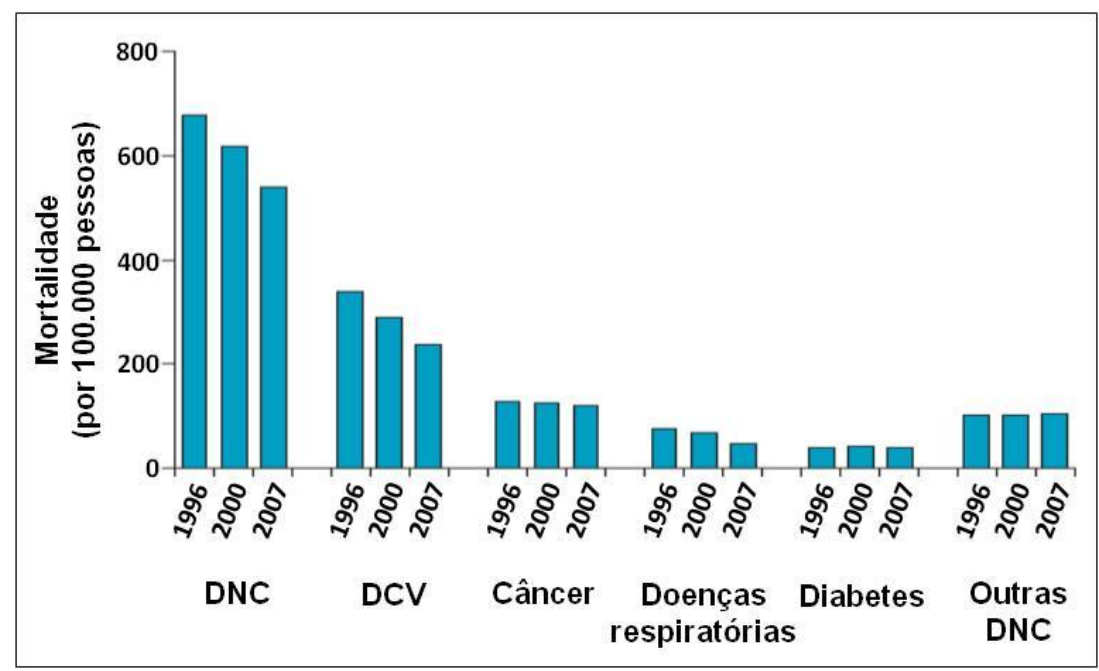

Figura 3. Tendências recentes na mortalidade por doenças não-comunicáveis: 1996, 2000 e 2007-Brasil ${ }^{2}$

Notas: DNC=doenças não-comunicáveis; DCV=doenças cardiovasculares.

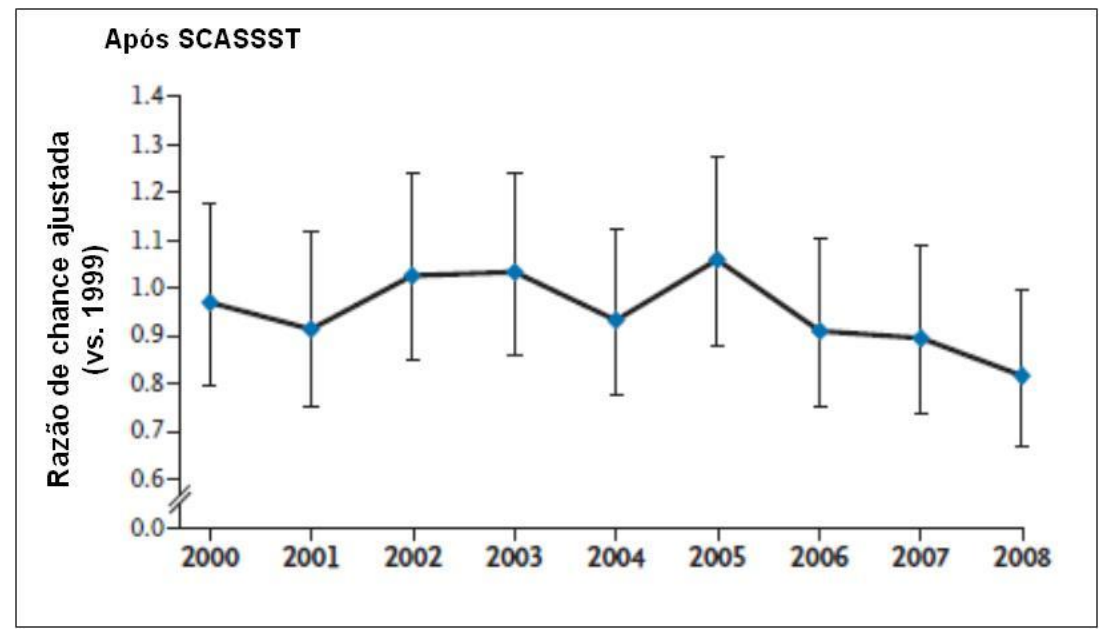

Figura 4. Razão de chance ajustada para mortalidade em 30 dias: 2000-2008 - EUA ${ }^{7}$ Notas: Barras I representam intervalos de confiança=95\%; IAM=Infarto Agudo do Miocárdio; SCASSST=Síndrome Coronária Aguda sem supradesnivelamento do segmento ST. 


\subsection{Síndrome Coronária Aguda}

\subsubsection{Definição}

A SCA envolve uma constelação de sinais e sintomas que são compatíveis com isquemia miocárdica aguda. O termo Síndrome Coronária Aguda (SCA) apareceu no ACC/AHA Guidelines for the Management of Patients With Unstable Angina and NonST-Segment Elevation Myocardial Infarction, publicado em $2000^{13}$. Ainda nesse contexto, a Sociedade Europeia de Cardiologia e o Colégio Americano de Cardiologia redigiram um documento consensual para a redefinição de IAM, corroborando os trabalhos prévios e enfatizando a elevação dos marcadores de necrose miocárdica, com ênfase à troponina e sua relação com implicações prognósticas mais desfavoráveis ${ }^{14}$. Posteriormente, Hamm e cols. em um trabalho de Saúde Pública, reconheceram a importância da utilização das diretrizes no diagnóstico, estratificação de risco e tratamento, com a implementação das novas terapias antiplaquetárias (clopidogrel e inibidores de glicoproteínas IIb/llla) e antitrombóticas (heparinas de baixo peso molecular), aliados ao papel da abordagem invasiva precoce ${ }^{15}$. Finalmente em 2007, uma força tarefa publicou um artigo intitulado: "Definição Universal de Infarto do Miocárdio", pela Sociedade Europeia de Cardiologia, o Colégio Americano de Cardiologia, a Associação Americana de Cardiologia e a Federação Mundial de Cardiologia, definindo os novos critérios para IAM, por meio de uma nova classificação ${ }^{16}$. 


\subsubsection{Implicações propositivas para este estudo}

Com base na importância dessa patologia no cenário mundial, todos os pacientes com dor torácica sugestiva de origem isquêmica - no período estipulado pelo estudo - submeteram-se a uma avaliação no Pronto-Socorro, inicialmente, por meio de uma anamnese completa, seguida de um eletrocardiograma e uma coleta laboratorial, incluindo os marcadores de necrose miocárdica. Naqueles submetidos à internação hospitalar, procedeu-se a uma estratificação de risco precoce pelo escore de risco TIMI $^{17}$ recomendado pelas diretrizes nacionais ${ }^{18}$ e internacionais ${ }^{6}$, implicando diretamente na estratégia terapêutica a ser aplicada em determinado paciente, podendo ser mais conservadora ou mais agressiva ${ }^{6,19,20}$.

Nesse contexto, este estudo considerou as variáveis clínicas, eletrocardiográficas e laboratoriais, com ênfase na utilização de medicamentos prévios à internação hospitalar, em especial, o uso de inibidores de enzima de conversão da angiotensina e seu potencial para inibição dos níveis de troponina I cardíaca em pacientes com SCASSST.

\subsubsection{Fisiopatologia da Síndrome Coronária Aguda}

A doença aterosclerótica é uma inflamação crônica que se inicia na mais tenra idade $^{21}$, que a depender de vários fatores de risco e condições associadas ${ }^{22}$, poderá 
levar à formação de placas que poderão romper-se levando a eventos cardiovasculares como angina, IAM, acidente vascular encefálico (AVE) ou morte súbita ${ }^{23}$ (Figura 5).

Com a progressão da doença arterial coronária (DAC), poderá ocorrer uma súbita redução do fluxo sanguíneo coronário em decorrência da formação de dois principais tipos morfológicos de placas ateroscleróticas: ruptura - 59\% a $75 \%$ de casos de trombose aguda - ou erosão - $36 \%$ a $44 \%$ dos casos, além de raros casos de nódulos calcificados ${ }^{24,25}$, conforme demonstração esquemática dessas alterações na Figura 5 e, do ponto de vista anatomopatológico, nas Figuras 6 e 7, respectivamente ${ }^{26}$.

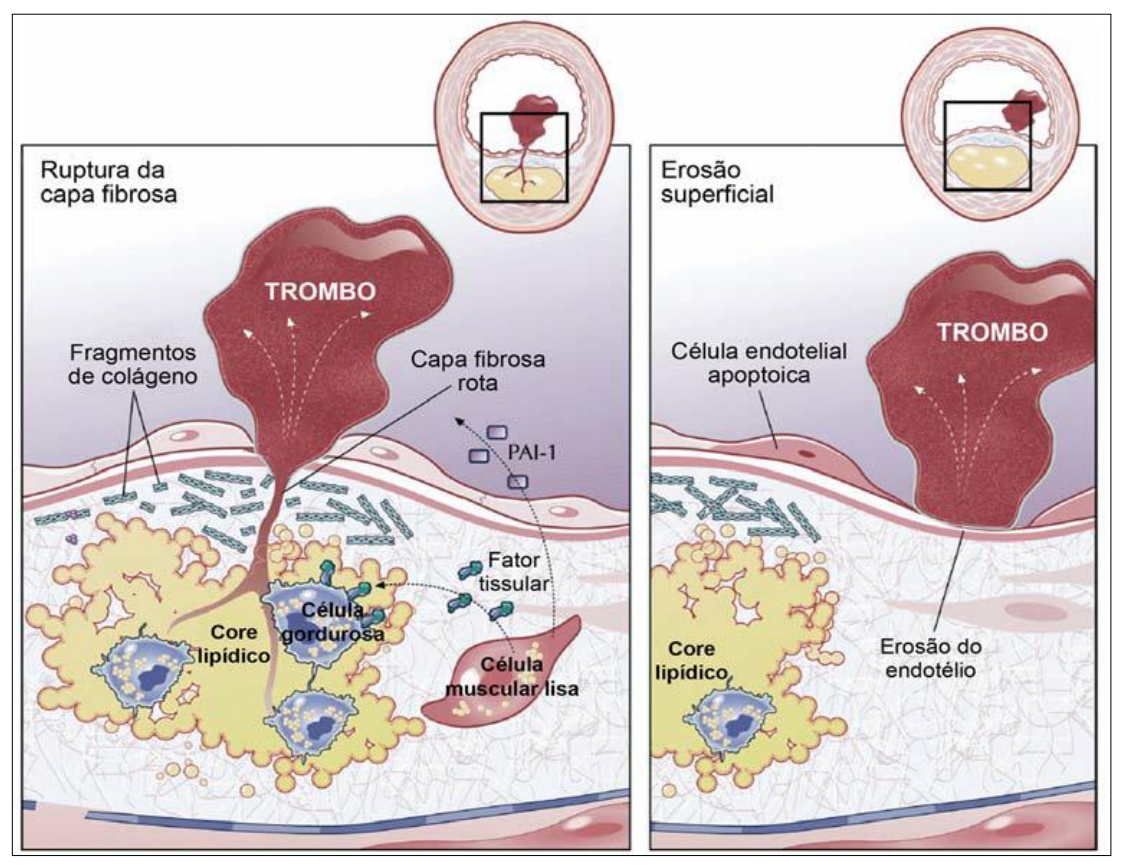

Figura 5. Representação esquemática da fisiopatologia da SCASSST. ${ }^{23}$ 


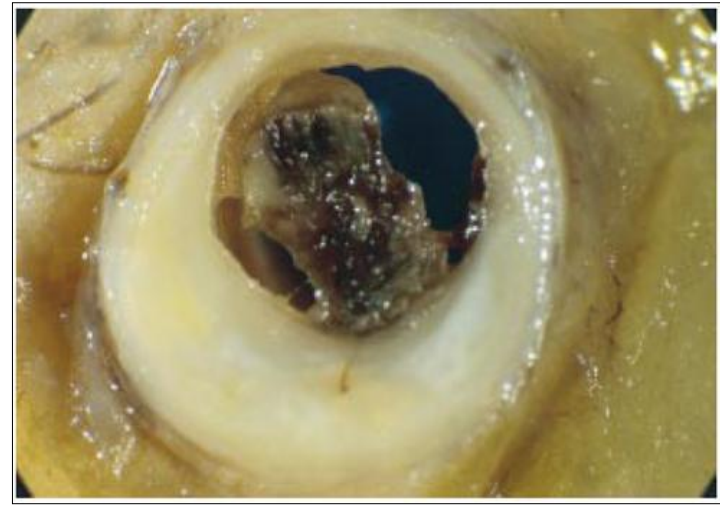

Figura 6. Trombose por erosão - A artéria coronária está ocluída por um trombo que está aderido à superfície da placa, que se encontra intacta ${ }^{26}$

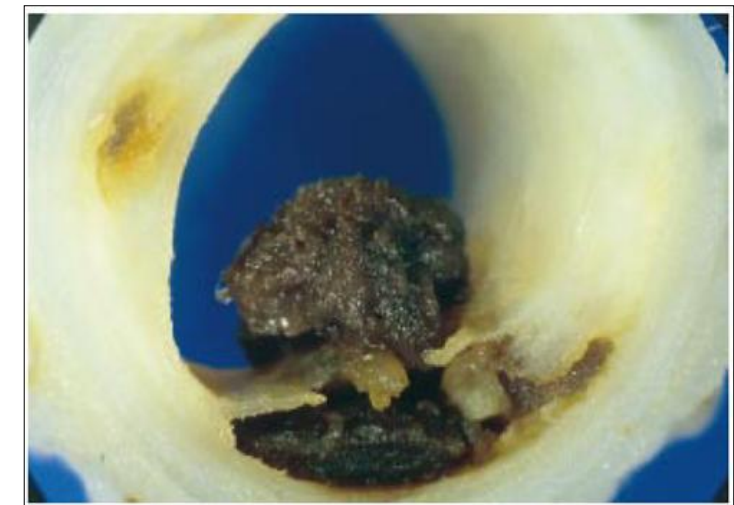

Figura 7. Trombose por ruptura - A capa da placa está rota e projeta-se para dentro da luz arterial. O trombo forma-se com o núcleo lipídico que se projeta para dentro da luz, sem oclui-la totalmente. Típica lesão de SCASSST $^{26}$

Outras situações envolvem um estreitamento progressivo da luz arterial por aterosclerose avançada; vasoespasmo em um segmento estreito da artéria coronária; uma inflamação localizada na artéria que pode levar a um estreitamento com desestabilização de uma placa de ateroma, seguida de ruptura e trombose; além de condições que aumentem a demanda por oxigênio miocárdico, como por exemplo, na febre ou tireotoxicose; casos que diminuam a oferta de oxigênio como na anemia profunda; ou ainda que diminuam o fluxo sanguíneo coronário, caso de hipotensão arterial sistêmica e raros casos de dissecção coronária. Outros mecanismos de trombose ocorrem sem a presença de placas ateromatosas, como em portadores de condições pró-trombóticas, como a síndrome antifosfolípide, além de gravidez, tabagismo e pacientes em uso de contraceptivos orais.

O cenário mais frequente é o determinado pela placa de "alto-risco" ou vulnerável propensa à ruptura ${ }^{26}$. Sob condições apropriadas, a capa fibrosa protetora sobre uma lesão ateromatosa pode romper-se, expondo o núcleo lipídico trombogênico aos fatores de coagulação e às plaquetas, levando à trombose. Nesses pacientes, 
observa-se também a ocorrência de microembolização de agregados plaquetários e de outros componentes advindos da ruptura da placa que são os responsáveis pela liberação de marcadores de necrose miocárdicos. As placas que se rompem apresentam características morfológicas comuns: capa fibrosa delgada, uma população abundante de macrófagos, uma quantidade escassa de células musculares lisas e um núcleo lipídico extracelular amolecido (Figura 5$)^{23}$.

Mas, as circunstâncias que levam à ruptura são complexas e ainda não completamente elucidadas, e sabe-se que uma combinação de fatores inflamatórios e mecânicos (estresse) são primordiais para o evento.

A capa fibrosa é uma estrutura metabolicamente ativa, submetida constantemente à síntese e à degradação de colágeno e de outros componentes da matriz extracelular. Citocinas e células inflamatórias, sobretudo os macrófagos e linfócitos T controlam o nível de colágeno e a integridade mecânica da capa fibrosa. Portanto, qualquer desregulação desse controle, geralmente, mediada por inflamação, pode levar a um desbalanço na síntese de colágeno, criando áreas com quantidades menores dos mesmos, assim sujeitas à ruptura. Estas células e as enzimas por elas produzidas são responsáveis pelos efeitos deletérios na composição da matriz extracelular. O processo, ocorrendo na junção da placa de ateroma com a região de vaso normal ("ombro da placa") e adjacente ao núcleo lipídico, torna-se o local onde mais frequentemente ocorrem as rupturas. Estas provocam trombose por alguns caminhos: 1) por meio do contato com o colágeno na matriz extracelular da placa podendo promover a ativação plaquetária, 2) por meio da produção de fator tecidual por macrófagos e células musculares lisas que ativam a cascata de coagulação. Os dois mecanismos interagem para a perpetuação do processo. 
Neste cenário, há uma intensa reação inflamatória aliada a um processo hemostático, levando à ruptura/erosão da placa, que depende de outros fatores de risco e condições associadas para ocorrência do evento coronariano agudo como angina, IAM, AVE ou morte súbita.

\subsection{Sistema Renina-Angiotensina-Aldosterona (SRAA)}

Desde o final do século XIX, quando Tigerstedt e Bergman documentaram os efeitos pressores da renina em rins de coelhos, o entendimento do SRAA tem apresentado constante evolução em seu conhecimento e em sua aplicação clínica ${ }^{27}$. Em meados da década de 1950, foram reconhecidas as duas formas de angiotensina (Ang), sendo a primeira um decapeptídeo (Ang I) e a segunda um octapeptídeo (Ang II). Este último produzido por clivagem enzimática da Ang I, por uma enzima denominada enzima conversora da angiotensina (ECA). Em 1958, Gross observou que o sistema renina-angiotensina estava envolvido na regulação da aldosterona.

Investigações posteriores demonstraram que os produtos da atividade da renina uma enzima - funcionavam como uma chave para a regulação fisiológica do tônus vascular, balanço de sal e água e controle da pressão sanguínea ${ }^{28}$. Esta é sintetizada, armazenada e secretada na circulação renal pelas células justaglomerulares granulosas que se localizam nas paredes das arteríolas aferentes quando estas entram no glomérulo. O controle da secreção da renina é feito predominantemente por três vias, sendo duas localizadas nos rins (via da mácula densa e via dos barorreceptores intrarrenais) e uma terceira que atua por meio do sistema nervoso central, via esta 
mediada pela liberação de norepinefrina dos nervos noradrenérgicos renais (via dos receptores beta-adrenérgicos) $)^{29}$.

Nesse processo, ocorre a participação de receptores específicos de superfície celular de Ang e dos quatro conhecidos, os mais importantes são denominados AT1 e AT2, sendo os primeiros responsáveis pelos efeitos biológicos da Ang $\|^{30}$.

Do ponto de vista fisiológico, os aumentos da secreção de renina intensificam a formação de Ang II, assim, estimulando os receptores de AT1 nas células justaglomerulares, inibindo a secreção de renina (mecanismo de retroalimentação negativa de alça curta). A Ang II também aumenta a pressão arterial pela estimulação dos receptores AT1. Esta pressão elevada inibe a liberação de renina de três modos: a) ativando os barorreceptores de alta pressão, reduzindo o tônus simpático renal; b) aumentando a pressão nos vasos pré-ganglionares e c) reduzindo a reabsorção de cloreto de sódio no túbulo proximal. Este mecanismo foi denominado de retroalimentação negativa de alça longa.

A atuação dos Inibidores da ECA, os bloqueadores de receptores da angiotensina (BRA) e os inibidores de renina interrompem os mecanismos de retroalimentação negativa tanto da alça curta como da alça longa, aumentando assim a liberação de renina.

O substrato da renina é o angiotensinogênio, uma glicoproteína globular de peso molecular que varia entre 55.000 e 60.000 daltons. Este é sintetizado e secretado pelo fígado, e sua síntese é estimulada por fatores, como inflamação, insulina, estrogênios, glicocorticoides, hormônio tireoideano e Ang II.

A ECA é uma glicoproteína com peso molecular de 170.000 daltons, e tem como um dos seus numerosos substratos, a bradicina. No plasma, a conversão da Ang I em 
Ang II é lenta, porém, in vivo, há um metabolismo rápido em razão da atividade da ECA ligada à membrana na superfície luminal das células endoteliais em todo o sistema vascular. O gene da ECA contém um polimorfismo de inserção/deleção que explica $47 \%$ das variações fenotípicas observadas nos níveis séricos de ECA. Seu alelo de deleção associa-se a níveis elevados de ECA e pode aumentar o risco de cardiopatia isquêmica, espasmo da artéria coronária, reestenose após colocação de stent coronário, disfunção de endotélio vascular, hipertrofia vascular, AVE isquêmico, hipertensão no gênero masculino, nefropatia diabética, estenose da artéria renal, além de outros ${ }^{31-34}$.

O SRAA é considerado um sistema endócrino em que a renina circulante (origem renal) atua sobre o angiotensinogênio circulante de origem hepática, produzindo a Ang I no plasma. Por sua vez, este é convertido pela ECA plasmática e endotelial pulmonar em Ang II, que irá agir em órgãos-alvo. Mas, verificou-se que este sistema era auxiliado por um sistema renina-angiotensina dito local ou tecidual que é classificado em extrínseco e intrínseco. Além destas vias, há evidências de que a quimase, de origem mastocitária contribui de modo significativo para a conversão tecidual da Ang I em Ang II, sobretudo, no coração e rins.

Na Figura 8, observa-se a representação esquemática das vias clássica e alternativa de formação de angiotensina $\|^{35}$ e, na Figura 9 , sua relação com o desenvolvimento e progressão da aterosclerose ${ }^{36}$. 


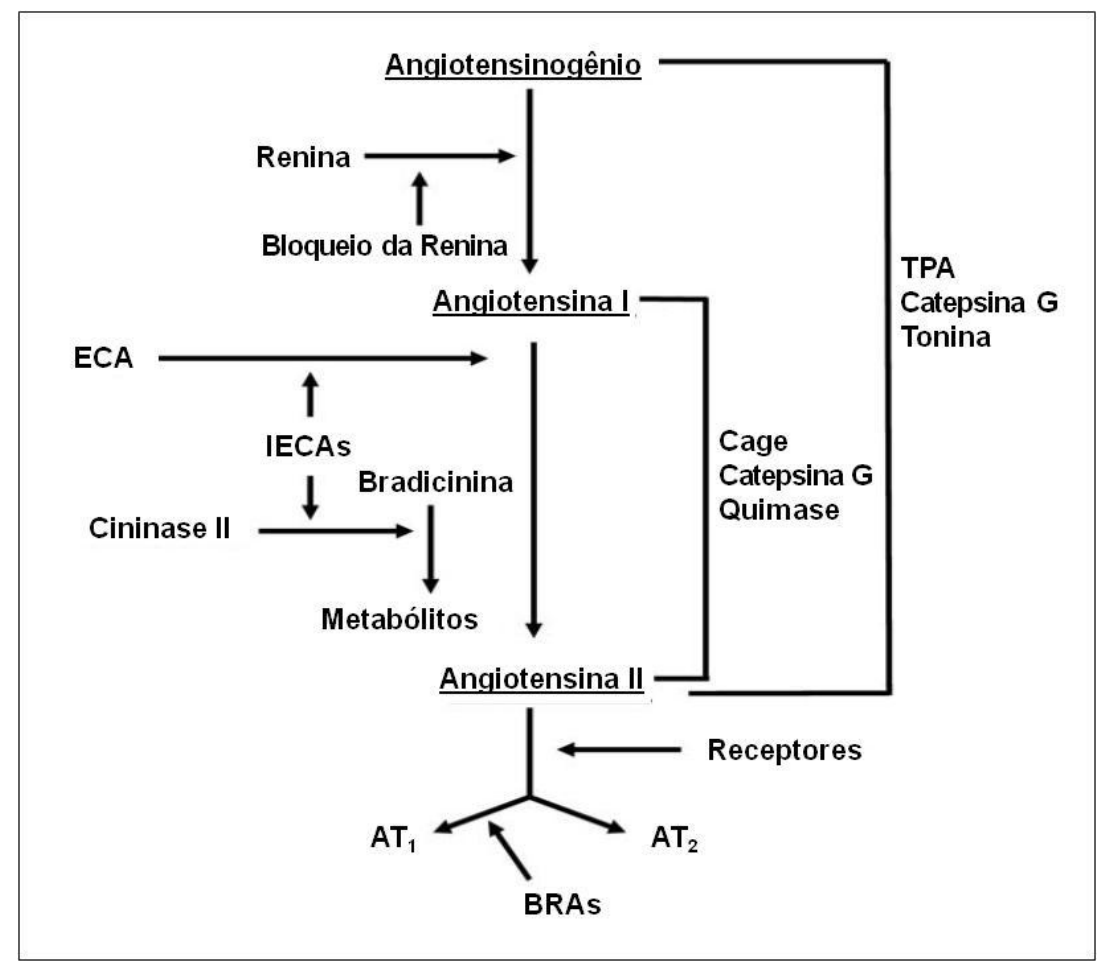

Figura 8. Vias clássica e alternativa da formação de angiotensina $\|^{35}$ Notas: ECA=enzima de conversão da angiotensina; IECA=Inibidores de ECA; $t-P A=$ ativador do plasminogênio tecidual; Cage=enzima geradora de quimostatina sensível à angiotensina II; AT1=receptores de angiotensina 1; AT2=receptores de angiotensina 2 ; BRAs=bloqueador de receptores de angiotensina II.

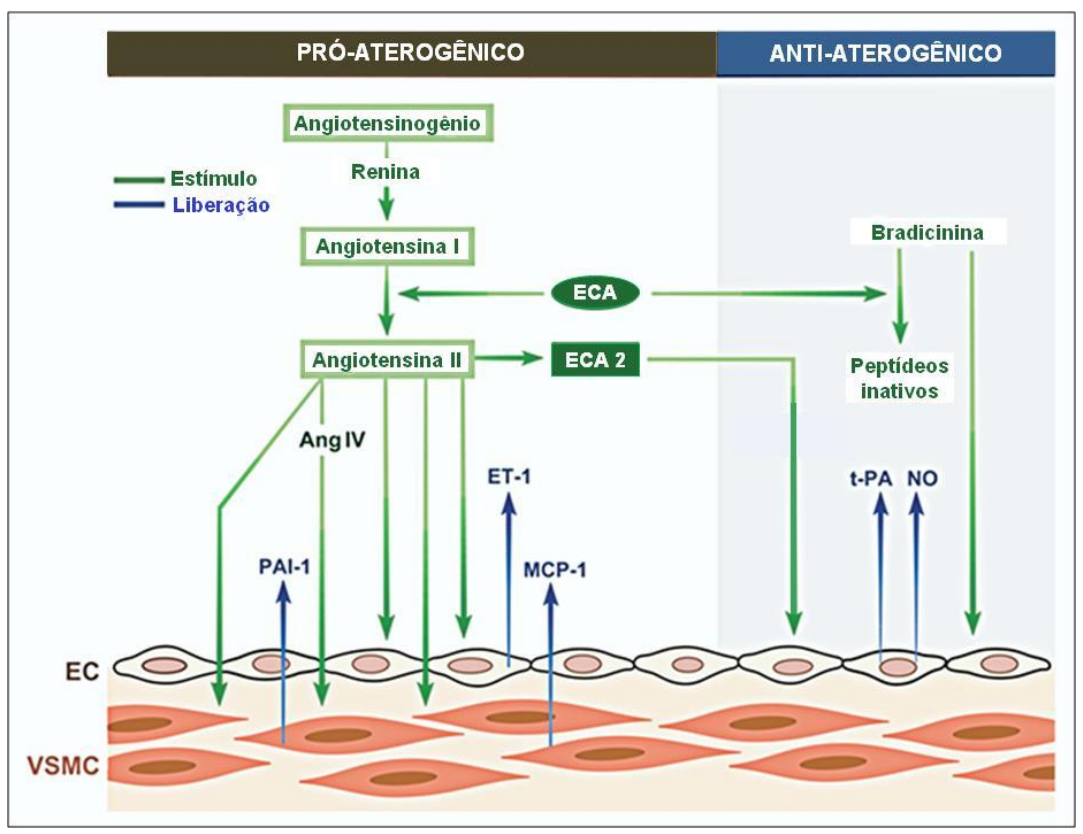

Figura 9. Angiotensina II e sua relação com o processo aterosclerótico ${ }^{36}$ Notas: $E C A=$ enzima de conversão da angiotensina; Ang IV=Angiotensina IV ; ET-1=Endotelina 1; MCP-1=proteína quimioatrativa de macrófagos-1; PAl-1=inibidor do ativador do

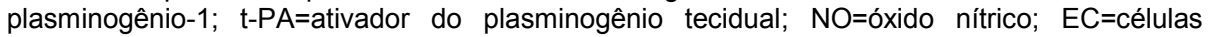
endoteliais; VSMC=células musculares lisas vasculares. 


\subsubsection{Funções do Sistema Renina-Angiotensina-Aldosterona}

De uma perspectiva evolucionária, o SRAA existe para manter a homeostase em períodos de estresse ou injúria. A ativação desse sistema em situações agudas é direcionada à preservação do volume intravascular, manutenção da pressão arterial e reparo de injúria tecidual ${ }^{28}$.

Ao contrário, em situações crônicas, sua estimulação exerce efeitos que são deletérios ao sistema cardiovascular, mediados por uma grande quantidade de processos patológicos que incluem a vasoconstrição crônica, a elevação da pressão arterial, o crescimento/migração das células musculares lisas vasculares, a disfunção endotelial, o estresse oxidativo, a liberação de citocinas, a ativação de células imunes e inflamatórias, a fibrose e a trombose ${ }^{28}$. Por intermédio desses mecanismos, contribui para a hipertrofia miocárdica e vascular, o remodelamento ventricular esquerdo, a aterosclerose e a glomeruloesclerose. Estas alterações estruturais formam o substrato anatômico que precede os eventos, como a angina, o IAM, o AVE e a doença renal em estágio terminal ${ }^{37-38}$.

Nesse contexto, a Ang II é um dos produtos mais importantes da regulação celular ao nível tecidual para o funcionamento do sistema cardiovascular, cujo aspecto mais importante é sua capacidade de inibir a secreção de sódio e água pelos rins. Mas, os efeitos da Ang II sobre a resistência periférica, a função renal e a estrutura cardiovascular são mediados por diversos mecanismos denominados diretos e indiretos, que são apresentados na Figura $10^{29}$. 


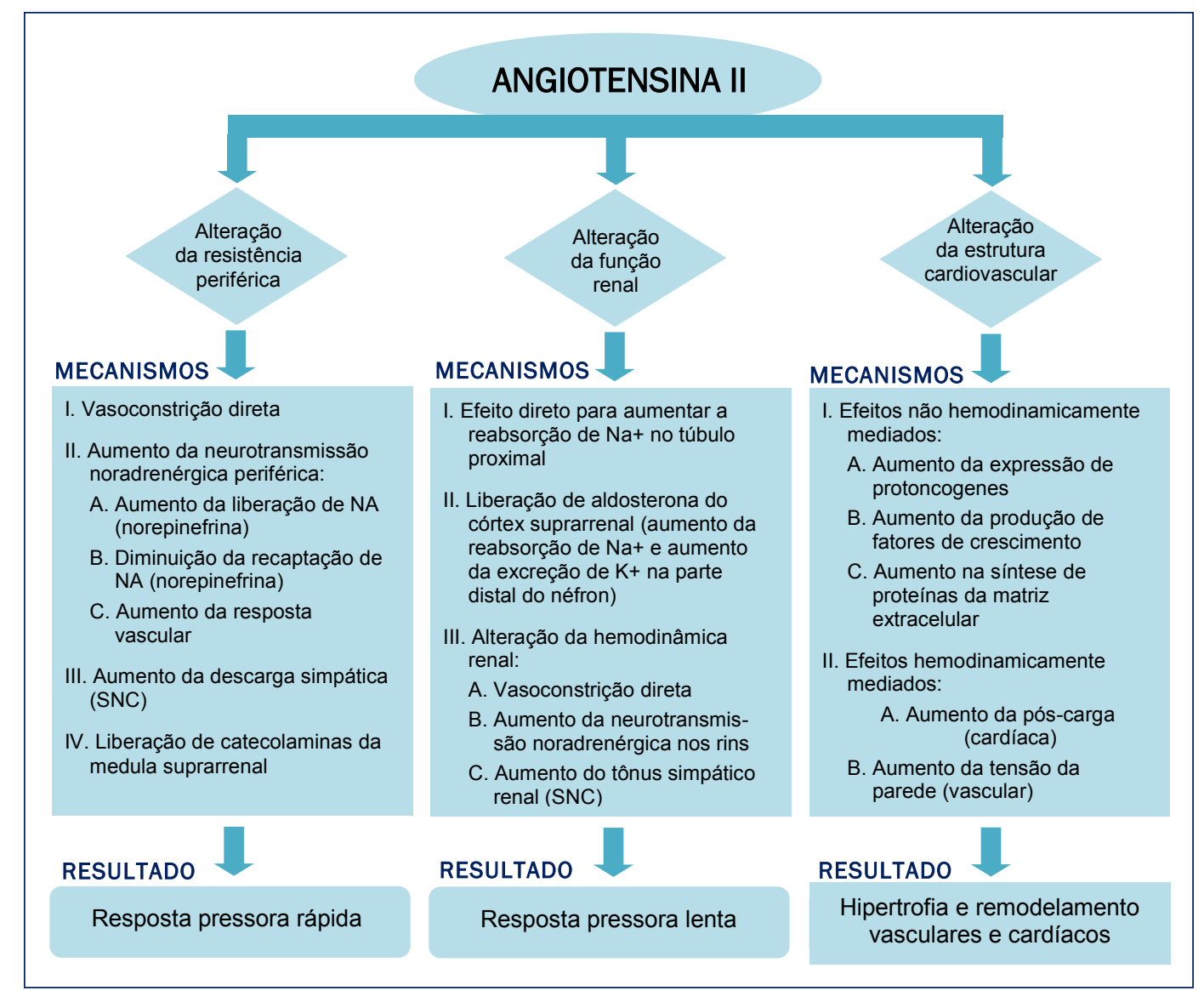

Figura 10. Principais efeitos da angiotensina II e dos mecanismos mediadores não hemodinâmicos ${ }^{29}$

\subsubsection{Importância das alterações patológicas nas estruturas cardiovasculares e sua relação com o SRAA}

O sistema cardiovascular pode ser alterado por vários mecanismos pela atuação da Ang II, conforme observado na Figura 10, levando a doenças cardíacas, cujas alterações na morfologia do coração e/ou dos vasos sanguíneos estão associadas a um risco de morbidade e mortalidade aumentadas.

De forma geral, essas alterações patológicas consistem em hipertrofia e/ou remodelamento. Nesse aspecto, há a hipertensão arterial sistêmica (HAS), onde existe 
um aumento da relação entre a parede e a luz dos vasos sanguíneos com a hipertrofia concêntrica. Há também a hipertrofia excêntrica cardíaca e a fibrose, que estão associadas à insuficiência cardíaca congestiva (ICC) e ao IAM e, por último, o espessamento da superfície da íntima da parede do vaso sanguíneo, que está relacionado à aterosclerose e à reação intimal nos procedimentos de intervenção transluminal percutânea.

É importante frisar que há o envolvimento de células musculares lisas vasculares, miócitos cardíacos e fibroblastos nessas alterações, efeito esse mediado pela Ang II, denominado efeito não hemodinâmico. Por outro lado, há os efeitos ditos hemodinâmicos sobre a estrutura celular com alterações na pré-carga cardíaca, em que há expansão do volume por retenção de sódio e também na pós-carga com aumento da pressão arterial, que contribuem para a hipertrofia e remodelamento cardíacos (Figura 10).

\subsubsection{Inibidores da enzima de conversão da angiotensina}

Os benefícios clínicos do bloqueio do SRAA demonstram-se sobre um grande número de efeitos que independem do controle da pressão arterial, incluindo redução no estresse oxidativo e disfunção endotelial, melhora no metabolismo da glicose, além de inibição do crescimento da placa aterosclerótica ${ }^{39}$. Todos esses efeitos benéficos atuam no remodelamento cardiovascular e proteção contra eventos clínicos desfavoráveis como IAM ou ICC. ${ }^{40-41}$ 
Com o desenvolvimento dos IECA e dos BRA, mostrou-se que a supressão do SRAA tornou-se uma estratégia terapêutica para a prevenção e tratamento das patologias cardiovasculares.

Na Figura 2, observa-se que o uso de medicamentos como IECA, BRAs e betabloqueadores, aumentou consideravelmente nos últimos anos ${ }^{7}$, e que houve redução de eventos clínicos, inclusive de mortalidade em pacientes com SCASSST (Figuras 3 e 4).

Os IECA e os BRA reduzem os efeitos da Ang II ao diminuírem sua produção ou bloquearem sua interação com os receptores da AT1.

Desse modo, ambas as classes provaram seus efeitos ao reduzirem os riscos de sérios eventos cardiovasculares em pacientes com HAS, ICC, IAM e nefropatia diabética ${ }^{42}$.

Os efeitos farmacológicos essenciais desses agentes sobre o sistema cardiovascular consistem em inibir a conversão da Ang I, que é relativamente inativa, em Ang II ativa, mostrando sua seletividade sobre a Ang I.

Contudo, a ECA é uma enzima com muitos substratos, sua inibição induz a efeitos não relacionados com a redução dos níveis de Ang II, como por exemplo, aumentando os níveis de bradicinina. Esta estimula a produção do fator de relaxamento do endotélio (óxido nítrico) e da prostaciclina que, por sua vez, provocam vasodilatação, inibição da migração e da proliferação das células musculares lisas e inibição da agregação plaquetária.

Além dessas atuações, os IECA interferem na retroalimentação negativa de alça curta e longa na liberação de renina. 
Os IECA foram classificados em três grandes grupos, baseados em sua estrutura química: 1) IECA com radicais sulfidrila, estes relacionados com o captopril; 2) IECA com radicais dicarboxila, estruturalmente relacionados com o enalapril e 3) IECA contendo fósforo, que se relacionam com o fosinopril.

$\mathrm{Na}$ atualidade, existem 12 inibidores aprovados pelo Food and Drug Administration para uso clínico. De modo geral, os IECA diferem quanto às suas propriedades: a) potência; b) decorrente da inibição direta pelo fármaco ou por meio de um pró-fármaco em um metabólito ativo e c) relacionada à sua farmacocinética.

Todos os IECA possuem indicações terapêuticas, efeitos adversos e contraindicações semelhantes, e com exceção do fosinopril e do espirapril (não comercializados), que são eliminados pelo fígado e rins, equitativamente, os demais são depurados pelos rins, o que implica redução de sua dose em pacientes com comprometimento renal.

Quanto às indicações terapêuticas dos IECA, podem ser utilizados na HAS, na disfunção sistólica de ventrículo esquerdo, no IAM e em pacientes com alto risco de eventos cardiovasculares. Quanto ao uso nos pacientes com IAM, há evidências sobre sua utilização no período peri-infarto com redução de mortalidade, sobretudo em hipertensos e diabéticos, e nos pacientes com infartos extensos e que evoluem com disfunção sistólica ${ }^{43}$. Naqueles de alto risco, sabe-se que os IECA, exercem um efeito pró-fibrinolítico ao reduzirem os níveis plasmáticos do inibidor do ativador de plasminogênio I, além de melhorar a disfunção vasomotora endotelial em pacientes coronarianos. Nesse contexto, o estudo HOPE ${ }^{44}$ demonstrou benefícios importantes nos pacientes, com redução da taxa de IAM, AVE e morte, mesmo nos que não tinham disfunção de ventrículo esquerdo, porém com evidências de doença vascular ou diabetes, além de outros fatores de risco para doença cardiovascular. 
Assim, os IECA atuam na redução da isquemia miocárdica, por meio de seus efeitos anti-inflamatórios, hemodinâmicos, antiadrenérgicos, antiproliferativos e antitrombóticos e, em última instância, na prevenção da ruptura/erosão da placa aterosclerótica $^{45}$.

\subsection{Troponinas cardíacas}

\subsubsection{Estrutura e funções das troponinas}

As troponinas cardíacas denominadas I e T são proteínas regulatórias cardíacas que controlam a interação cálcio-mediada, agindo na presença de trifosfato de adenosina, determinado pelas proteínas contráteis actina e miosina.

De maneira específica, a troponina constitui-se em um complexo proteico composto por três subunidades: troponina $T(T n T)$, que se liga à tropomiosina; a troponina C (TnC), sensível ao cálcio e a troponina I (Tnl), que inibe e modula a interação entre actina e miosina, que são decisivas no processo de contração muscular.

Todo o mecanismo de ação das troponinas está esquematizado na Figura11 ${ }^{46}$. Nesta, o filamento fino de actina (A) interage com a cabeça da miosina (B) quando os íons $\mathrm{Ca}^{2+}$ chegam a $\mathrm{TnC}$ (C). A complexa interação entre a $\mathrm{TnC}$ e as outras troponinas deixa a tropomiosina a "descoberto" em um sítio da actina à qual a cabeça da miosina 
pode ligar-se. A conformação molecular é a seguinte: A, o filamento fino de actina contém TnC e liga-se aos sítios de $\mathrm{Ca}^{+2}$. Quando a TnC não é ativada pelo $\mathrm{Ca}^{2+}$, a Tnl inibe a interação actina-miosina. A TnT é uma proteína alongada que interage com os outros componentes do filamento fino, participando assim do ciclo de ativação (D). B, a estrutura molecular da cabeça da miosina é composta de cadeias pesadas e leves. A cadeia pesada tem dois grandes domínios: o primeiro de $70 \mathrm{kDa}$ que interage com a actina em uma fenda na presença de uma molécula de ATP. No outro domínio de 20 kDa também chamado de "alavanca", há uma hélice alongada que se estende e dobrase sobre duas cadeias leves, circundando-as como um colar. Uma cadeia leve essencial é parte da estrutura. A outra cadeia leve é regulatória e pode responder à fosforilação para influenciar a extensão da interação actina-miosina. C, TnC com sítios no domínio regulatório para ativação pelo cálcio e para interação com a Tnl. D, Cálcio ligado à $\mathrm{TnC}$ induz a mudanças conformacionais na mesma que se alonga (compare sístole com diástole). Tnl une-se à TnC, e a inibição normal da Tnl sobre a actinatropomiosina é suspensa. Existe uma poderosa força de interação entre TnC e TnT.

Estas mudanças permitem um reposicionamento da tropomiosina em relação à actina, com redução de seus efeitos inibitórios normais, como mostra o painel inferior da Figura 11. Assim, o novo ciclo de contração pode reiniciar-se. 


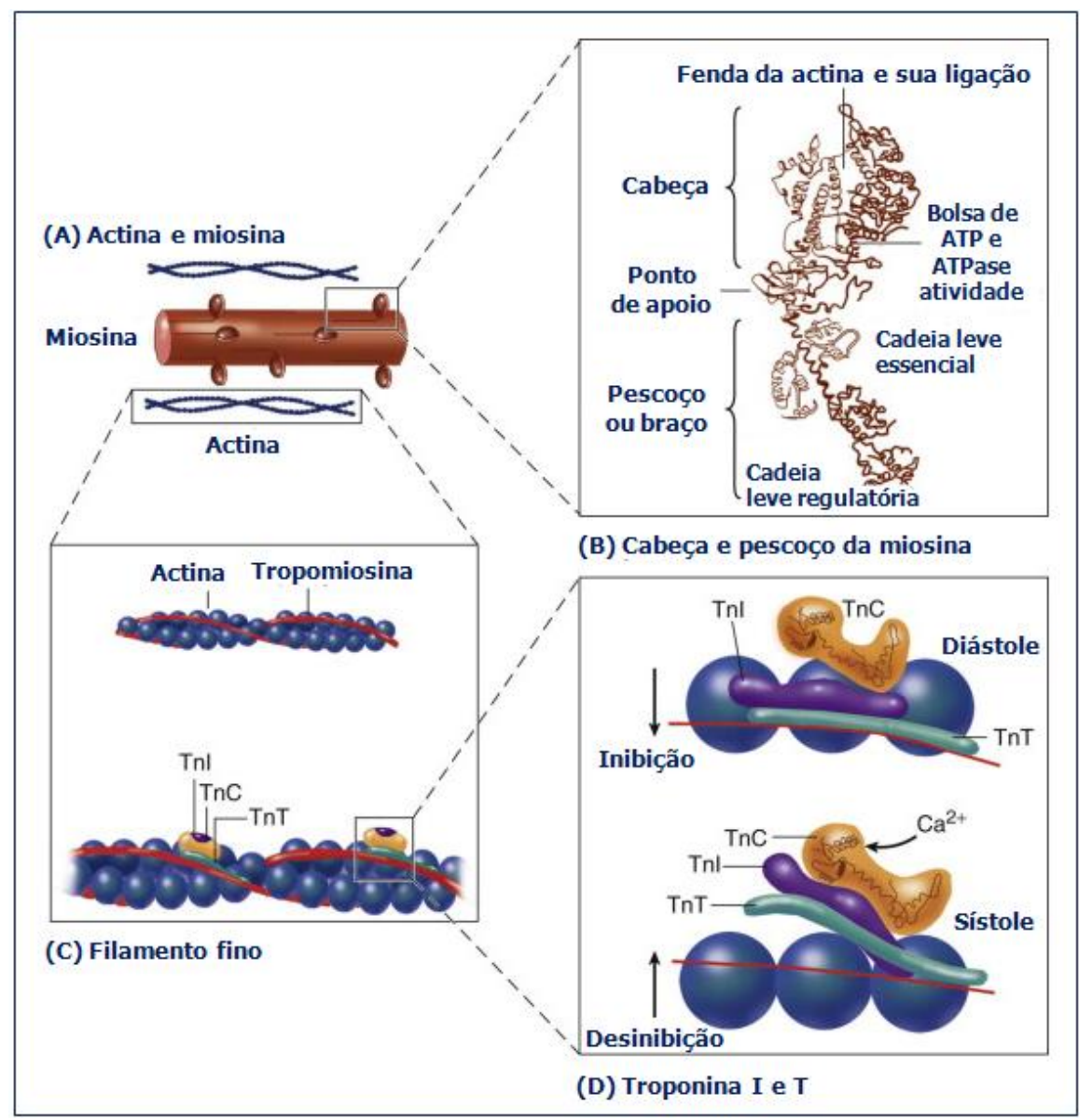

Figura 11. Esquema do sistema contrátil das troponinas ${ }^{46}$ Notas: ATP=adenosina trifosfato; $\mathrm{Tnl}=$ troponina $\mathrm{I} ; \mathrm{TnC}=$ troponina $\mathrm{C} ; \mathrm{TnT}=$ troponina $\mathrm{T}$; $\mathrm{Ca}^{2+}=$ cálcio ionizável.

\subsubsection{Troponinas - injúria miocárdica e prognóstico}

A injúria miocárdica pode ser definida como a ruptura da integridade da membrana miocitária cardíaca, com a perda de uma grande variedade de substâncias biologicamente ativas, que vão difundir-se nos interstícios cardíacos, linfáticos e toda a microvasculatura cardíaca, podendo atingir até a circulação periférica. Entre estas substâncias, incluem-se as proteínas estruturais (macromoléculas) denominadas troponinas e mioglobinas. 
O primeiro relato do uso de troponinas como marcador de necrose miocárdica foi publicado por Bernadette Cummins e cols. em $1987^{47}$. Desde então, as TnT e Tnl, vêm se estabelecendo como os biomarcadores preferenciais para a detecção de injúria miocárdica, em razão de sua maior especificidade e sensibilidade quando comparadas a outros marcadores como mioglobina, CPK, CK-MB massa e CK-MB atividade ${ }^{48}$. Desse modo, tornou-se o biomarcador de escolha pela Sociedade Europeia de Cardiologia e do Colégio Americano de Cardiologia para o diagnóstico de $\operatorname{IAM}^{14}$ e, assim, foram mantidas na última redefinição de IAM em $2007^{16}$. Nesse sentido, um aspecto que deve ficar bastante claro, é que a definição de IAM pressupõe que a injúria miocárdica detectada com a elevação desse marcador deve ser secundária a uma isquemia miocárdica, conforme definido em $2007^{16}$, diferenciando-a de outras situações clínicas não isquêmicas ${ }^{49}$. Aliado a esse fato, deverá apresentar uma elevação e um descenso (curva enzimática), em presença de sintomatologia compatível.

Estudos mostram que mesmo em indivíduos saudáveis, sem patologias cardíacas reconhecidas, podem ser detectadas quantidades mínimas de troponinas, tornando difícil o entendimento de qual seria o menor valor de referência para o diagnóstico de injúria miocárdica. Neste sentido, em 2006, foi publicado um estudo que avaliou a presença de TnT em uma população geral, utilizando ensaios de troponinas mais sensíveis, com um valor de detecção mínima de $0,01 \mathrm{ng} / \mathrm{mL}$, em que foi encontrada a presença desse marcador em $0,7 \%$ dessa população. No estudo, observou-se que os quatro maiores preditores de TnT detectáveis foram o diabete melito, a doença renal crônica, a hipertrofia ventricular esquerda e a insuficiência cardíaca $^{50}$.

No entanto, em pacientes com IAM, a concentração de troponina, normalmente, começa a elevar-se após 3 a 4 horas do início da sintomatologia, atingindo neste 
período cerca de $80 \%$ dos pacientes com $\operatorname{IAM}^{51}$, apresenta um descenso entre 48 e 72 horas e pode permanecer alterada por até 10 dias no caso da Tnl e até 14 dias para a TnT (Figura 12). A TnT pode ser dosada no sangue em pessoas saudáveis, porém, tem sido detectada em pacientes com doença musculoesquelética crônica, como polimiosite e dermatomiosite, além de pacientes com doença renal ${ }^{52-53}$. Múltiplos estudos têm demonstrado que a sensibilidade da TnT para o diagnóstico de IAM segue uma sequência temporal, isto é, varia de cerca de $50 \%$ dentro das primeiras 4 horas do início da dor precordial, passando por cerca de $75 \%$ por volta de 6 horas, atingindo $100 \%$ de sensibilidade após 12 horas da dor, permanecendo elevada por até 14 dias, fato que limita seu uso na fase precoce do IAM por médicos emergencistas ${ }^{52,54-56}$.

De outro modo, a Tnl tem sido detectada em pacientes com injúria miocárdica e não é encontrada em doenças musculares, sendo assim, é um específico marcador cardíaco. Após um evento agudo, a Tnl aumenta em cerca de 4 a 6 horas e atinge um pico por volta de 12 a 18 horas, permanecendo elevada por até 10 dias $^{57,58}$ (Figura 12).

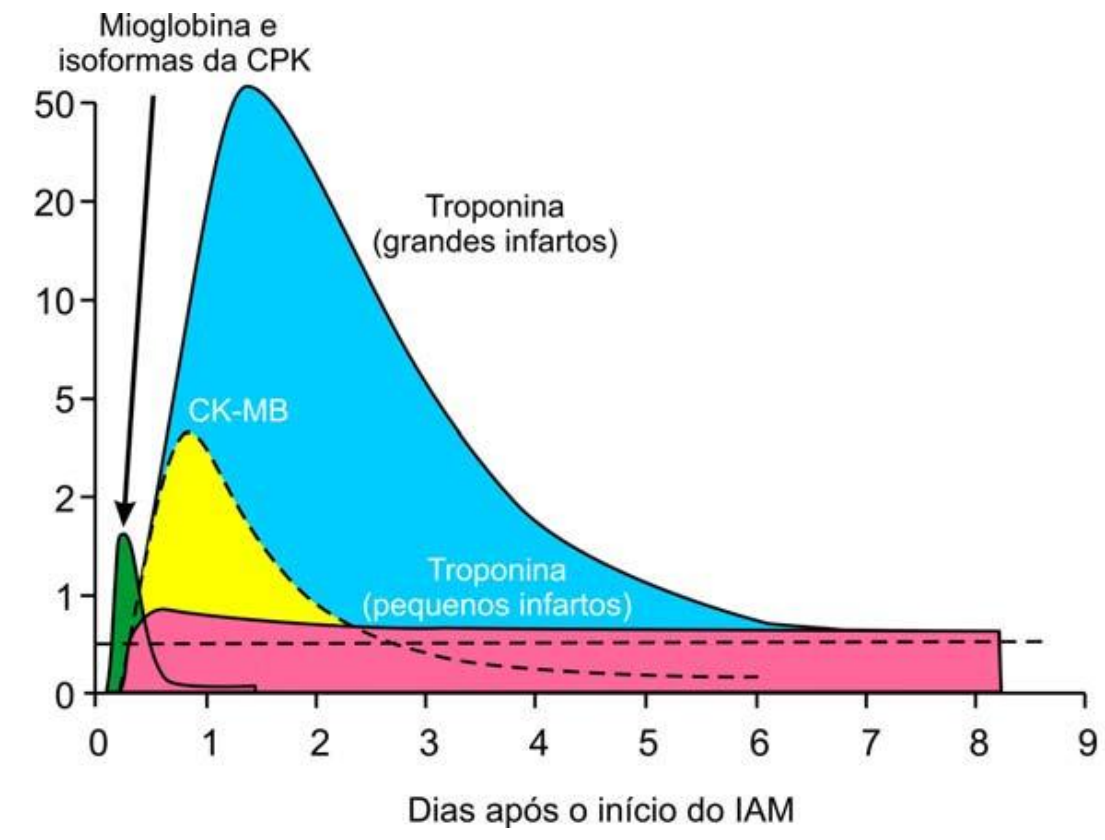

Figura 12. Liberação temporal de mioglobina, CK-MB e Troponinas, após um episódio de $\mathrm{IAM}^{51}$

Notas: $\mathrm{CPK}=$ creatinafosfoquinase; $\mathrm{CK}-\mathrm{MB}=$ fração $\mathrm{MB}$ da creatinafosfoquinase; Tnl= troponina I; $\mathrm{TnT}=$ troponina $\mathrm{T}$ 
No presente estudo, para avaliar a concentração desse marcador e sua relação com os desfechos clínicos considerados foi utilizado o maior valor da Tnl coletado durante a internação nas primeiras 24 horas. Portanto, excluem-se assim, a possibilidade de medidas precoces e eventualmente reduzidas, antes de atingirem o pico de sua elevação.

A presença desse marcador, independente da sintomatologia e das alterações eletrocardiográficas, confere um pior prognóstico ao paciente com SCASSST ${ }^{17,59-61}$, também evidenciados por um considerável número de estudos que demonstraram a associação entre a elevação de troponinas cardíacas e a presença de eventos adversos precoces e tardios como IAM, reinfarto e morte, além de revascularização precoce (até 48 horas) ${ }^{62-68}$ (Figura 13 e Tabela 1).

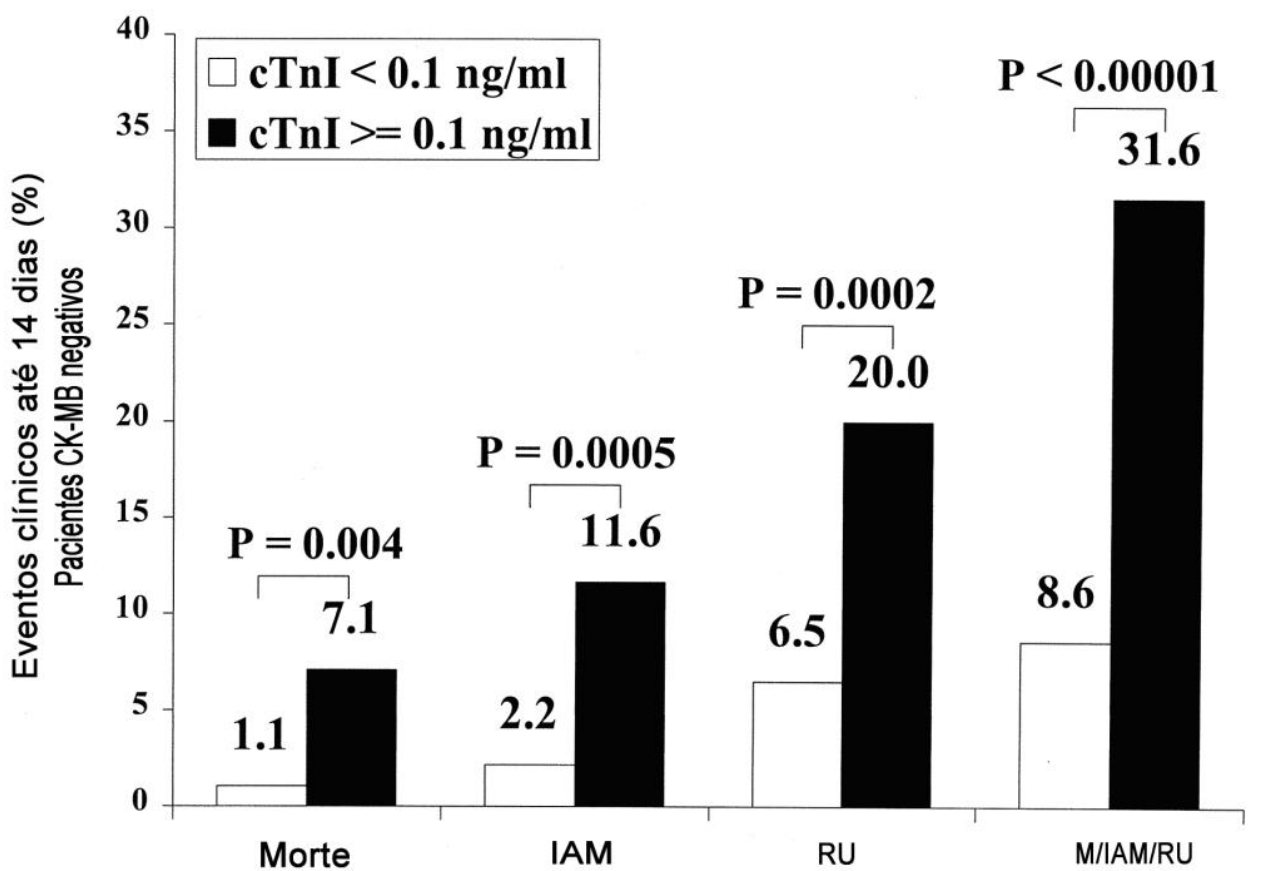

Figura 13. Eventos clínicos até 14 dias estratificados pela mensuração da Troponina ${ }^{64}$ Notas: TnI = Troponina I; M= Morte; IAM= Infarto Agudo do Miocárdio; $\mathrm{RU}=$ Revascularização Urgente 
Tabela 1. Risco de morte ou de IAM associados com um teste de troponina positiva em pacientes com Angina Instável ${ }^{13}$

\begin{tabular}{|c|c|c|c|c|}
\hline \multirow[t]{2}{*}{ Subgrupo } & \multicolumn{2}{|c|}{$\begin{array}{c}\text { Teste de troponina } \\
\text { Mortes / Total de pacientes }\end{array}$} & \multirow{2}{*}{$\begin{array}{c}\text { Sumário } \\
\text { RR }\end{array}$} & \multirow[t]{2}{*}{$95 \%$ IC } \\
\hline & Negativo & Positivo & & \\
\hline TnT & $43 / 667$ & 62 / 301 & 3.7 & $2.5-5.6$ \\
\hline Tnl & $7 / 163$ & $10 / 35$ & 5.7 & $1.8-18.6$ \\
\hline TnT e Tnl combinados & 47 / 737 & 67 / 322 & 3.8 & $2.6-5.5$ \\
\hline
\end{tabular}

Notas: RR=risco relativo; Tnl=troponina I; TnT=troponina T; 95\% IC=intervalo de confiança em 95\%.

Além disso, quanto maior a elevação desse marcador maior a gravidade clínica, com um prognóstico mais desfavorável ${ }^{65,69,70}$. No GUSTO IV, cerca de 7.800 pacientes foram estratificados em quatro quartis, conforme a elevação da $\mathrm{TnT}$, onde a mortalidade em 30 dias aumentou de $1,1 \%$ a $7,4 \%$ do primeiro ao quarto quartil ${ }^{71}$; correlação observada nos estudos de Antman e cols $^{48}$. (Figura 14), Christian e cols $^{72}$. (Figura 15), GUSTO ${ }^{11 a^{73}}$ (Figura 16) e FRISC ${ }^{65}$ (Figura 17), e em uma metanálise com diferentes durações de seguimento ${ }^{62}$.

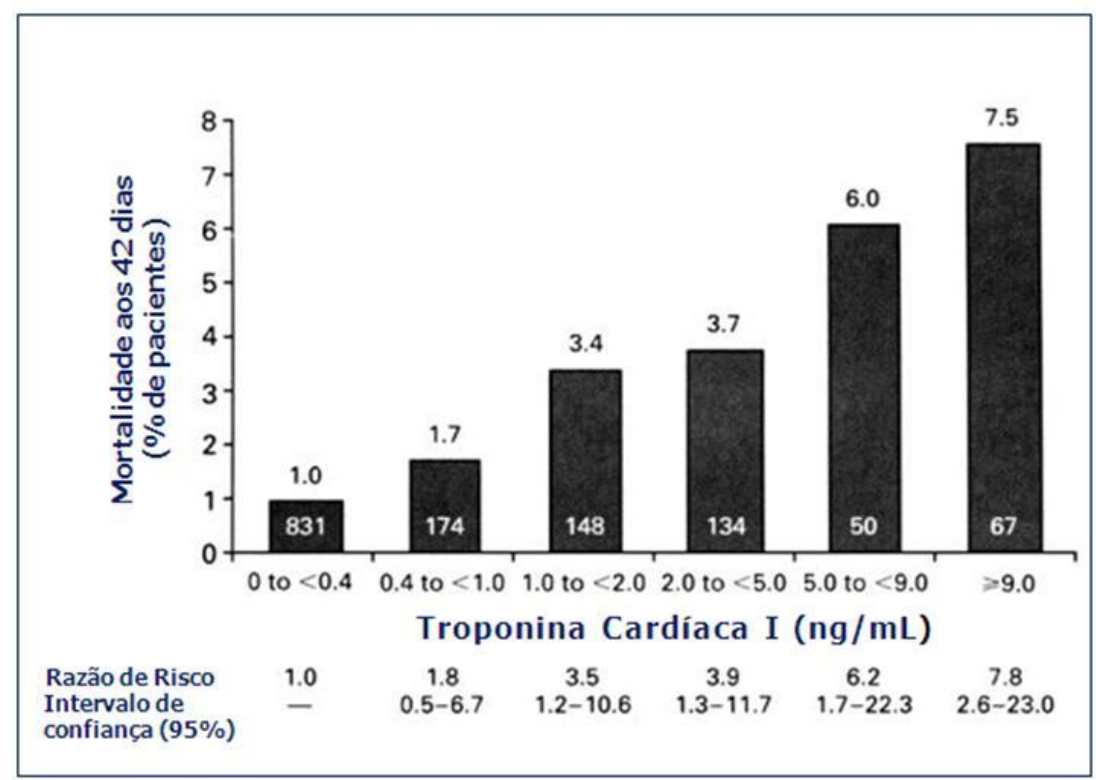

Figura 14. Taxa de mortalidade aos 42 dias de acordo com os níveis de Troponina $\mathrm{I}^{48}$

Nota: Os números dentro das barras correspondem ao de pacientes com níveis de troponina I em cada variação da mesma, e os números acima da barra são de porcentagens. 


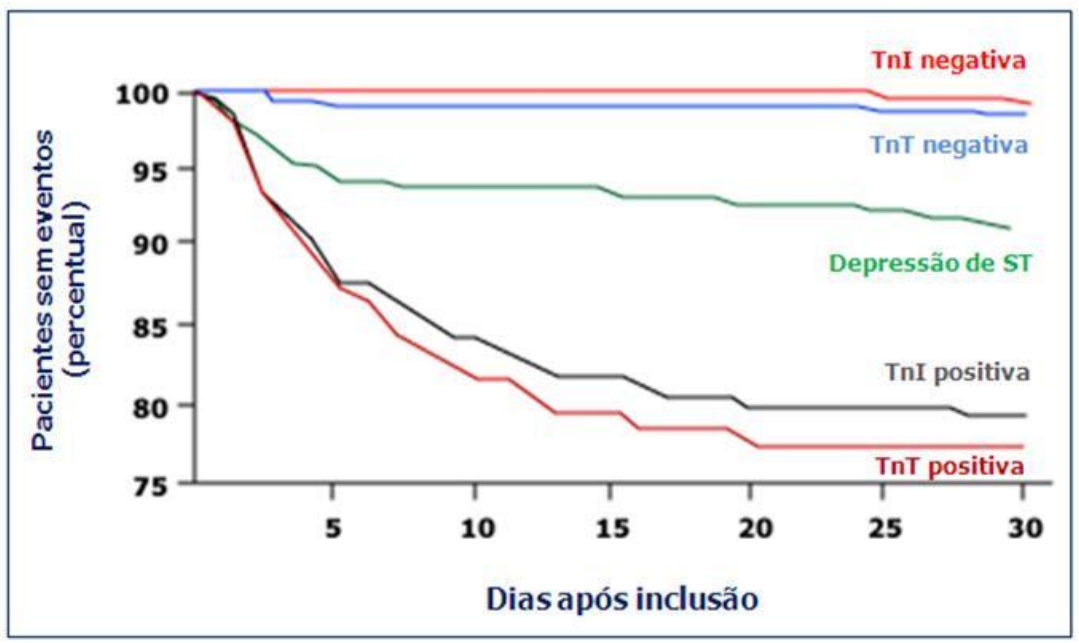

Figura 15. Troponinas cardíacas são preditoras em angina instável ${ }^{72}$ Notas: Tnl: Troponina I; TnT: troponina T.

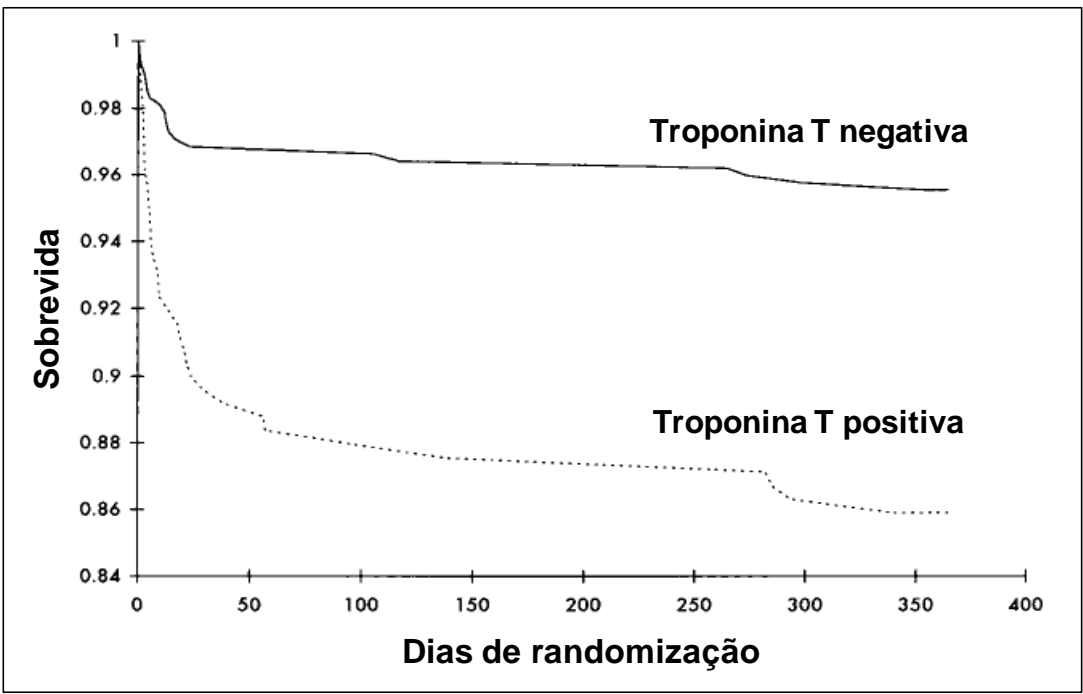

Figura 16. Curva de Kaplan-Meier: estimativa de sobrevida durante o primeiro ano para pacientes com dosagem de Troponina $\mathrm{T}^{73}$

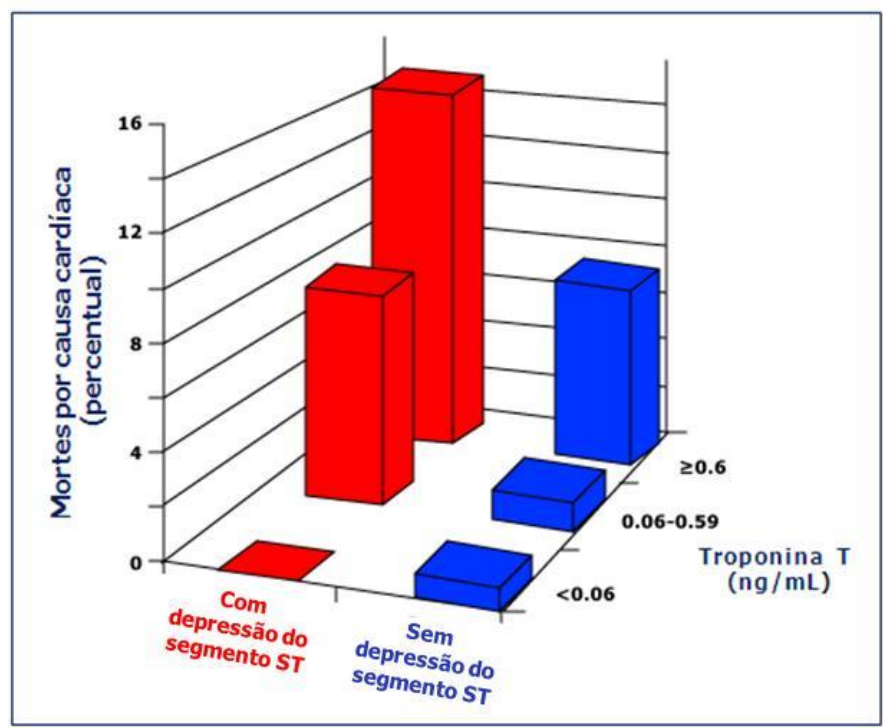

Figura 17. Depressão do segmento ST e troponinas são preditoras em SCASSST ${ }^{65}$ 
Outras observações associadas à elevação desse marcador envolvem maior número de vasos acometidos por lesões coronárias; maior ocorrência de infradesnivelamento do segmento $\mathrm{ST}^{69}$; maior quantidade de trombo à angiografia; menor taxa de fluxo TIMI 3; função ventricular esquerda mais grave e mais ondas $Q$ anormais ao eletrocardiograma ${ }^{74}$.

\subsubsection{Troponina versus CK-MB atividade como marcadores prognósticos}

Observou-se que até 30\% dos pacientes com SCASSST apresentavam CK-MB normal com troponina positiva, aumentando os casos diagnosticados como IAM e o consequente aumento dos eventos cardiovasculares ${ }^{75}$. Em nossa casuística em um centro terciário de cardiologia, a taxa de pacientes com CK-MB normal e troponina positiva foi de $12,6 \%$.

Na comparação da troponina com a CK-MB, as primeiras são as recomendadas para o diagnóstico de $\operatorname{IAM}^{16}$ em razão de sua maior sensibilidade e especificidade, pois sabe-se que há mais troponina por grama de miocárdio, e quando há injúria miocárdica, maior quantidade de enzimas chega à circulação periférica (maior sensibilidade). Quanto à especificidade, somente há falsos-positivos causados por interferência da fibrina ou por anticorpos de reação-cruzada ${ }^{76}$. Além disso, há estudos bem fundamentados que demonstram a superioridade da troponina com relação à CKMB na confirmação de necrose miocárdica em pacientes com SCASSST ${ }^{77-79}$. Destes, o CRUSADE $^{78}$ randomizou 29.357 pacientes, mostrando que os resultados foram discordantes em $28 \%$ dos pacientes na mensuração dos dois marcadores citados. Como 
esperado, a troponina foi mais sensível, com 18,2\% apresentando troponina positiva e CK-MB negativa; outros $10,2 \%$ tinham CK-MB positiva e troponina negativa, com a mortalidade maior no primeiro grupo. Os que tinham ambos os marcadores negativos $(11,9 \%)$ tinham mortalidade semelhante ao grupo CK-MB positiva e troponina negativa. $E$, por último, os que eram ambos positivos $(59,7 \%)$ apresentaram um significativo aumento da mortalidade, quando comparados aos demais.

A importância clínica dos achados refletiu-se na terapêutica implementada nesses pacientes, pois, apesar da elevação da troponina conferir gravidade ao prognóstico, os grupos CK-MB positiva e troponina negativa e o CK-MB negativa e troponina positiva, foram tratados de forma semelhante quanto ao uso de antitrombóticos e revascularização percutânea precoce. Com isso, corroborou-se a hipótese de que a elevação da CK-MB isolada tem limitado valor prognóstico em pacientes com SCASSST, quando comparada à elevação de troponina. Esses

resultados foram confirmados por outros estudos ${ }^{48,73,77,80}$, incluindo, o registro GRACE $^{79}$.

\subsubsection{Troponinas qualitativas versus quantitativas}

Nesta pesquisa utilizou-se o marcador de necrose miocárdica - troponina I cardíaca - mensurada pelo método de quimioluminescência automatizada por meio do IMMULITE ${ }^{\Theta}$ DPC MedLab, cujo cutoff (ponto de corte) para a troponina I cardíaca foi de 0,5 ng/mL, ou seja, foi considerada elevada quando detectável no soro com valores maiores ou iguais a $0,5 \mathrm{ng} / \mathrm{mL}$; pois, quando os valores fossem menores que esses não 
eram detectados pela técnica empregada. Desse modo, trata-se de uma medida qualitativa do marcador em questão.

Normalmente, as troponinas não são detectadas em pessoas saudáveis, no entanto, o cutoff para a confirmação de sua presença em pacientes com SCASSST leva em consideração uma população saudável do local onde a mensuração está sendo realizada. Independente do método utilizado, para a confirmação de necrose miocárdica, este marcador deverá ser mensurado no percentil 99 do limite superior de referência em indivíduos saudáveis com um máximo de imprecisão de 10\% do coeficiente de variação ${ }^{81,82}$ e, mantendo-se assim, na última definição de IAM publicada em $2007^{16}$, resultando em um impacto no aumento da frequência de IAMs diagnosticados ${ }^{83}$.

Existem cerca de 20 tipos de mensurações de troponinas que empregam diferentes reagentes, diversos métodos de calibração e inúmeros desempenhos clínicos $^{84,85}$. Dentro desse contexto, alguns cenários clínicos podem ser aventados, levando-se em conta a concentração desse marcador e sua variação através do tempo, podendo evidenciar uma isquemia miocárdica clássica ou uma injúria miocárdica (outras patologias não cardiológicas) ${ }^{49}$, entre elas, a miocardite em que os níveis de troponina permanecem elevados por muitas semanas ${ }^{76}$. Algumas variáveis como raça, gênero, idade, peso, história pregressa de doença coronária, além de comorbidades como doença renal, ainda não tiveram suas implicações clínicas devidamente estudadas na determinação dos níveis de troponina considerados "positivos" nessas circunstâncias, como marcadores de necrose celular.

Hamm e cols. foram pioneiros ao relacionar a elevação qualitativa das troponinas na avaliação de pacientes com dor torácica e correlacioná-la a um aumento de eventos isquêmicos. Na discussão, demonstraram que, quando a TnT foi 
mensurada após 6 horas do início da dor, nenhum paciente com IAM foi indevidamente liberado da emergência. Neste estudo, as taxas de eventos em 30 dias para pacientes com troponina negativa eram de $0,3 \%$ para $\mathrm{Tnl}$ e $1,1 \%$ para $\mathrm{TnT}$, sendo consideradas baixas, ou seja, com alto valor preditivo negativo ${ }^{86}$.

Em 2000, Ron Domburg e cols. publicaram um estudo que mensurou o valor da TnT qualitativa em 163 pacientes com dor torácica e suspeita de SCA e que foram acompanhados por 3 anos. O valor de cutoff utilizado foi de 0,2 $\mu \mathrm{g} / \mathrm{L}$ e foram obtidas dosagens seriadas na admissão hospitalar, 3, 6, 12, 24, 48, 72 e 96 horas após a admissão. Levando-se em conta que estudos prévios já haviam demonstrado o valor prognóstico da TnT quantitativa, obtiveram também dosagens de TnT pelo método ELISA - cutoff de 0,1 $\mathrm{\mu g} / \mathrm{L}$ - nos mesmos intervalos de tempo. Os resultados demonstraram que realizadas, pelo menos, duas dosagens da TnT qualitativa, sendo uma na admissão e outra às 12 horas da mesma, este marcador mostrou-se um estratificador de risco para eventos cardíacos como morte e IAM recorrente em 3 anos, tornando-se uma ferramenta de grande utilidade na emergência. Além disso, as duas metodologias obtiveram resultados similares, quando observadas as dosagens 12 horas após a admissão hospitalar ${ }^{87}$.

Em uma metanálise publicada em $2001^{62}$, incluindo 13.736 pacientes com SCASSST, de estudos coorte e trials, 5.360 pacientes dosaram TnT e 6.603 Tnl. Observou-se que pacientes com troponina positiva tinham de 3 a 8 vezes maiores riscos de morte e IAM a curto prazo em comparação aos troponina-negativos, com maior risco nos estudos de coorte. A metanálise enfatiza a identificação de pacientes troponina-negativos para serem seguramente liberados para casa, citando o estudo de Hamm e cols ${ }^{86}$. Trata-se, portanto, de uma medida qualitativa das troponinas. 
Em 2001, outro grande estudo que randomizou 2.220 pacientes, demonstrou uma redução de risco de eventos isquêmicos em pacientes com troponinas elevadas (qualitativa) foi o TACTICS-TIMI $18^{88}$, em que foram utilizados dois kits de TnT $(>0,1$ $\mathrm{ng} / \mathrm{mL}$ e $>0,01 \mathrm{ng} / \mathrm{mL}$ ). Em ambos, quando o valor da TnT foi superior ao limite estabelecido, resultados similares foram encontrados, isto é, a taxa de redução de desfechos primários (morte, IAM não fatal ou re-hospitalização por SCA em 6 meses) foi significativa naqueles submetidos à estratégia invasiva precoce. No entanto, o maior objetivo do estudo foi determinar que a presença de troponina positiva na apresentação clínica dos pacientes, que o autor denominou de "hipótese troponina" era útil em determinar a estratégia terapêutica empregada com o uso expressivo de antitrombóticos como heparina de baixo peso molecular e inibidores de glicoproteínas Ilb/IIla, além de estratégia invasiva precoce.

Em um estudo prospectivo realizado em 2004 com 1.773 pacientes admitidos em Unidade Coronária com SCASSST (965 pacientes) e SCACSST (808 pacientes), a presença de troponina positiva foi fortemente associada a eventos adversos em 30 dias. Em um modelo multivariado que incluía variáveis clínicas e mensurações quantitativas do desvio do segmento ST; a elevação da Tnl acima do limite estipulado $(\geq 0,1 \mu \mathrm{g} / \mathrm{L})$ foi o mais importante preditor de ocorrência de eventos compostos de morte ou reinfarto e morte isolada; após a idade avançada (> 70 anos) e a classe Killip maior que $1^{89}$

A predição de eventos cardíacos isquêmicos também foi avaliada, quando da inclusão de 4.447 pacientes no estudo GUSTO-IV ${ }^{90}$. Uma análise qualitativa por meio da mensuração de Tnl, além da mensuração quantitativa de TnT em dois cutoff diferentes: $>0,1 \mu \mathrm{g} / \mathrm{L}$ versus $\leq 0,1 \mu \mathrm{g} / \mathrm{L}$ e $\leq 0,01 \mu \mathrm{g} / \mathrm{L}$ versus $>0,01 \mu \mathrm{g} / \mathrm{L}$ foi realizada. Houve uma concordância entre os resultados da Tnl e da TnT ( $\leq />0,1 \mu \mathrm{g} / \mathrm{L})$ em 3.596 
pacientes $(80,9 \%)$. Observou-se também que a presença de $\mathrm{Tnl}$ correspondeu às elevações de $\operatorname{TnT}(0,01 \mu \mathrm{g} / \mathrm{L})$ em 1.990 pacientes $(90,4 \%)$, porém, uma Tnl negativa correspondeu à $\operatorname{TnT}(\leq 0,01 \mu \mathrm{g} / \mathrm{L})$ em somente 1.217 pacientes $(54,2 \%)$ da amostra. Quando foram analisados os eventos adversos combinados (morte e IAM) em 30 dias, observou-se que, em presença de $\operatorname{TnT}>0,1 \mu \mathrm{g} / \mathrm{L}$, a taxa de eventos foi elevada independente da positividade ou não da Tnl. De outro modo, pacientes com $\operatorname{TnT} \leq 0,1$ $\mu \mathrm{g} / \mathrm{L}$ apresentaram baixa taxa de eventos, independente dos resultados da Tnl. Contudo, notou-se que a $\operatorname{TnT}(>0,1 \mu \mathrm{g} / \mathrm{L}$ versus $\leq 0,1 \mu \mathrm{g} / \mathrm{L})$ estratificou os pacientes em alto e baixo risco respectivamente para eventos em 30 dias quando comparada à $\mathrm{Tnl}$ negativa $(4,8$ versus $5,7 \% ; p<0,001)$ e à $\mathrm{Tnl}$ positiva $(5,7$ versus $10,3 \% ; p=0,002)$. Outro resultado observado foi que qualquer elevação de $\operatorname{TnT}>0,01 \mu \mathrm{g} / \mathrm{L}$ também estratificou os pacientes em alto risco em 30 dias, independente do resultado da Tnl. No entanto, na análise de regressão logística ajustada para um grande número de fatores de risco, a Tnl foi um significativo preditor de eventos isquêmicos em 30 dias (OR=1,91; IC 95\%, 1,48 a 2,48). Concluiu-se, portanto, que a Tnl possui sensibilidade e especificidade suficientes para seu uso no atendimento de emergência e em unidades coronarianas ${ }^{91}$.

Em 2006, estudo publicado no Journal of the American College of Cardiology procurou demonstrar o desempenho da Tnl, como uma variável contínua e seu valor prognóstico e, para tanto, incluiu 34.227 pacientes, dos quais 12.135 em um único centro e 22.092 validados em vários centros. As troponinas foram categorizadas em quatro níveis: zero, negativa $(0,01-0,08 \mu \mathrm{g} / \mathrm{L})$, indeterminada $(0,09-0,20 \mu \mathrm{g} / \mathrm{L})$ e positiva $(>0,21 \mu \mathrm{g} / \mathrm{L})$. A mortalidade hospitalar foi de $1,8 \%, 3,3 \%, 5,0 \%$ e $9,4 \%$, respectivamente para um centro e $2,3 \%, 3,9 \%, 6,6 \%$ e $11,9 \%$, para a fase de validação. Para os dados combinados, o relativo aumento da razão de morte comparada com pacientes com Tnl "zero", foram: “negativa": 1,80 (IC 95\%, 1,56 a 2,08); “indeterminada”: 3,04 (IC 95\%, 
2,53 a 3,65); "positiva": 5,81 (IC 95\%, 4,89 a 6,91). Considerando-se o cutoff desse ensaio de $0,20 \mu \mathrm{g} / \mathrm{L}$, nota-se a significância prognóstica da Tnl considerada "negativa" com relação ao nível "zero". O modelo prediz uma taxa de mortalidade ajustada de 2,1\% para Tnl "zero", uma taxa de 5,3\% para $\mathrm{Tnl}$ de $0,08 \mu \mathrm{g} / \mathrm{L}$ (limite superior da normalidade) e 7,0\% para Tnl de 0,21 $\mu \mathrm{g} / \mathrm{L}$ (limite inferior de positividade). Portanto, os achados do estudo demonstram que a presença de qualquer nível detectável de Tnl está associada com um aumento de mortalidade, e que este aumento varia em proporção direta às magnitudes de aumento desse marcador ${ }^{92-93}$.

O valor dos marcadores de necrose miocárdica na emergência para a detecção precoce de SCA permanece um desafio, pois há relatos que até $80 \%$ dos pacientes com IAM ocorrem em pessoas sem prévia história de sintomas cardíacos, aliado ao fato de alta hospitalar indevida nesses casos que varia de $2 \%$ a $8 \%{ }^{94}$. Levando-se isso em consideração, um estudo americano no Estado de Illinois implementou uma avaliação em 252 pacientes com multimarcadores cardíacos na admissão, 2 e 4 horas - incluindo-se a Tnl - com o intuito de reduzir o tempo de diagnóstico e o custo ${ }^{95}$, pois cerca de metade dos pacientes admitidos com dor torácica, cujo diagnóstico inicial era de SCA, eram liberados com outros diagnósticos. Nesse estudo, se as três dosagens fossem negativas, o paciente seria encaminhado para um teste de esforço, que se negativo era liberado; e se positivo, era admitido para tratamento. Outro estudo semelhante realizado em Detroit, nos EUA, com 955 pacientes com dor torácica possivelmente cardíaca, também demonstrou que dosagens de Tnl na emergência foram preditoras independentes de prognóstico em até 5 anos $^{96}$.

Em 2004, a Sociedade de Cardiologia Britânica redefiniu O IAM pela concentração de troponina em: $\leq 0,06 \mu \mathrm{g} / \mathrm{L}$ (angina instável), > 0,06 a 0,5 $\mu \mathrm{g} / \mathrm{L}$ (necrose miocárdica), e $\geq 0,5 \mu \mathrm{g} / \mathrm{L}(\mathrm{IAM})^{97}$. Baseado no registro EMMACE 2, observou- 
se em uma população de 2.484 pacientes, que a dicotomização destes em Tnl "positiva" e "negativa" facilitaria a estratificação de risco dessa população em que havia 29,9\% com SCACSST e 70,2\% com SCASSST. Após considerações de influências do "mundo real", como as características dos pacientes e o tratamento preconizado para SCA; aqueles que tinham troponina "positiva", ou seja, maior que 0,06 $\mu \mathrm{g} / \mathrm{L}$, apresentavam mortalidade aumentada em curto, médio e longo prazos. Isto conforme os autores, poderia facilitar a aplicação da medicina baseada em evidências, haja vista que, no nível intermediário de dosagem ( $>0,06$ a $<0,5 \mu \mathrm{g} / \mathrm{L})$, a terapêutica aplicada não havia sido contemplada de acordo com as diretrizes britânicas ${ }^{98}$.

Em outro estudo foram analisados 2.092 pacientes em três níveis de concentração plasmática de Tnl (<0,05 ng/mL (64\%), 0,05 -0,19 ng/mL (8\%) e $\geq 0,20$ ng/mL (28\%)), obtida em duas fases (validação e implementação) nos anos de 20082009. Ficou claro que, ao se reduzir o limiar diagnóstico da $\mathrm{Tnl}$ para 0,05 ng/mL, houve um aumento do número de pacientes diagnosticados como IAM em $29 \%$, demonstrando que as concentrações intermediárias apresentavam risco alto de eventos adversos, fato este que mostrou uma implicação importante em políticas de saúde pública ${ }^{99}$.

Sabe-se que um marcador ideal deveria ter alta sensibilidade e alto valor preditivo negativo para avaliação e alta hospitalar na emergência. De outra forma, deveria ter alta especificidade e valor preditivo positivo para confirmar pacientes de alto risco para complicações cardiovasculares. Tendo isso em conta, recentemente, novos marcadores denominados "altamente precisos", de "alta sensibilidade", ou ainda, "ultrassensíveis", demonstrando cerca de dez vezes maior sensibilidade que os previamente conhecidos foram desenvolvidos ${ }^{100-101}$. Estes apresentam altíssima sensibilidade e moderada a alta especificidade, podendo, assim, de um lado, melhorar 
a abordagem terapêutica dos pacientes confirmados com SCASSST pelo uso de antiagregantes plaquetários, antitrombínicos e tratamento invasivo precoce; e, de outro, reduzir a taxa de internação e seus custos elevados.

Baseado em dois estudos recentes ${ }^{102-103}$, o estudo MERLIN-TIMI 36 com 6.560 pacientes com SCASSST que avaliou 4.513, em que foi mensurada a Tnl, conforme a redefinição de $\mathrm{IAM}^{16}$, com cutoff de $0,04 \mu \mathrm{g} / \mathrm{L}$ (65\% dos pacientes), e no intervalo entre $0,04 \mu \mathrm{g} / \mathrm{L}$ e $0,1 \mu \mathrm{g} / \mathrm{L}$ (10,9\% dos pacientes). Os resultados demonstraram um aumento significativo na taxa de morte ou IAM, aos 30 dias e em 12 meses, para o cutoff $\geq 0,04 \mu \mathrm{g} / \mathrm{L}$ versus $<0,04 \mu \mathrm{g} / \mathrm{L}$. Quando observados os eventos adversos no intervalo entre $0,04 \mu \mathrm{g} / \mathrm{L}$ e $0,1 \mu \mathrm{g} / \mathrm{L}$, notou-se que houve significativamente maior mortalidade ou IAM aos 30 dias quando comparado com o cutoff de $0,04 \mu \mathrm{g} / \mathrm{L}(\mathrm{p}<0,001)^{104}$.

Ainda com relação às troponinas ultrassensíveis, em 2009, Per Venge e cols. ${ }^{105}$ mensuraram a Tnl em 542 indivíduos saudáveis (329 homens e 213 mulheres) e compararam com 1.503 pacientes do GUSTO IV ${ }^{71}$, diagnosticados com SCASSST. O protótipo de Tnl utilizada mostrou uma sensibilidade suficiente para mensurar a troponina em praticamente todos os pacientes saudáveis. Não houve diferença entre os gêneros, e as mensurações foram independentes da idade. Um achado de relevância foi a grande diferença de resultados entre os indivíduos saudáveis e os da coorte do GUSTO IV. A análise da curva ROC para discriminar pessoas saudáveis de doentes ocorreu no nível de troponina de $0,0064 \mu \mathrm{g} / \mathrm{L}$, cujo valor preditivo negativo (VPN) foi de 68,5\%; porém, pode-se elevar este VPN para $90 \%$, reduzindo o nível de troponina para 0,0032 $\mu \mathrm{g} / \mathrm{L}$. Abaixo desse nível não houve nenhum evento adverso - morte ou IAM em 30 dias e 1 ano no estudo GUSTO IV.

Diante de todos os estudos apresentados, e a relação dos inúmeros pontos de corte para o marcador de necrose miocárdica - troponina - e suas consequências 
clínicas em curto, médio e longos prazos e, mais recentemente, com as novas troponinas de alta sensibilidade, ainda não há um consenso sobre a concentração mínima (se esta existe) desse marcador que deverá delimitar os pacientes com SCA em baixo e alto risco para eventos adversos graves e, consequentemente, uma estratégia agressiva nesses últimos, com o objetivo de reduzir esses eventos. Questiona-se a possibilidade de definir limites mínimos de concentração de troponina para guiar os clínicos na difícil tarefa de determinar os pacientes que se beneficiariam de terapêutica mais precoce, sem de outro modo interferir em sua segurança.

Para finalizar, levando-se em conta todas as evidências acima relatadas, um fato de fundamental importância é que todos os escores de risco preconizados atualmente

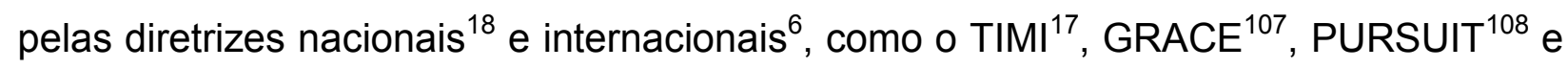
Braunwald $^{109}$ utilizam em suas pontuações, a presença do marcador de necrose miocárdica - troponina -, ou seja, como uma variável categórica, portanto, uma medida qualitativa.

\subsubsection{Atuais recomendações das troponinas para o diagnóstico de IAM}

As seguintes recomendações para o uso de biomarcadores de injúria cardíaca para o diagnóstico e estratificação de risco foram preconizadas pela associação das seguintes entidades: ESC/ACC/AHA/WHF, além da Academia Nacional de Bioquímica Clínica de Medicina Laboratorial (NACB) $)^{16,82}$ :

As troponinas cardíacas são os marcadores recomendados para o diagnóstico de IAM, bem como sua estratificação de risco. Na ausência desse marcador, a CK-MB 
massa ou atividade é uma alternativa aceitável. O uso da CPK não é recomendado, mas, havendo somente este, deverá estar acima de duas vezes de seu limite máximo; e ainda, se houver elevação e descenso de seus valores (curva enzimática), tanto de CPK ou CK-MB, teremos evidências adicionais para corroborar o diagnóstico.

Após procedimentos como a angioplastia transluminal percutânea seguida ou não de colocação de stent, convencionou-se que uma elevação maior que 3 vezes da troponina, acima do percentil 99 do limite superior de referência em pacientes com troponina prévia normal, seria considerada como IAM. Se a troponina estiver elevada antes do procedimento, e não se estabilizou, não há dados atuais para caracterizar o IAM. No entanto, se os valores estabilizaram-se ou reduziram-se, uma nova ascensão associada a critérios eletrocardiográficos ou por imagem poderá definir um novo evento. Um subtipo de IAM ocorrerá quando uma trombose de stent é documentada por um estudo angiográfico ou autópsia.

Quanto aos casos de pós-revascularização cirúrgica, convencionou-se uma elevação da troponina maior que 5 vezes acima do percentil 99 do limite superior de referência, após 72 horas do procedimento, em associação com novas ondas $Q$ patológicas ou novo bloqueio de ramo esquerdo, ou documentação angiográfica de oclusão de uma artéria nativa, ou de uma "ponte" de safena, ou torácica interna (enxerto direto ou livre), ou ainda, um exame de imagem (por exemplo, ecocardiograma) evidenciando uma nova alteração de contratilidade. 


\section{OBJETIVOS}

- Determinar o papel da inibição da enzima de conversão da angiotensina na elevação da troponina I cardíaca em pacientes com Síndrome Coronária Aguda sem supradesnivelamento do segmento ST.

- Avaliar os desfechos clínicos em até 180 dias. 


\section{CASUÍSTICA E MÉTODOS}

\subsection{Tipo de estudo}

Trata-se de estudo prospectivo observacional em pacientes com mais de 18 anos de idade, internados com o diagnóstico de SCASSST.

\subsection{Local do estudo}

O estudo foi realizado no Pronto-Socorro do Instituto Dante Pazzanese de Cardiologia que apresenta 11 leitos e três salas de emergências. É um centro terciário de cardiologia, onde são internados cerca de 60 pacientes por mês com diagnóstico de SCASSST, de uma média de 3.000 pacientes atendidos. 


\subsection{População-alvo}

Os pacientes foram recrutados de 8 de setembro de 2009 a 10 de outubro de 2010, no período das 7 às 19 horas, de segunda a sexta-feira, totalizando 457 pacientes consecutivos internados, com o diagnóstico de SCASSST.

\subsection{Desenho do estudo}

De acordo com a avaliação inicial, os pacientes foram selecionados, levando-se em conta a história clínica, o exame físico e as alterações laboratoriais. Todos vieram ao Pronto-Socorro e foram internados quando preenchiam os critérios de inclusão, ou seja, maiores de 18 anos e com dor precordial considerada isquêmica, nas últimas 48 horas, com duração maior que 10 minutos, e/ou dispneia e síncope com características de origem isquêmica. Os pacientes que se apresentaram com precordialgia de causas secundárias foram excluídos, bem como IAM com elevação do segmento ST, alterações eletrocardiográficas confundidoras como bloqueio de ramo esquerdo, ritmo de marcapasso ou fibrilação atrial, ou ainda, recusa em participar do estudo.

Aqueles que aceitaram participar do estudo, assinaram um Termo de Consentimento Livre e Esclarecido (TCLE)(Anexo A).

A seguir, após a realização da anamnese com história de precordialgia e o exame físico, os pacientes fizeram eletrocardiograma, além dos marcadores de necrose miocárdica. Além disso, responderam a um questionário clínico com nome 
completo, endereço, idade (em anos completos, a partir de 18 anos e sem limite superior), gênero, telefone, data de nascimento, número do registro no hospital, data e horário de atendimento no PS e data e hora da internação. Todos os antecedentes pessoais $(A P)$ e medicamentos utilizados previamente à internação foram assinalados. Entre os AP, considerou-se com hipertensão arterial sistêmica (HAS), pacientes com medida de pressão arterial acima dos níveis de $140 / 90 \mathrm{mmHg}$ ou em uso de medicação anti-hipertensiva; diabete melito, quando relatado pelo paciente e em uso de hipoglicemiante oral ou insulina; história familiar para doença arterial coronária em parentes de primeiro grau (pai, mãe e irmãos), com idade igual ou inferior a 55 anos para o gênero masculino e igual ou inferior a 65 anos para o gênero feminino; tabagismo, quando o consumo de cigarro era de, pelo menos, um por dia, até um ano anterior à inclusão no estudo - os não fumantes eram os que nunca fumaram ou deixaram o hábito há mais de um ano - dislipidêmicos, quando houve em qualquer momento da vida um nível de colesterol ou triglicérides elevado relatado por um médico, e feito tratamento dietético ou medicamentoso. Todos os pacientes foram questionados sobre dispneia aos esforços conforme a classificação da NYHA, em algum período de sua vida.

Todos os medicamentos em uso foram anotados, dando-se ênfase aos usuários de AAS, betabloqueadores, bloqueadores dos canais de cálcio, inibidores da enzima de conversão da angiotensina e estatinas. Todos estes deveriam estar em uso há, pelo menos 30 dias prévios à internação.

As alterações eletrocardiográficas analisadas foram o infradesnivelamento do segmento ST, consideradas quando a depressão fosse igual ou superior a $0,5 \mathrm{~mm}$ em, pelo menos, duas derivações contíguas (paredes anterior, anterosseptal, lateral, lateralalta e inferior) ou maior que 0,5 mm em uma derivação, em ambas, com exceção da 
derivação AVR. Outra alteração eletrocardiográfica analisada foi a inversão de onda T, com amplitude igual ou superior a 1,0 mm em duas derivações contíguas (paredes anterior, anterosseptal, lateral, lateral-alta e inferior), também com exceção de AVR.

Aos pacientes internados foi realizada uma análise laboratorial, em que constava: glicemia de chegada; marcadores de necrose miocárdica: CPK, CK-MB atividade e CK-MB massa, Troponina I cardíaca, além da bioquímica: sódio, potássio, ureia, creatinina e hemograma completo.

Os pacientes internados foram acompanhados até a alta hospitalar e, após a mesma, foram reavaliados através de contato telefônico ou pelo prontuário médico, no qual são avaliados os desfechos clínicos aos 180 dias.

Tudo o que se relacionou à conduta médica foi registrado em prontuário médico para qualquer averiguação posterior que se fizesse necessária.

Para cada paciente, há um TCLE e uma ficha clínica individualizada (Anexo B).

A seguir, um fluxograma do desenho da pesquisa (Figura 18). 


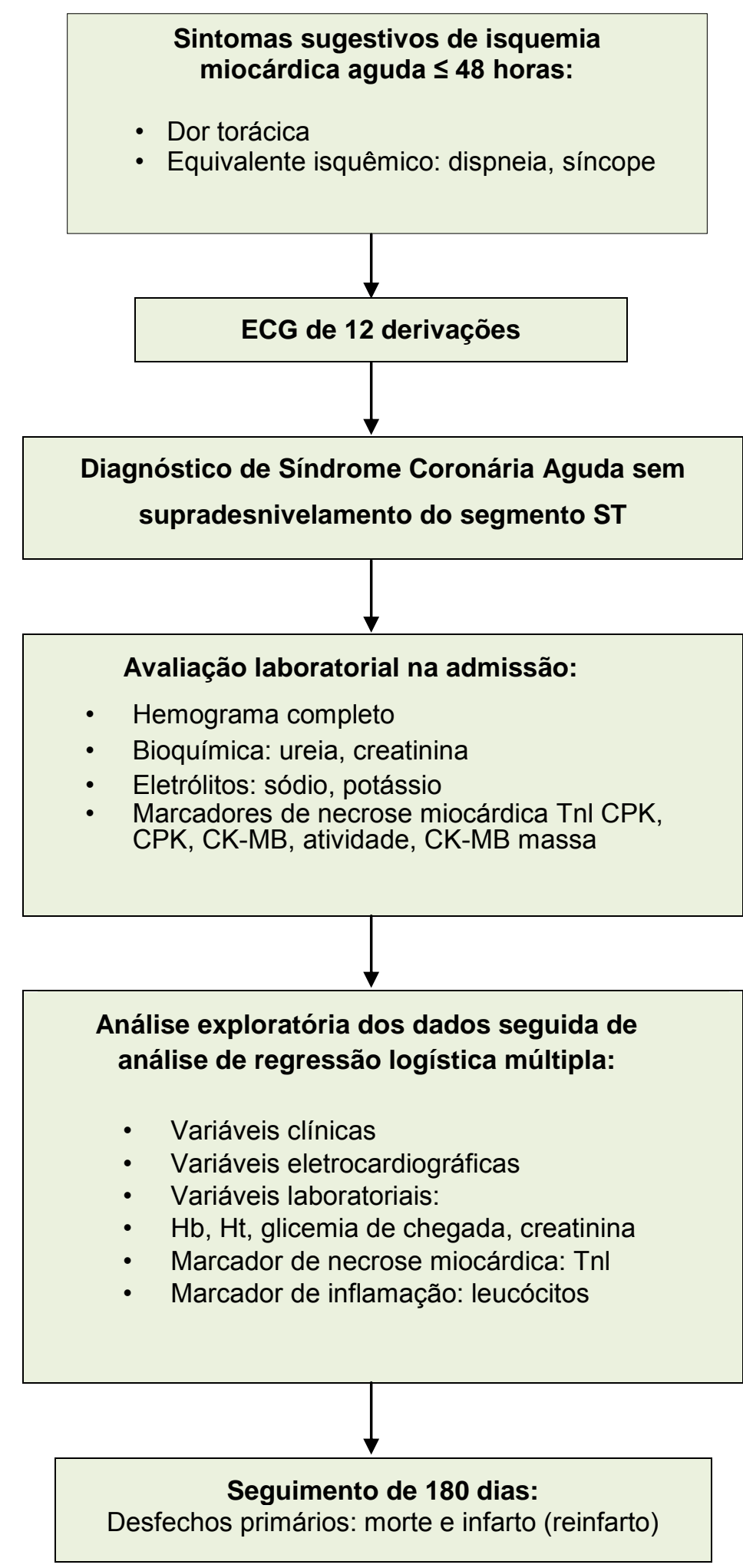

Figura 18. Fluxograma do desenho da pesquisa

Notas: $E C G=$ eletrocardiograma; $T n I=$ troponina I cardíaca; $C P K=$ creatinafosfoquinase; $C K-M B=$ fração $M B$ da creatinafosfoquinase; $\mathrm{Hb}=$ hemoglobina; $\mathrm{Ht}=$ hematócrito. 


\subsection{Variáveis analisadas}

Para a realização deste estudo, as seguintes variáveis foram analisadas: idade; gênero; antecedentes pessoais como hipertensão arterial sistêmica, diabete melito, dislipidemia, tabagismo, antecedentes familiares para doença coronariana em parentes de primeiro grau (pais, irmãos e filhos); medicamentos utilizados previamente à internação: ácido acetilsalicílico, betabloqueadores, inibidores de enzima de conversão da angiotensina, bloqueadores dos canais de cálcio e estatinas; alterações eletrocardiográficas: inversão de onda "T" acima de 1,0 mm, depressão do segmento "ST" acima de 0,5 mm; exames laboratoriais: glicemia de chegada, $\mathrm{Hb}, \mathrm{Ht}$, leucócitos, creatinina, potássio, marcadores de necrose miocárdica: Troponina I, Creatinafosfoquinase (CPK), CK-MB atividade, CK-MB massa.

\subsection{Desfechos analisados}

Neste estudo, os seguintes desfechos clínicos foram analisados: infarto (reinfarto) e morte por qualquer causa até os 180 dias após a data de admissão.

De acordo com as diretrizes da $A H A^{16}$, a determinação dos níveis de CK-MB massa permanece útil no diagnóstico de infarto (reinfarto), em razão de sua meia-vida curta, quando comparada à troponina e sua disponibilidade na maioria dos serviços de emergência. Neste caso, diante da recorrência de sintomas isquêmicos, uma mensuração da CK-MB massa serve como base para a comparação com amostras obtidas, após 6 e 12 horas do novo evento, corroborando ou não a hipótese. Uma 
troponina acima do valor normal para o diagnóstico de um novo evento será válida se a dosagem de admissão hospitalar for negativa. No entanto, o diagnóstico de infarto (reinfarto) dentro das primeiras 24 horas de um evento agudo de SCASSST é de difícil caracterização, pois os níveis de marcadores de necrose podem ainda estar elevados. Portanto, nesta pesquisa, foi considerado infarto (reinfarto) quando houve uma elevação do segmento ST acima de 0,1 mV ao ECG em, pelo menos, duas derivações contíguas (não existentes no ECG de admissão), associadas à sintomatologia isquêmica compatível. Quando ultrapassou as 24 horas, com o descenso do marcador de necrose CK-MB massa, o infarto (reinfarto) foi diagnosticado por uma re-elevação da CK-MB massa acima do limite superior da normalidade, a positivação da troponina ou o aparecimento de novas ondas $Q$.

Nos casos de pacientes submetidos a intervenção coronária percutânea, com ou sem colocação de stent, ou revascularização cirúrgica, permanecem as recomendações observadas no item 1.4.5.

\subsection{Métodos estatísticos aplicados}

A amostra constituiu-se de 457 pacientes que foram consecutivamente internados no Pronto-Socorro, entre 8 de setembro de 2009 e 10 de outubro de 2010.

As medidas qualitativas observadas foram gênero, antecedentes pessoais (hipertensão arterial sistêmica, dislipidemia, insuficiência cardíaca congestiva, síndrome coronária aguda prévia, procedimentos de revascularização do miocárdio prévios, diabete melito, história familiar para doença arterial coronária, tabagismo, 
acidente vascular encefálico, doença arterial periférica e doença arterial coronária prévia com coronariografia demonstrando lesão acima de 50\%; medicamentos utilizados prévios à internação (AAS, betabloqueadores, estatinas, nitratos, inibidores de enzima de conversão da angiotensina, diuréticos, bloqueadores de canais de cálcio, clopidogrel, digitálicos); tipo de apresentação da dor na admissão (típica, atípica, equivalentes isquêmicos: dispneia ou síncope); presença de dois ou mais episódios de dor nas últimas 48 horas; instabilidade hemodinâmica na admissão (classe de KillipKimball) ${ }^{110}$; diagnóstico na admissão (Angina Instável, IAMSSST) e alterações eletrocardiográficas (depressão do segmento ST, inversão de onda T).

As medidas quantitativas foram a idade (em anos), pressão arterial sistólica e diastólica, frequência cardíaca, marcadores de lesão miocárdica (Troponina I, CPK, CK-MB atividade e CK-MB massa), potássio, creatinina, glicemia de chegada, leucócitos, hematócrito e hemoglobina.

Estatísticas descritivas de frequências absolutas ( $n$ ) e relativas (\%) foram apresentadas para as medidas qualitativas e estatísticas sumárias de média, mediana, desvio padrão (DP) e percentis 25 e 75 (intervalo interquartílico - IIQ) para as medidas quantitativas.

As associações entre as medidas qualitativas e os grupos: troponina positiva (> $0,5 \mathrm{ng} / \mathrm{mL}$ ) e negativa ( $\leq 0,5 \mathrm{ng} / \mathrm{mL})$; uso e não uso de IECA antes da admissão e óbito e não óbito em até 180 dias foi avaliada pelo teste qui-quadrado de Pearson $(\text { Pereira })^{111}$ ou exato de Fisher (Armitage) $)^{112}$. Para a comparação das medidas quantitativas entre dois grupos, foi aplicado o teste não paramétrico de Mann-Whitney $\left(\right.$ Siegel, 1988) ${ }^{113}$. 
Nesta pesquisa foram utilizados também modelos de regressão logística múltipla, para avaliação dos efeitos de múltiplas variáveis no óbito em 180 dias e na troponina $>0,5 \mathrm{ng} / \mathrm{mL}$. As variáveis para o modelo logístico inicial foram selecionadas entre as que apresentaram, pelo menos $70 \%$ das observações ( $n \geq 319$ ), com frequência absoluta de, pelo menos, cinco ocorrências por categoria quando medida qualitativa; com nível descritivo menor que $15 \%(p<0,15)$ na análise bidimensional (univariada), e aquelas em que o pesquisador acreditava ser de relevância clínica nos desfechos analisados. O método de stepwise backward foi utilizado para selecionar as variáveis que permaneceram no modelo final. Os resultados foram apresentados em razão de chances (odds ratio) e seus intervalos de confiança (IC) de 95\% e nível descritivo (valor de p). Para o modelo final na análise de regressão logística, ficaram as variáveis com nível de significância menor que 10\% $(p<0,10)$. O ajuste dos modelos foi avaliado pela estatística C (área sob a curva ROC) dos valores preditos pelos modelos $^{114}$. O valor clínico da estatística $C$ varia de acordo com a seguinte classificação: menor que 0,6 (sem valor clínico); entre 0,6 e 0,7 (valor clínico limitado); entre 0,7 e 0,8 (bom valor prognóstico) e maior que 0,8 (ótima acurácia preditiva) ${ }^{115}$.

O nível de significância dos testes foi de $5 \%$, ou seja, as diferenças foram consideradas significativas quando o valor de $p$ dos testes foi menor que $5 \%$. Os casos em que o valor de $p$ situa-se entre $5 \%$ e $10 \%$ também sugerem diferenças entre os grupos porém com evidências mais fracas.

Software utilizado: SPSS (Statistical Package for the Social Sciences) versão 19. 


\subsubsection{Cálculo amostral}

O cálculo da amostra foi baseado em pesquisa realizada por dos Santos e cols. ${ }^{116}$ em que se observou que a proporção de óbitos no grupo com troponina $<0,5$ $\mathrm{ng} / \mathrm{mL}$ e no grupo com troponina $\geq 0,5 \mathrm{ng} / \mathrm{mL}$ em uma população de 1.207 pacientes foi de $3,5 \%$ versus $9,5 \%$, respectivamente, e significativamente diferentes (valor de $p<$ 5\%). Com estas estimativas, foi calculado, pela estatística de teste $z$ (distribuição normal) para comparação entre duas proporções, um tamanho de amostra mínimo para cada grupo de 207 pacientes, totalizando 414 nos dois grupos, considerando o teste monocaudal, com nível de significância de $5 \%$ e poder de $80 \%$. 


\section{RESULTADOS}

\subsection{Características basais}

Da população estudada de 457 pacientes, 291 eram do gênero masculino $(63,7 \%)$, com média de idade de 62,17 anos $( \pm 11,04)$. Antecedentes pessoais: hipertensão arterial sistêmica em 390 pacientes (85,3\%), dislipidemia em 347 pacientes (75,9\%), insuficiência cardíaca congestiva em 294 pacientes (64,3\%), síndrome coronária aguda prévia em 275 pacientes $(60,2 \%)$, procedimentos de revascularização do miocárdio prévios em 226 pacientes (49,5\%), diabete melito em 160 pacientes (35,0\%), história familiar para doença arterial coronária em 172 pacientes $(37,6 \%)$, tabagismo em 110 pacientes $(24,1 \%)$, doença arterial coronária prévia com, pelo menos, uma artéria com estenose acima de 50\% em 287 pacientes $(62,8 \%)$, demonstrando uma seleção de pacientes de alto risco para doença cardiovascular (Tabela 2).

De todos os pacientes estudados, 391 (85,6\%) apresentaram dor torácica típica, $14(3,1 \%)$ dispneia, além de quatro $(0,9 \%)$ que apresentaram síncope à admissão. A classe funcional I para insuficiência cardíaca de Killip-Kimball estava presente em 451 $(98,7 \%)$ dos pacientes admitidos. O diagnóstico na admissão foi de IAMSSST em 169 pacientes (37\%), $287(62,8 \%)$ de angina instável III B e só um paciente $(0,2 \%)$ de angina instável III C (Tabela 2). 
Tabela 2. Características basais da população do estudo

\begin{tabular}{|c|c|c|}
\hline Característica & $\begin{array}{l}\text { Pacientes } \\
\text { (total }=457 \text { ) }\end{array}$ & $\%$ \\
\hline Idade, média (DP) & $62,2(11,0)$ & - \\
\hline Gênero masculino & 291 & 63,7 \\
\hline \multicolumn{3}{|l|}{ Antecedentes pessoais } \\
\hline - Hipertensão arterial sistêmica & 390 & 85,3 \\
\hline - Dislipidemia & 347 & 75,9 \\
\hline - Insuficiência cardíaca congestiva - (NYHA $\geq \mathrm{II})^{*}$ & 294 & 64,3 \\
\hline - Síndrome Coronária Aguda prévia & 275 & 60,2 \\
\hline * Apenas angina instável & 65 & 14,2 \\
\hline * Apenas infarto do miocárdio & 182 & 39,8 \\
\hline * Angina e infarto do miocárdio & 28 & 6,1 \\
\hline - Angina estável prévia & 250 & 54,7 \\
\hline - Procedimentos de revascularização do miocárdio prévios & 226 & 49,5 \\
\hline * Apenas intervenção coronária percutânea (ICP) & 118 & 25,8 \\
\hline * Apenas cirurgia de revascularização do miocárdio (RM) & 67 & 14,7 \\
\hline * ICP e cirurgia de RM & 41 & 9,0 \\
\hline - Diabete melito & 160 & 35,0 \\
\hline - História familiar para doença arterial coronária & 172 & 37,6 \\
\hline - Tabagismo & 110 & 24,1 \\
\hline - Acidente vascular encefálico & 30 & 6,6 \\
\hline - Doença arterial periférica & 11 & 2,4 \\
\hline - Doença arterial coronária $\geq 50 \%$ & 287 & 62,8 \\
\hline \multicolumn{3}{|l|}{ Apresentação na admissão } \\
\hline \multicolumn{3}{|l|}{ - Sintomas } \\
\hline * Dor torácica típica & 391 & 85,6 \\
\hline * Dor torácica atípica & 66 & 14,4 \\
\hline * Dispneia** & 14 & 3,1 \\
\hline * Síncope** & 4 & 0,9 \\
\hline - Dor precordial no momento da admissão & 281 & 61,5 \\
\hline \multicolumn{3}{|l|}{ - Número de episódios de dor nas últimas 48 horas } \\
\hline * Dois ou mais episódios & 253 & 55,4 \\
\hline * Um episódio & 204 & 44,6 \\
\hline - Instabilidade hemodinâmica na admissão***. & 8 & 1,8 \\
\hline - Frequência cardíaca (bpm) & $75,86( \pm 16,56)$ & - \\
\hline - Pressão arterial sistólica (mmHg) & $139,61( \pm 28,24)$ & - \\
\hline - Pressão arterial diastólica (mmHg) & $82,69( \pm 17,07)$ & - \\
\hline \multicolumn{3}{|l|}{ - Insuficiência cardíaca congestiva - Classe de Killip-Kimball } \\
\hline$* 1$ & 451 & 98,7 \\
\hline$* 11$ & 2 & 0,4 \\
\hline$*$ III & 3 & 0,7 \\
\hline$*$ IV & 1 & 0,2 \\
\hline \multicolumn{3}{|l|}{ Diagnóstico } \\
\hline - IAMSSST & 169 & 37,0 \\
\hline - Angina instável III B & 287 & 62,8 \\
\hline - Angina instável III C & 1 & 0,2 \\
\hline
\end{tabular}

Notas: *NYHA - Classificação segundo a New York Heart Association; ${ }^{* *}$ Sintomas associados à dor torácica; ${ }^{* * * P r e s s a ̃ o ~}$ arterial sistólica $<90 \mathrm{mmHg}$; DP=desvio-padrão; IAMSSST=infarto agudo do miocárdio sem supradesnivelamento do segmento ST. 
Do ponto de vista medicamentoso, previamente à internação, 337 pacientes (73,9\%) faziam uso de ácido acetilsalicílico, 289 (63,4\%) de betabloqueadores, 278 $(61,0 \%)$ de estatinas, $242(53,3 \%)$ de inibidores da enzima de conversão da angiotensina, $174(38,2 \%)$ de nitratos e $164(36,1 \%)$ de diuréticos, e outros medicamentos, conforme descritos nos dados da Tabela 3.

Tabela 3. Medicamentos prévios à admissão hospitalar

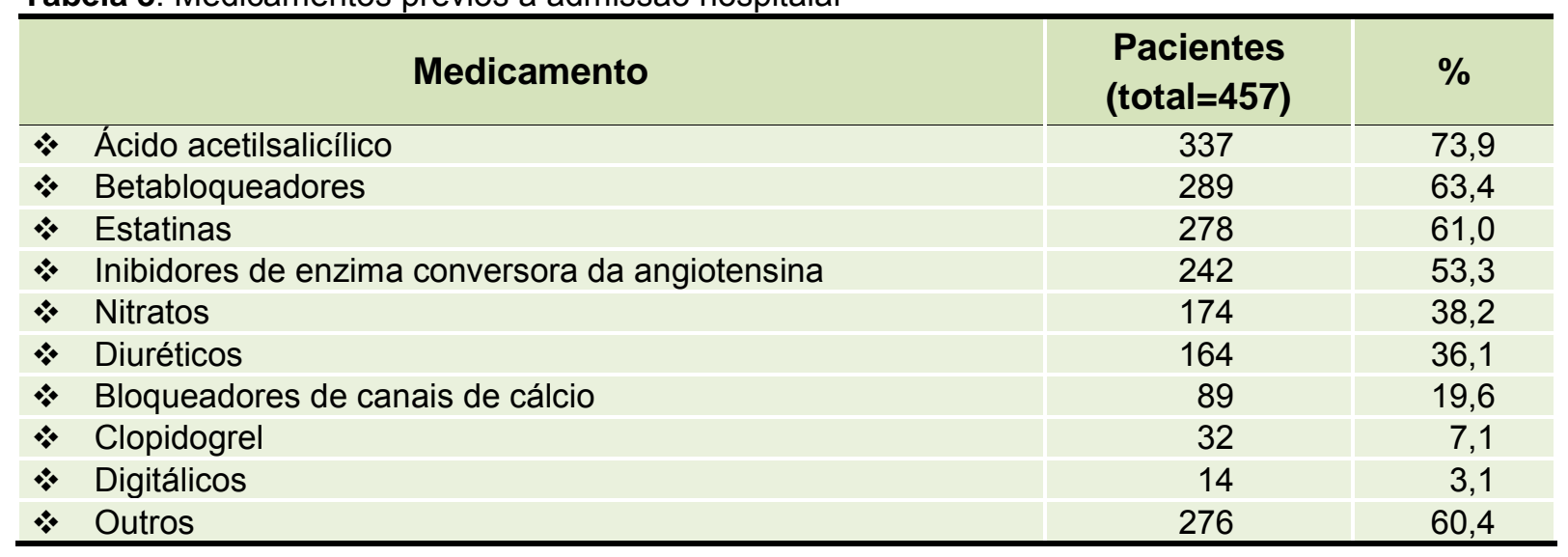

Pela relevância da dosagem qualitativa da troponina nesta pesquisa, nos dados da Tabela 4 são apresentadas as características da população estudada, conforme o valor de corte desse marcador, definido pelo método laboratorial utilizado pelo pesquisador. Diante dessas considerações, observou-se que os pacientes com troponina elevada $(>0,5 \mathrm{ng} / \mathrm{mL})$ eram mais idosos; apresentavam mais ICC (CF $\geq$ II) na admissão; realizaram mais ICP e RM durante a internação; havia mais pacientes com depressão do segmento $\mathrm{ST} \geq 0,5 \mathrm{~mm}$, em uma ou mais derivações e com glicemia e creatinina mais elevadas ao chegarem à emergência. 
Tabela 4. Características basais de acordo com o valor da troponina

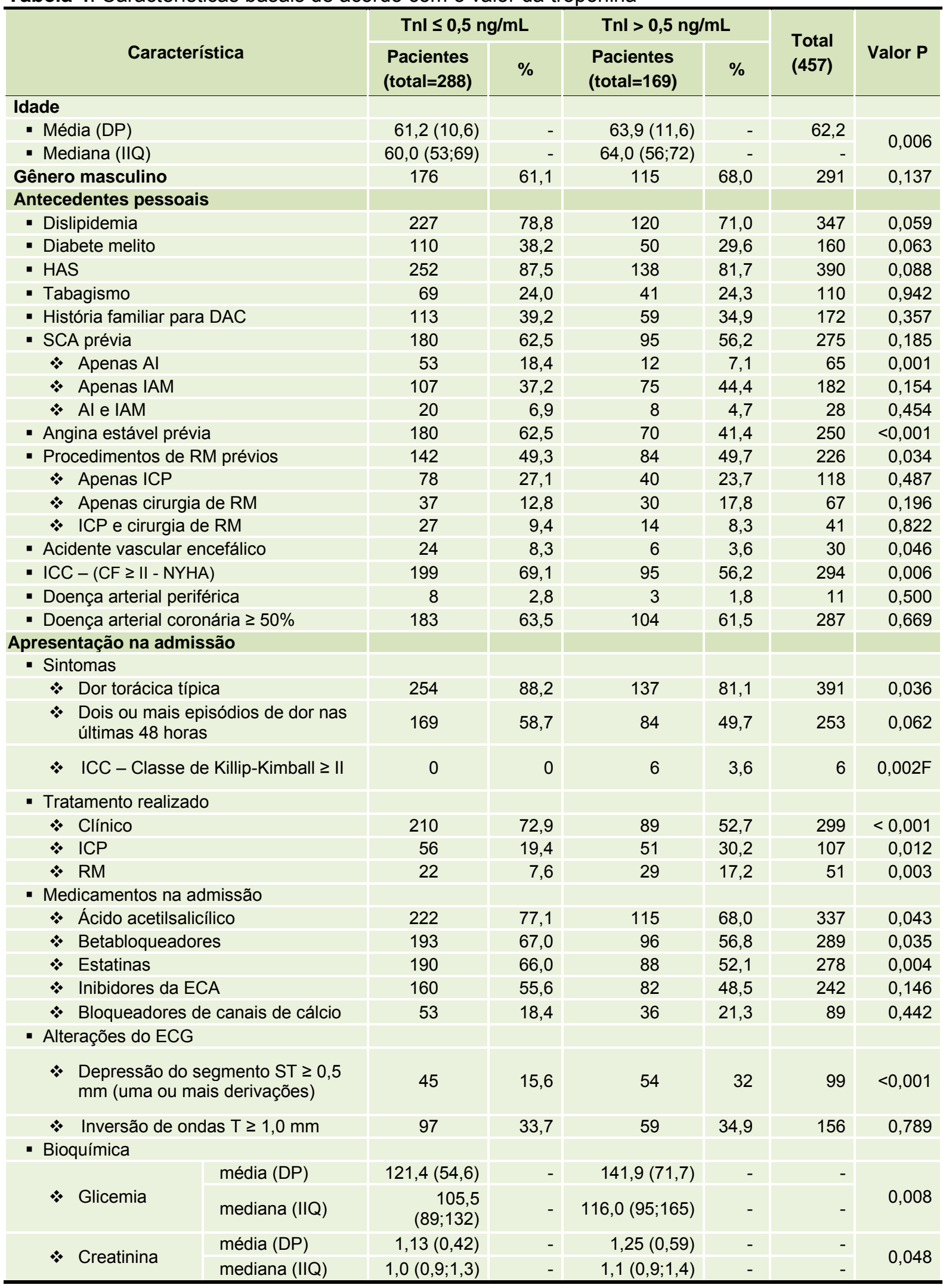

Notas: NYHA - Classificação segundo a New York Heart Association; DP=desvio-padrão; IIQ=intervalo interquartílico; $\mathrm{Tnl}=$ troponina I; HAS=hipertensão arterial sistêmica; $\mathrm{DAC}=$ doença arterial coronária; SCA=síndrome coronária aguda; $\mathrm{Al}=$ =angina instável; $\mathrm{IAM}=$ infarto agudo do miocárdio; $\mathrm{RM}=$ revascularização do miocárdio; $\mathrm{ICP}=$ =intervenção coronária percutânea; ICC=insuficiência cardíaca congestiva; ECA=enzima conversora da angiotensina; ECG=eletrocardiograma. 
Nos dados da Tabela 5 foram descritos as características demográficas e os fatores clínicos na apresentação no setor de emergências, levando-se em consideração o uso ou não de IECA previamente à internação.

Tabela 5. Características basais de acordo com uso ou não uso prévio de IECA

\begin{tabular}{|c|c|c|c|c|c|c|}
\hline \multirow{2}{*}{ Característica } & \multicolumn{2}{|c|}{ Uso prévio } & \multicolumn{2}{|c|}{ Não uso prévio } & \multirow{2}{*}{$\begin{array}{l}\text { Total } \\
(457)\end{array}$} & \multirow{2}{*}{$\begin{array}{c}\text { Valor } \\
\mathbf{p}\end{array}$} \\
\hline & $\begin{array}{l}\text { Pacientes } \\
\text { (total=242) }\end{array}$ & $\%$ & $\begin{array}{l}\text { Pacientes } \\
\text { (total=215) }\end{array}$ & $\%$ & & \\
\hline $\begin{array}{l}\text { - Idade } \begin{array}{c}\text { Média (DP) } \\
\text { Mediana (IIQ) }\end{array}\end{array}$ & $\begin{array}{l}61,6(10,3) \\
60(54 ; 69)\end{array}$ & - & $\begin{array}{l}62,8(11,8) \\
62(54 ; 72)\end{array}$ & - & $62,2(11,0)$ & - \\
\hline Gênero masculino & 148 & 61,2 & 143 & 66,5 & 291 & 0,235 \\
\hline \multicolumn{7}{|l|}{ Antecedentes pessoais } \\
\hline - HAS & 221 & 91,3 & 169 & 78,6 & 390 & $<0,001$ \\
\hline - Dislipidemia & 191 & 78,9 & 156 & 72,6 & 347 & 0,112 \\
\hline - ICC (CF $\geq \mathrm{II}$ - NYHA) & 167 & 69,0 & 127 & 59,1 & 294 & 0,027 \\
\hline - SCA prévia & 167 & 69,0 & 108 & 50,2 & 275 & $<0,001$ \\
\hline - Apenas Al & 34 & 14,0 & 31 & 14,4 & 65 & 1,000 \\
\hline * Apenas IAM & 113 & 46,7 & 69 & 32,1 & 182 & 0,002 \\
\hline$*$ Al e IAM & 20 & 8,3 & 8 & 3,7 & 28 & 0,068 \\
\hline - Procedimentos de RM prévios & 135 & 55,8 & 91 & 42,3 & 226 & 0,004 \\
\hline * Apenas ICP & 73 & 30,2 & 45 & 20,9 & 118 & 0,032 \\
\hline * Apenas cirurgia de RM & 37 & 15,3 & 30 & 14,0 & 67 & 0,787 \\
\hline * ICP e cirurgia de RM & 25 & 10,3 & 16 & 7,4 & 41 & 0,360 \\
\hline - Diabete melito & 82 & 33,9 & 78 & 36,3 & 160 & 0,592 \\
\hline - História familiar para DAC & 93 & 38,4 & 79 & 36,7 & 172 & 0,710 \\
\hline - Tabagismo & 62 & 25,6 & 48 & 22,3 & 110 & 0,411 \\
\hline - Acidente vascular encefálico & 18 & 7,4 & 12 & 5,6 & 30 & 0,424 \\
\hline - Doença arterial periférica & 3 & 1,2 & 8 & 3,7 & 11 & 0,084 \\
\hline $\begin{array}{l}\text { - Doença arterial coronária } \geq \\
50 \%\end{array}$ & 169 & 69,8 & 118 & 54,9 & 287 & 0,001 \\
\hline \multicolumn{7}{|l|}{ Apresentação na admissão } \\
\hline \multicolumn{7}{|l|}{ - Medicamentos na admissão } \\
\hline * Ácido acetilsalicílico & 199 & 82,2 & 138 & 64,2 & 337 & $<0,001$ \\
\hline Betabloqueadores & 167 & 69,0 & 122 & 56,7 & 289 & 0,008 \\
\hline * Estatinas & 169 & 69,8 & 109 & 50,7 & 278 & $<0,001$ \\
\hline * Nitratos & 97 & 40,1 & 77 & 35,8 & 174 & 0,368 \\
\hline * Diuréticos & 98 & 40,5 & 66 & 30,7 & 164 & 0,032 \\
\hline $\begin{array}{l}\text { Bloqueadores de canais } \\
\text { de cálcio }\end{array}$ & 47 & 19,4 & 42 & 19,5 & 89 & 0,937 \\
\hline * Clopidogrel & 20 & 8,3 & 12 & 5,6 & 32 & 0,274 \\
\hline * Digitálicos & 11 & 4,5 & 3 & 1,4 & 14 & 0,053 \\
\hline
\end{tabular}


Característica

- Sintomas

* Dor torácica típica

* Dor torácica atípica

- Dispneia*

* Síncope*

Dor precordial no momento da admissão

Número de episódios de dor nas últimas 48 horas

Dois ou mais episódios

Instabilidade hemodinâmica na admissão**

Frequência cardíaca (bpm)

Pressão arterial sistólica $(\mathrm{mmHg})$

Pressão arterial diastólica $(\mathrm{mmHg})$

ICC - Classe de Killip-Kimball

II

Alterações do ECG

Depressão do segmento $S T \geq 0,5$ $\mathrm{mm}$ (uma ou mais derivações)

Inversão de ondas $T \geq 1,0 \mathrm{~mm}$

Diagnóstico

\section{IAMSSST}

Angina instável III B

Angina instável III C

\begin{tabular}{|c|c|c|}
\hline \multicolumn{2}{|c|}{ Uso prévio } & \multicolumn{2}{c|}{ Não uso prévio } \\
\hline $\begin{array}{c}\text { Pacientes } \\
\text { (total=242) }\end{array}$ & $\%$ & $\begin{array}{l}\text { Pacientes } \\
\text { (total=215) }\end{array}$
\end{tabular}

Total

(457)

Valor

p

\begin{tabular}{|r|r|r|r|r|r|}
\hline 212 & 87,6 & 179 & 83,3 & 391 & 0,187 \\
\hline 30 & 12,4 & 36 & 16,7 & 66 & 0,235 \\
\hline 4 & 1,2 & 11 & 5,1 & 14 & 0,016 \\
\hline 153 & 63,2 & 0 & 0,0 & 4 & 0,058 \\
\hline & & 128 & 59,5 & 281 & 0,419 \\
\hline 144 & 59,5 & 109 & 50,7 & 253 & 0,059 \\
\hline 5 & 2,1 & 3 & 1,4 & 8 & 0,585 \\
\hline 34,61 & - & 77,29 & - & 75,86 & 0,197 \\
\hline 83,30 & - & 139,77 & - & 139,61 & 0,915 \\
\hline
\end{tabular}

\begin{tabular}{|r|r|r|r|r|r|}
\hline 239 & 98,8 & 212 & 98,6 & 451 & $0,891 \mathrm{~F}$ \\
\hline 1 & 0,4 & 1 & 0,5 & 2 & \\
\hline 1 & 0,4 & 2 & 0,9 & 3 & \\
\hline 1 & 0,4 & 0 & 0,0 & 1 & \\
\hline 43 & 17,8 & 56 & 26,0 & 99 & 0,032 \\
\hline 90 & 37,2 & 66 & 30,7 & 156 & 0,144 \\
\hline 82 & 33,9 & 87 & 40,5 & 169 & $0,174 \mathrm{~F}$ \\
\hline 160 & 66,1 & 127 & 59,1 & 287 & \\
\hline 0 & 0,0 & 1 & 0,5 & 1 & \\
\hline
\end{tabular}

Notas: *Sintomas associados à dor torácica; **Pressão arterial sistólica < $90 \mathrm{mmHg}$; NYHA - Classificação segundo a New York Heart Association; IECA=inibidor de enzima de conversão da angiotensina; HAS=hipertensão arterial sistêmica; ICC=insuficiência cardíaca congestiva; SCA=síndrome coronária aguda; $A \mid=a n g i n a$ instável; $\mid A M=i n f a r t o$ agudo do miocárdio; RM=revascularização do miocárdio; ICP=intervenção coronária percutânea; $D A C=$ doença arterial coronária; ECG=eletrocardiograma; IAMSSST=infarto agudo do miocárdio sem elevação do segmento ST; $\mathrm{mm}=$ milímetros; $\mathrm{F}=$ teste de Fisher.

Observa-se que os pacientes que faziam uso de IECA antes da admissão hospitalar, eram mais hipertensos; apresentaram história de ICC CF $\geq I$ (NYHA) em algum momento de seu histórico clínico; história de IAM prévio, realizaram mais ICP; maior quantidade de coronárias acometidas (lesões acima de 50\%) e eram usuários de mais AAS, betabloqueadores, estatinas, diuréticos e digitálicos. Todos essas 
características demonstravam inequivocamente uma população de alto risco para doença cardiovascular.

\subsection{Análise eletrocardiográfica}

Os dados da Tabela 6 demonstram as alterações eletrocardiográficas consideradas de importância observadas nos pacientes em sua admissão.

Tabela 6. Variáveis eletrocardiográficas qualitativas

\begin{tabular}{l|c|c}
\hline \multicolumn{1}{|c|}{ Variável } & $\begin{array}{c}\text { Pacientes } \\
\text { (total=457) }\end{array}$ & $\%$ \\
\hline $\begin{array}{l}\text { Depressão do segmento ST } \geq 0,5 \mathrm{~mm} \text { em duas } \\
\text { derivações contíguas (exceção de aVR) }\end{array}$ & 64 & 14,0 \\
\hline $\begin{array}{l}\text { Depressão do segmento ST } \geq 0,5 \mathrm{~mm} \text { em, pelo menos, } \\
\text { uma derivação (exceção de aVR) }\end{array}$ & 99 & 21,7 \\
\hline $\begin{array}{l}\text { Inversão da onda T } \geq 1 \mathrm{~mm} \text { em duas derivações } \\
\text { contíguas (exceção de aVR) }\end{array}$ & 156 & 34,1 \\
\hline Nota: mm=milímetros. & &
\end{tabular}

\subsection{Análise laboratorial}

Conforme o protocolo observado no Anexo $\mathrm{C}$, foi realizada a coleta de sangue, assim que os pacientes assinaram o Termo de Consentimento Livre e Esclarecido. Os resultados dos exames laboratoriais estão apresentados nos dados da Tabela 7. 
Tabela 7. Alterações laboratoriais da população do estudo

\begin{tabular}{|c|c|c|c|c|c|}
\hline \multirow{2}{*}{ Exame } & \multirow{2}{*}{ Média } & \multirow{2}{*}{$\begin{array}{l}\text { Desvio- } \\
\text { padrão }\end{array}$} & \multirow{2}{*}{ Mediana } & \multicolumn{2}{|c|}{ Valor de referência } \\
\hline & & & & Homem & Mulher \\
\hline Troponina I*(ng/mL) & 3,55 & 13,24 & 0,16 & $\leq 0,5$ & $\leq 0,5$ \\
\hline CPK (U/L) & 198,98 & 300,37 & 100,00 & 39 a 308 & 26 a 192 \\
\hline CK-MB atividade (U/L) & 11,92 & 20,99 & 6,00 & 0 a 6 & 0 a 6 \\
\hline CK-MB massa (ng/mL) & 11,10 & 33,62 & 1,80 & 0 a 3,6 & 0 a 3,6 \\
\hline Glicemia (mg/dL) & 129,21 & 62,37 & 109,00 & 70 a 99 & 70 a 99 \\
\hline Creatinina (mg/dL) & 1,17 & 0,50 & 1,10 & 0,8 a 1,3 & 0,6 a 1,0 \\
\hline Potássio (mmol/L) & 4,33 & 0,60 & 4,30 & 3,5 a 5,1 & 3,5 a 5,1 \\
\hline Leucócitos (x/uL) & 8016 & 2921 & 7700 & 3500 a 11000 & 3500 a 11000 \\
\hline Hematócrito (\%) & 41,19 & 5,46 & 41,40 & 40 a 52 & 35 a 47 \\
\hline Hemoglobina (g/dL) & 13,64 & 1,85 & 13,70 & 13 a 18 & 12 a 16 \\
\hline
\end{tabular}

Notas: $\mathrm{CPK}=$ creatinafosfoquinase; $\mathrm{CK}-\mathrm{MB}=$ fração $\mathrm{MB}$ da creatinafosfoquinase. Obs:* Apesar desta pesquisa utilizar a troponina como medida qualitativa, nesta tabela foram observadas a média, o desvio padrão e a mediana dos valores coletados nos pacientes.

\subsection{Tratamento durante a internação}

Os pacientes foram medicados, conforme as diretrizes nacionais ${ }^{18} \mathrm{e}$ internacionais $^{6}$, com alta porcentagem de uso de AAS, clopidogrel, estatinas, betabloquedores, IECA, enoxaparina e nitroglicerina endovenosa. Os dados da Tabela 8 demonstram a utilização dos medicamentos durante o período hospitalar. 
Tabela 8. Medicamentos utilizados durante a internação hospitalar

\begin{tabular}{|c|c|c|c|}
\hline & Medicamento & $\begin{array}{l}\text { Pacientes } \\
\text { (total=457) }\end{array}$ & $\%$ \\
\hline$*$ & Ácido acetilsalicílico & 451 & 98,7 \\
\hline$*$ & Clopidogrel & 440 & 96,3 \\
\hline$*$ & Estatinas & 438 & 95,8 \\
\hline$*$ & Betabloqueadores VO & 433 & 94,7 \\
\hline$*$ & Inibidores da enzima conversora da angiotensina & 358 & 78,3 \\
\hline$*$ & Enoxaparina & 347 & 75,9 \\
\hline$*$ & Nitroglicerina EV & 317 & 69,4 \\
\hline$*$ & Nitratos VO & 170 & 37,2 \\
\hline$*$ & Diuréticos & 157 & 34,4 \\
\hline 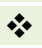 & Heparina não fracionada & 124 & 27,1 \\
\hline$*$ & Bloqueadores dos canais de cálcio & 112 & 24,5 \\
\hline$*$ & Antagonistas da angiotensina II & 95 & 20,8 \\
\hline$*$ & Heparina SC & 43 & 9,4 \\
\hline 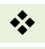 & Amiodarona & 33 & 7,2 \\
\hline$\star$ & Nitrato SL na admissão & 11 & 2,4 \\
\hline$*$ & Digitálicos & 8 & 1,8 \\
\hline$\star$ & Betabloqueadores EV na admissão & 4 & 0,9 \\
\hline$*$ & Tirofiban & 2 & 0,4 \\
\hline & Outros & 362 & 79,2 \\
\hline
\end{tabular}

Notas: $\mathrm{VO}=$ via oral; $\mathrm{EV}=$ endovenosa; $\mathrm{SC}=$ subcutâneo; $\mathrm{SL}=$ sublingual.

De acordo com a avaliação clínica, baseada no escore TIMI $^{30}$ e levando-se em consideração outros marcadores independentes, 319 (69,8\%) pacientes realizaram cineangiocoronariografia (cine) durante a internação.

Dos 457 pacientes da pesquisa clínica, 299 (65,4\%) fizeram somente tratamento medicamentoso, 107 (23,4\%) intervenção coronária percutânea (ICP) e 51 (11,2\%) foram submetidos à revascularização cirúrgica (RM) durante a internação. No entanto, quando foram somente analisados os pacientes submetidos à cine nessa internação, houve a indicação de ICP em 103 pacientes (32,3\%) e RM em 43 pacientes (13,5\%). Além desses, faz-se mister documentar que quatro pacientes realizaram ICP e oito RM com cine realizada previamente à internação (Tabela 9). 
Tabela 9. Cine na internação e tratamento realizado

\begin{tabular}{|c|c|c|c|c|c|c|}
\hline \multirow{3}{*}{ Cine na internação } & \multicolumn{2}{|c|}{ Sim } & \multicolumn{2}{|c|}{ Não } & \multicolumn{2}{|c|}{ Total } \\
\hline & Pacientes & $\%$ & Pacientes & $\%$ & Pacientes & $\%$ \\
\hline & 319 & 69,8 & 138 & 30,2 & 457 & 100,0 \\
\hline \multicolumn{7}{|l|}{ Tratamento realizado } \\
\hline Clínico & 173 & 54,2 & 126 & 91,3 & 299 & 65,4 \\
\hline Intervenção coronária percutânea & 103 & 32,3 & 4 & 2,9 & 107 & 23,4 \\
\hline Revascularização do miocárdio & 43 & 13,5 & 8 & 5,8 & 51 & 11,2 \\
\hline Total & 319 & 100,0 & 138 & 100,0 & 457 & 100,0 \\
\hline
\end{tabular}

Nos dados da tabela 10 , demonstra-se que a elevação da troponina $(>0,5 \mathrm{ng} / \mathrm{mL})$ conferia diferença significativa no tipo de tratamento realizado, ou seja, o tratamento percutâneo e a revascularização cirúrgica eram feitos, respectivamente 2,6 e 3,1 vezes mais quando comparados ao tratamento clínico.

Tabela 10. Tratamento realizado de acordo com o valor da troponina

\begin{tabular}{|c|c|c|c|c|}
\hline \multirow{2}{*}{\multicolumn{2}{|c|}{ Tratamento }} & \multicolumn{2}{|c|}{ Troponina I } & \multirow{2}{*}{ Total } \\
\hline & & $\leq 0,5 \mathrm{ng} / \mathrm{mL}$ & $>0,5 \mathrm{ng} / \mathrm{mL}$ & \\
\hline \multirow{4}{*}{ Clínico $^{(1)}$} & Número de pacientes & 210 & 89 & 299 \\
\hline & Tratamento indicado $(\%)^{(2)}$ & 70,2 & 29,8 & 100,0 \\
\hline & Troponina I (\%) $)^{(3)}$ & 72,9 & 52,7 & 65,4 \\
\hline & Resíduo padronizado & 4,4 & $-4,4$ & - \\
\hline \multirow{4}{*}{$\begin{array}{l}\text { Intervenção } \\
\text { coronária }^{(1)} \\
\text { percutânea }^{(1)}\end{array}$} & Número de pacientes & 56 & 51 & 107 \\
\hline & Tratamento indicado $(\%)^{(2)}$ & 52,3 & 47,7 & 100,0 \\
\hline & Troponina I (\%) $)^{(3)}$ & 19,4 & 30,2 & 23,4 \\
\hline & Resíduo padronizado & $-2,6$ & 2,6 & - \\
\hline \multirow{4}{*}{$\begin{array}{c}\text { Revascularização } \\
\text { do miocárdio }\end{array}$} & Número de pacientes & 22 & 29 & 51 \\
\hline & Tratamento indicado $(\%)^{(2)}$ & 43,1 & 56,9 & 100,0 \\
\hline & Troponina I (\%) $)^{(3)}$ & 7,6 & 17,2 & 11,2 \\
\hline & Resíduo padronizado & $-3,1$ & 3,1 & - \\
\hline \multirow{3}{*}{ Total } & Número de pacientes & 288 & 169 & 457 \\
\hline & Tratamento indicado (\%) $)^{(2)}$ & 63,0 & 37,0 & 100,0 \\
\hline & Troponina I (\%) & 100,0 & 100,0 & 100,0 \\
\hline
\end{tabular}

Notas: (1) Valor $p<0,001$. (2) Distribuição (\%) dos pacientes por mensuração da troponina. (3) Distribuição (\%) dos pacientes por tipo de tratamento. 
Nos dados da Tabela D1 (Anexo D), fica caracterizado que o fator uso ou não uso de IECA antes da admissão hospitalar não influenciou o tipo de tratamento realizado pelos pacientes.

\subsection{Evolução no período hospitalar}

Inicialmente, os pacientes foram internados no Pronto-Socorro, porém, alguns, posteriormente, foram transferidos à Unidade Coronária, onde seguiram tratamento sob a supervisão do pesquisador. O tempo médio de internação foi de 6,1 dias.

Durante o período de internação, $47(10,5 \%)$ pacientes do total da amostra apresentaram algum tipo de complicação: dez (21,3\%) faleceram; dez (21,3\%) evoluíram com ICC; seis $(12,8 \%)$ com arritmias cardíacas não fatais; seis $(12,8 \%)$ com choque cardiogênico (Chc); quatro $(8,5 \%)$ com IAM; três $(6,4 \%)$ com edema agudo de pulmão; três $(6,4 \%)$ com parada cardiorrespiratória revertida, além de outras descritas nos dados da Tabela 11.

A causa mortis observada nos dez pacientes foi: Chc (cinco pacientes); IAM (três pacientes) e choque séptico (ChS)(dois pacientes). 
Tabela 11. Complicações durante a internação hospitalar

\begin{tabular}{|c|c|c|}
\hline Complicação & $\begin{array}{l}\text { Pacientes } \\
\text { (total=457) }\end{array}$ & $\%$ \\
\hline * Óbito & 10 & 2,2 \\
\hline * Insuficiência cardíaca congestiva & 10 & 2,2 \\
\hline * Arritmia cardíaca & 6 & 1,3 \\
\hline * Choque cardiogênico & 6 & 1,3 \\
\hline * Infarto agudo do miocárdio & 4 & 0,8 \\
\hline * Edema agudo de pulmão & 3 & 0,6 \\
\hline * Parada cardiorrespiratória & 3 & 0,6 \\
\hline * Angina refratária ou recorrente & 2 & 0,4 \\
\hline * Acidente vascular encefálico & 2 & 0,4 \\
\hline * Reinfarto & 1 & 0,2 \\
\hline Total & 47 & \\
\hline
\end{tabular}

\subsection{Desfechos clínicos}

Os desfechos primários analisados foram óbito por todas as causas e infarto (reinfarto) em até 180 dias (Tabela 12). Nos dados desta Tabela, ficou evidente que a maioria dos óbitos foi de causa cardiovascular, predominando $\mathrm{ChC}$ em onze pacientes $(39,2 \%)$ e IAM em oito pacientes $(28,6 \%)$ quando considerados com relação ao total de óbitos. Ainda nos dados das Tabelas D2 e D3 (Anexo D) foram determinadas todas as características demográficas e os fatores clínicos dos pacientes e as alterações laboratoriais daqueles que faleceram em até 180 dias, respectivamente. 
Tabela 12. Causas de óbito em até 180 dias

\begin{tabular}{|c|c|c|}
\hline Causa do óbito & $\begin{array}{l}\text { Pacientes } \\
\text { (total=457) }\end{array}$ & $\%$ \\
\hline * Choque cardiogênico & 11 & 2,4 \\
\hline * Infarto agudo do miocárdio & 8 & 1,7 \\
\hline * Choque séptico & 3 & 0,6 \\
\hline * Disfunção de múltiplos órgãos e sistemas & 1 & 0,2 \\
\hline * Choque hemorrágico & 1 & 0,2 \\
\hline * Coma a esclarecer & 1 & 0,2 \\
\hline * Arritmia cardíaca & 1 & 0,2 \\
\hline * Tromboembolismo pulmonar & 1 & 0,2 \\
\hline * Morte súbita & 1 & 0,2 \\
\hline Total & 28 & \\
\hline
\end{tabular}

\subsection{Análise estatística das variáveis selecionadas}

Para esta pesquisa, foram selecionadas todas as variáveis já devidamente enumeradas no item 3.7, assim, optou-se pela elaboração de dois modelos de análise estatística, conforme observado nos dados das Tabelas 13 e 14 (modelos iniciais e finais de troponina $>0,5 \mathrm{ng} / \mathrm{mL}$ ) e Tabelas 15 e 16 (modelos iniciais e finais de óbito em 180 dias). 
Tabela 13. Modelo inicial de troponina $>0,5 \mathrm{ng} / \mathrm{mL}$

\begin{tabular}{|c|c|c|c|c|c|}
\hline Variável analisada & Efeito & EP & OR & IC 95\% & $\mathbf{p}$ \\
\hline Idade (anos) & 0,008 & 0,013 & 1,008 & {$[0,983 ; 1,034]$} & 0,5123 \\
\hline Gênero masculino & $-0,502$ & 0,321 & 0,606 & {$[0,323 ; 1,137]$} & 0,1186 \\
\hline \multicolumn{6}{|l|}{ Antecedentes pessoais } \\
\hline - Hipertensão Arterial Sistêmica & $-0,409$ & 0,389 & 0,664 & {$[0,310 ; 1,425]$} & 0,2938 \\
\hline - Diabete melito & $-0,653$ & 0,362 & 0,520 & {$[0,256 ; 1,059]$} & 0,0716 \\
\hline - Dislipidemia & $-0,288$ & 0,339 & 0,750 & {$[0,386 ; 1,457]$} & 0,3954 \\
\hline - Angina Instável & $-0,404$ & 0,406 & 0,668 & {$[0,301 ; 1,481]$} & 0,3204 \\
\hline - Infarto Agudo do Miocárdio & 0,386 & 0,349 & 1,470 & {$[0,742 ; 2,915]$} & 0,2695 \\
\hline - Revascularização Miocárdica prévia & 0,277 & 0,369 & 1,320 & {$[0,640 ; 2,723]$} & 0,4528 \\
\hline - Angina estável & $-0,984$ & 0,328 & 0,374 & {$[0,197 ; 0,711]$} & 0,0027 \\
\hline - Insuficiência Cardíaca Congestiva & $-0,338$ & 0,324 & 0,713 & {$[0,378 ; 1,345]$} & 0,2960 \\
\hline - Acidente Vascular Encefálico & $-0,821$ & 0,700 & 0,440 & {$[0,112 ; 1,736]$} & 0,2410 \\
\hline Dor típica na admissão & $-0,734$ & 0,403 & 0,480 & {$[0,218 ; 1,057]$} & 0,0683 \\
\hline \multicolumn{6}{|l|}{ Laboratório de admissão } \\
\hline - Creatinina & 0,420 & 0,348 & 1,522 & {$[0,769 ; 3,011]$} & 0,2281 \\
\hline - Glicemia & 0,007 & 0,003 & 1,007 & {$[1,002 ; 1,012]$} & 0,0097 \\
\hline \multicolumn{6}{|l|}{ Tratamento indicado } \\
\hline - Clínico & - & - & - & - & 0,0001 \\
\hline - Intervenção Coronária Percutânea & 1,179 & 0,346 & 3,250 & {$[1,650 ; 6$} & 0,0007 \\
\hline - Revascularização do Miocárdio & 1,525 & 0,448 & 4,596 & {$[1,912 ; 11,051]$} & 0,0007 \\
\hline \multicolumn{6}{|l|}{ Medicamentos prévios à internação } \\
\hline - Ácido acetilsalicílico & $-0,335$ & 0,394 & 0,715 & {$[0,330 ; 1,549]$} & 0,3949 \\
\hline - Betabloqueadores & $-0,118$ & 0,333 & 0,888 & {$[0,462 ; 1,708]$} & 0,7225 \\
\hline - Estatinas & $-0,146$ & 0,363 & 0,864 & {$[0,424 ; 1,761]$} & 0,6871 \\
\hline - IECA & $-0,409$ & 0,288 & 0,664 & {$[0,378 ; 1,168]$} & 0,1555 \\
\hline Depressão do segmento $S T \geq 0,5 \mathrm{~m}$ & 0,922 & 0,323 & 2,514 & {$[1,335 ; 4,733]$} & 0,0043 \\
\hline
\end{tabular}

Notas: EP=erro-padrão; OR=razão de chance; IC 95\%=intervalo de confiança; IECA=inibidores da enzima conversora da angiotensina.

Tabela 14. Modelo final de troponina $>0,5 \mathrm{ng} / \mathrm{mL}$

\begin{tabular}{|c|c|c|c|c|c|c|}
\hline \multicolumn{2}{|c|}{ Variável analisada } & Efeito & EP & OR & IC 95\% & $\mathbf{p}$ \\
\hline \multirow{2}{*}{ Antecedentes pessoais } & Diabete melito & $-0,698$ & 0,343 & 0,498 & {$[0,254 ; 0,975]$} & 0,0419 \\
\hline & Angina estável & $-1,254$ & 0,278 & 0,285 & {$[0,165 ; 0,492]$} & $<0,001$ \\
\hline \multicolumn{2}{|l|}{ Dor típica na admissão } & $-0,878$ & 0,375 & 0,416 & {$[0,199 ; 0,867]$} & 0,0193 \\
\hline \multicolumn{2}{|l|}{ Glicemia na admissão } & 0,008 & 0,003 & 1,008 & {$[1,003 ; 1,013]$} & 0,0034 \\
\hline \multicolumn{2}{|l|}{ Tratamento clínico } & & - & - & - & 0,0002 \\
\hline \multicolumn{2}{|c|}{ Intervenção coronária percutânea } & 1,089 & 0,325 & 2,973 & {$[1,572 ; 5,622]$} & 0,0008 \\
\hline \multicolumn{2}{|c|}{ Revascularização do miocárdio } & 1,400 & 0,413 & 4,055 & {$[1,806 ; 9,103]$} & 0,0007 \\
\hline \multicolumn{2}{|c|}{ Uso de IECA prévio à internação } & $-0,520$ & 0,263 & 0,594 & {$[0,355 ; 0,996]$} & 0,0482 \\
\hline \multicolumn{2}{|c|}{ Depressão do segmento $S T \geq 0,5 \mathrm{~mm}$} & 0,971 & 0,307 & 2,641 & {$[1,447 ; 4,818]$} & 0,0016 \\
\hline
\end{tabular}


Por este modelo, observa-se que os antecedentes pessoais de diabete melito e angina estável reduzem as chances da troponina ser maior que $0,5 \mathrm{ng} / \mathrm{mL}$ em $50,2 \%$ $(p=0,0419)$ e $71,5 \%(p<0,001)$, respectivamente; a presença de dor típica na admissão reduz a chance da troponina ser maior que $0,5 \mathrm{ng} / \mathrm{mL}$ em $58,4 \%(p=0,0193)$; cada $1 \mathrm{mg} / \mathrm{dL}$ a mais na glicemia de admissão, aumenta a chance da troponina ser maior que $0,5 \mathrm{ng} / \mathrm{mL}$ em $0,8 \%(p=0,0034) ;$ o tratamento percutâneo e o cirúrgico aumentaram as chances da troponina ser maior que $0,5 \mathrm{ng} / \mathrm{mL}$ em 2,9 $(p=0,0008)$ e $4(p=0,0007)$ vezes quando comparados ao tratamento clínico; o uso de IECA previamente à internação reduziu a chance da troponina ser maior que $0,5 \mathrm{ng} / \mathrm{mL}$ em $40,6 \%(p=0,0482)$ e a presença de depressão do segmento ST maior ou igual a $0,5 \mathrm{~mm}$ aumentou a chance da troponina ser maior que $0,5 \mathrm{ng} / \mathrm{mL}$ em 2,6 vezes $(p=0,0016)$.

Tabela 15. Modelo inicial de óbito em 180 dias

\begin{tabular}{|c|c|c|c|c|c|c|}
\hline \multicolumn{2}{|c|}{ Variável analisada } & $\begin{array}{c}\text { Efeito } \\
\text { B }\end{array}$ & $\begin{array}{l}\text { EP } \\
\text { se }\end{array}$ & $\begin{array}{l}\text { OR } \\
\text { exp }\end{array}$ & IC 95\% & $\begin{array}{l}P \\
\text { sig }\end{array}$ \\
\hline \multicolumn{2}{|l|}{ Idade (anos) } & 0,096 & 0,026 & 1,101 & $(1,045 ; 1,159)$ & $<0,001$ \\
\hline \multicolumn{2}{|c|}{ Insuficiência Cardíaca Congestiva prévia } & 0,957 & 0,627 & 2,604 & $(0,762: 8,893)$ & 0,127 \\
\hline \multicolumn{2}{|c|}{ Uso de diurético antes da internação } & 1,859 & 0,553 & 6,416 & $(2,171 ; 18,962)$ & 0,001 \\
\hline \multicolumn{2}{|c|}{ Pressão arterial sistólica na admissão $(\mathrm{mmHg})$} & $-0,019$ & 0,010 & 0,982 & $(0,962: 1,002)$ & 0,076 \\
\hline \multicolumn{2}{|c|}{ Frequência cardíaca na admissão (bpm) } & 0,021 & 0,013 & 1,021 & $(0,996: 1,047)$ & 0,094 \\
\hline \multicolumn{2}{|c|}{ Infra ST e Troponina normais } & & & & & 0,046 \\
\hline \multicolumn{2}{|l|}{ Somente Infra ST $>0,5 \mathrm{~mm}$} & 0,452 & 0,833 & 1,572 & $(0,307: 8,043)$ & 0,587 \\
\hline \multicolumn{2}{|c|}{ Somente Troponina $>0,5 \mathrm{ng} / \mathrm{mL}$} & 0,800 & 0,649 & 2,226 & $(0,624: 7,940)$ & 0,218 \\
\hline \multicolumn{2}{|c|}{ Troponina $>0,5 \mathrm{ng} / \mathrm{mL}$ e Infra ST $>0,5 \mathrm{~mm}$} & 1,995 & 0,715 & 7,355 & $(1,812: 29,859)$ & 0,005 \\
\hline \multirow{4}{*}{ Laboratório de admissão } & Creatinina & 0,119 & 0,412 & 1,126 & $(0,503 ; 2,524)$ & 0,773 \\
\hline & Potássio & 0,308 & 0,359 & 1,361 & $(0,674: 2,748)$ & 0,390 \\
\hline & Leucócitos & $<0,001$ & $<0,001$ & 1,000 & $(1,000 ; 1,000)$ & 0,213 \\
\hline & Hemoglobina & $-0,139$ & 0,145 & 0,870 & $(0,655 ; 1,156)$ & 0,337 \\
\hline \multirow{2}{*}{ Antecedentes pessoais } & Diabete melito & 0,649 & 0,522 & 1,913 & $(0,688: 5,325)$ & 0,214 \\
\hline & RM prévia & $-1,113$ & 0,530 & 0,328 & $(0,116 ; 0,928)$ & 0,036 \\
\hline
\end{tabular}

Notas: EP=erro-padrão; OR=razão de chance; IC 95\%=intervalo de confiança; CK-MB=fração MB da creatinafosfoquinase; $\mathrm{RM}=$ revascularização do miocárdio. 
Tabela 16. Modelo final de óbito em 180 dias

\begin{tabular}{|c|c|c|c|c|c|}
\hline Variável analisada & Efeito & EP & OR & IC 95\% & $\mathbf{p}$ \\
\hline Idade (anos) & 0,099 & 0,024 & 1,104 & $(1,054 ; 1,156)$ & $<0,001$ \\
\hline Uso de diurético antes da internação & 1,844 & 0,506 & 6,323 & $(2,346: 17,044)$ & $<0,001$ \\
\hline Pressão arterial sistólica na admissão $(\mathrm{mmHg})$ & $-0,018$ & 0,010 & 0,983 & $(0,964: 1,002)$ & 0,076 \\
\hline Depressão do segmento ST e troponina normais & & & & & 0,005 \\
\hline Somente depressão do segmento ST $>0,5 \mathrm{~mm}$ & 0,828 & 0,792 & 2,288 & $(0,485: 10,798)$ & 0,296 \\
\hline Somente troponina $>0,5 \mathrm{ng} / \mathrm{mL}$ & 0,758 & 0,601 & 2,135 & $(0,658: 6,927)$ & 0,207 \\
\hline $\begin{array}{l}\text { Depressão do segmento }>0,5 \mathrm{~mm} \text { e troponina }>0,5 \\
\mathrm{ng} / \mathrm{mL}\end{array}$ & 2,308 & 0,652 & 10,052 & $(2,798: 36,109)$ & $<0,001$ \\
\hline Antecedentes Pessoais RM Prévia & $-1,238$ & 0,498 & 0,290 & $(0,109 ; 0,769)$ & 0,013 \\
\hline
\end{tabular}

Por este modelo observou-se que a cada ano acrescido na idade, aumenta a chance de óbito em 10,4\% ( $p<0,001) ;$ o uso de diurético antes da admissão, aumenta a chance de óbito em 6,3 vezes $(p<0,001)$; cada $1 \mathrm{mmHg}$ a mais na pressão arterial sistólica, reduz a chance de óbito em $1,7 \%(p=0,076)$ e a presença de revascularização miocárdica prévia reduz a chance de óbito em $71 \%(p=0,013)$. Observou-se que havia interação entre as variáveis depressão do segmento ST maior ou igual a $0,5 \mathrm{~mm}$ e aumento de troponina acima de $0,5 \mathrm{ng} / \mathrm{mL}$. Desse modo, as duas variáveis foram avaliadas isoladas e em conjunto comparando-as com um grupo em que não havia estas duas alterações. Feitas estas observações, concluiu-se que, somente quando as duas variáveis estavam presentes, a chance de óbito aumentou em 10 vezes $(p<0,001)$. 


\section{DISCUSSÃO}

Desde os meados da década de 1980, o tratamento da doença coronária sofreu um grande avanço em termos de sua abordagem terapêutica com a era dos grandes estudos clínicos randomizados, aliados a uma atuação ímpar da indústria farmacêutica na produção de medicamentos, como novos antiagregantes plaquetários, antitrombínicos, anticoagulantes, betabloqueadores, inibidores da enzima de conversão da angiotensina (IECA) e hipolipemiantes da classe das estatinas. Tudo isso em consonância com as formas de estratificação de risco nas SCA que, em última instância, levariam a uma intervenção mais agressiva, cujo objetivo seria a redução de eventos clínicos graves em curto, médio e longo prazos, fortemente amparados por estudos baseados em evidências ${ }^{19}$.

Entre esses medicamentos, o uso dos IECA e sua atuação na SCA com ou sem supradesnivelamento do segmento ST, além de sua possível relação com a liberação do marcador de necrose miocárdica troponina tornou-se o cerne da discussão deste estudo clínico prospectivo e observacional realizado em um único centro de cardiologia, atrelando-se ao fato de que a presença desse marcador tem demonstrado inequivocamente um prognóstico desfavorável em pacientes admitidos com SCASSST ${ }^{17,59-68}$.

É uma população que apresenta um perfil de alto risco cardiovascular, independente da estratégia de estratificação utilizada na chegada dos pacientes à emergência, com uma alta mortalidade em todas as casuísticas realizadas no mundo ocidental $^{1-2}$. 
O uso dos IECA em pacientes com doença coronária foi demonstrado em vários trabalhos científicos ao longo das duas últimas décadas, tanto na SCASSST ${ }^{44,117-9}$ população alvo desta pesquisa - como nos pacientes com SCACSST, incluindo um que afirmou que os IECA são a classe de medicamentos que teve o maior impacto na medicina cardiovascular, por meio de seus efeitos na redução do risco de morte, IAM, AVE, diabete melito e falência renal ${ }^{120}$.

Nesse sentido, o racional para esta pesquisa foi basear-se no fato de que a redução da liberação de troponina I cardíaca em pacientes com SCASSST, poderia advir de uma 'proteção' por intermédio da inibição do sistema renina-angiotensinaaldosterona (SRAA), cujos efeitos deletérios estariam relacionados com a produção excessiva de angiotensina II, tanto local como sistêmica. Os vários benefícios abrangeriam um amplo espectro, desde a melhoria da atividade vasodilatadora coronária e periférica, redução da atividade plaquetária, aumento da fibrinólise endógena e redução da atividade anti-inflamatória, entre outros, conferindo o que se poderia denominar de efeito cardioprotetor ${ }^{40-42}$.

A troponina é considerada o mais sensível e específico marcador de necrose miocárdica para o diagnóstico de $\mathrm{IAM}^{16}$, apesar desse marcador poder estar elevado em outras situações clínicas, e assim, dificultar o diagnóstico diferencial de pacientes com dor torácica que adentram à emergência ${ }^{49}$. Nos anos de 1990, a troponina provocou uma verdadeira revolução no diagnóstico e no prognóstico desses pacientes - em curto, médio e longo prazos ${ }^{17,59-68}$. Além disso, na mesma época, com a introdução de novas abordagens na estratificação de risco de pacientes com SCASSST, em que Braunwald e cols. ${ }^{109}$ foram os pioneiros, outros escores desenharam-se com o objetivo de melhora da acurácia diagnóstica e prognóstica desses pacientes ${ }^{17,107-8}$ 
Nesse cenário de uma doença com alta mortalidade, um marcador com alta sensibilidade e especificidade e um medicamento que apresenta expressivas propriedades farmacológicas, haveria uma relação entre a inibição da enzima de conversão da angiotensina e os níveis de troponina? E isso implicaria em redução de eventos clínicos graves como morte ou re(infarto)? Levando esses fatores em consideração e tendo como base teórica estudos prévios ${ }^{116,121}$, esta pesquisa foi elaborada.

Um estudo realizado em 2001, por Kennon e cols. ${ }^{121}$ tentou correlacionar o uso de IECA e a redução da liberação de troponina em pacientes com SCASSST. Esse estudo realizou uma avaliação genética, evidenciando um polimorfismo gênico relacionado aos IECA, compostos por três genótipos distintos (DD,II,DI ou ID). A população estudada apresentava características demográficas diferentes da observada em nossa pesquisa, pois, embora houvesse uma alta porcentagem de IAM prévio e diabéticos, havia um índice de utilização de medicamentos previamente à internação como AAS, betabloqueadores, IECA e estatinas em baixos níveis, hoje inaceitáveis, para pacientes com esse grau de risco cardiovascular. Em sua conclusão, afirmam que a utilização de IECA reduziu os níveis de troponina em cerca de $75 \%$ e que poderia haver associação entre esta redução e seus efeitos benéficos tanto na reatividade vascular como no sistema de coagulação, podendo, desta forma, contribuir para a prevenção secundária em pacientes com doença coronária. Na avaliação genética, os resultados não demonstraram associação entre os níveis de troponina e o polimorfismo gênico (semelhante nos três grupos). Em contraposição a esse trabalho, os pacientes de nosso estudo são de mais alto risco cardiovascular, com história de SCA prévia (60,2\% x 27,3\%); IAM prévio (39,8\% x 35,9\%); procedimentos de RM prévios (49,5\% x $16,5 \%)$ e diabéticos $(35,0 \% \times 23,2 \%)$. Em nosso estudo, também foram utilizados 
medicamentos antes da admissão hospitalar em maior proporção como AAS $(73,9 \%$ x $55,1 \%)$; betabloqueadores $(63,4 \% \times 23,1 \%)$; IECA $(53,3 \% \times 14,8 \%)$ e estatinas $(61,0 \%$ x $15,6 \%$, portanto, à luz das mais recentes diretrizes nacionais ${ }^{18}$ e internacionais ${ }^{6}$, demonstrando assim pacientes com maior risco cardiovascular e sob tratamento clínico mais intensivo.

Um segundo estudo foi publicado em 2009, por dos Santos e cols. ${ }^{116}$ na elaboração do primeiro escore de risco nacional para pacientes com SCASSST. Nesse estudo observou-se que a utilização de IECA previamente à internação hospitalar conferiu 'proteção' aos pacientes, fato esse confirmado pela presença dessa variável no modelo final do escore de risco elaborado. Observação importante é que a população dessa pesquisa provém de um banco de dados com características semelhantes ao presente estudo, tanto em grau de risco cardiovascular, como na utilização de medicamentos prévios à internação.

Os benefícios da utilização de IECA em pacientes com SCASSST e SCACSST têm sido amplamente confirmados em grandes estudos clínicos, sobretudo naqueles que apresentam grandes infartos e consequente disfunção ventricular esquerda ${ }^{122-4}$. Apesar das evidentes diferenças em suas fisiopatologias, resultados interessantes puderam ser observados em um estudo retrospectivo publicado em 2010, em pacientes com SCACSST, realizado em um único centro dos EUA, com 511 pacientes incluídos entre 2004 e $2008^{125}$. Foram excluídos os que apresentavam história de doença cardiovascular, tanto nos leitos coronarianos, cerebrais ou periféricos, além dos diabéticos. Haveria a possibilidade de inclusão de pacientes com angina prévia, desde que nunca tivessem realizado cineangiocoronariografia. Os critérios de exclusão estão à margem das características clínicas encontradas no mundo real, diferindo assim dos maiores estudos relacionados à SCA. De qualquer forma, é o primeiro estudo tentando 
demonstrar o benefício do uso de IECA previamente a um evento de SCACSST. Seus resultados confirmaram que os pacientes que usavam IECA quando comparados aos que não utilizavam, apresentaram níveis de troponina significativamente menores na internação (79,8 ng/dL versus $120,0 \mathrm{ng} / \mathrm{dL} ; \mathrm{p}=0,016)$. Também foi observado que os hipertensos tratados com IECA em comparação com outros anti-hipertensivos tiveram redução da troponina de forma significativa $(79,8 \mathrm{ng} / \mathrm{dL}$ versus $146,2 \mathrm{ng} / \mathrm{dL} ; \mathrm{p}=0,003)$, apesar do controle dos níveis pressóricos equivalentes entre os dois grupos. Do ponto de vista medicamentoso, este efeito benéfico permaneceu, independente do uso concomitante de AAS e estatinas, medicações essas consideradas de alto efeito protetor na SCACSST. Por outro lado, observou-se que os níveis reduzidos de troponina em pacientes tratados com IECA não estavam relacionados com a extensão da disfunção ventricular esquerda - pela presença de uma proporção considerável de pacientes com infarto de parede anterior nesse grupo - sustentando a hipótese de utilização dessa classe de medicamentos, mesmo em pacientes sem comorbidades como doença vascular ou diabetes.

Um estudo realizado na Suécia analisou 87.241 pacientes que não utilizavam IECA previamente à internação hospitalar, em que foram incluídos 40.549 com SCACSST e 46.692 com SCASSST, no período entre 1995 e $2005^{126}$. Na alta hospitalar, foi prescrito IECA para $36,5 \%$ dos pacientes, nos quais foram avaliados os desfechos clínicos até o período de 1 ano. Os resultados corroboraram estudos prévios $^{122-4}$, com uma redução de mortalidade de $24 \%$ no período, sobretudo naqueles com história prévia ou atual de insuficiência cardíaca, além dos portadores de disfunção ventricular esquerda moderada a grave, demonstrando significativo benefício pelo uso desse medicamento $(p<0,001)$. No subgrupo de pacientes em uso de IECA com função ventricular esquerda preservada, houve redução de mortalidade, quando 
estivesse associada à disfunção renal moderada - diferente de estudos prévios ${ }^{44,117}$ em que uma redução de mortalidade e de novos episódios de IAM e AVE foi observada, independente da função renal. Os autores atribuem este fato, ao curto tempo de avaliação do estudo (1 ano), e, em decorrência disso, que o controle pressórico desses pacientes seria otimizado, com um tempo de tratamento mais prolongado, o que contribuiria para reduzir os desfechos clínicos. O risco de readmissão hospitalar por IAM em 1 ano foi de 17,4\% ( $p=0,794)$ em ambos os grupos usuários e não usuários de IECA -, porém, quando ajustados pelos fatores de risco e pelas medicações da alta hospitalar, os que usaram o medicamento tiveram redução de nova readmissão por IAM de 7\% (RR 0,93; IC 95\% 0,90 a 0,96). O risco de morte em 1 ano foi menor em pacientes sob uso de IECA (10,6\% versus $12,1 \% ; p<0,001)$, e após ajuste pelos fatores de risco e medicações na alta hospitalar, os pacientes tratados com IECA tiveram redução de morte de $24 \%$ (RR 0,76; IC 95\% 0,73 a 0,80), observando-se maior benefício do uso do medicamento em idosos e naqueles com história de insuficiência cardíaca congestiva. Os autores relataram suas limitações: dados de registro, não randomização, falta de controle das comorbidades, diferentes tratamentos utilizados (tipo e doses de IECA), além do fato da avaliação dos desfechos clínicos somente ser aplicada aos pacientes que sobreviveram à alta hospitalar, podendo alterar os resultados observados.

Em 2011, os investigadores dos estudos GRACE, GRACE $^{2}$ e CANRACE, realizaram uma análise retrospectiva de 1999 a 2008 com 13.632 pacientes ${ }^{127}$, em que tentaram correlacionar o uso de IECA previamente a uma internação por SCACSST (3.817 pacientes) e SCASSST (9.815 pacientes), com o intuito de avaliar a proporção de eventos clínicos graves intra-hospitalares. Foram comparados os usuários versus os não usuários de IECA, analisando características demográficas como antecedentes 
pessoais, medicações em uso, modo de apresentação clínica, alterações eletrocardiográficas na admissão e os exames laboratoriais, incluindo marcadores de necrose miocárdica (troponina e CK-MB). Alguns aspectos devem ser observados quando comparados à nossa população pesquisada. Apesar da semelhança quanto ao risco - elevado nos dois estudos - o período em que os dados foram obtidos, não contemplou uma terapêutica, conforme as diretrizes mais atuais dessas síndromes isquêmicas, e cerca de $20 \%$ dos pacientes com SCA e diabete melito não recebiam IECA. Nos resultados, observou-se que os usuários de IECA quando comparados aos não usuários, tiveram menor liberação de marcadores de necrose miocárdica dentro das primeiras 24 horas $(76,3 \%$ versus $67,3 \%, p<0,001$, respectivamente). A mortalidade hospitalar foi maior nos usuários de IECA $(p=0,012)$, porém, tornou-se não significativa quando o modelo foi ajustado a outros fatores prognósticos e uso de outras medicações. Nos pacientes usuários de IECA, aqueles com SCACSST tiveram mortalidade maior quando comparados aos com SCASSST, porém, após ajuste para fatores confundidores, taxas de reinfartos e a combinação de desfechos, como morte e reinfarto, a mortalidade tornou-se semelhante entre os dois grupos. Na conclusão do estudo, os autores afirmaram que o uso de IECA prévio não é independentemente associado à redução de eventos clínicos graves intra-hospitalares como reinfarto ou morte, após um quadro de SCACSST ou SCASSST. Conforme os autores, essa não correlação ocorreu em razão do alto risco cardiovascular dessa população, mesmo quando nos últimos anos do estudo a terapêutica havia sido otimizada. Observou-se que havia uma subutilização de antiplaquetários, anticoagulantes, cineangiocoronariografias e intervenções coronárias percutâneas em pacientes em uso de IECA. Havia também muitos pacientes com disfunção renal, o que provavelmente levou ao menor número de estudos hemodinâmicos e, consequentemente, à redução 
de intervenção coronária percutânea. Fatores como a não randomização; a exclusão de pacientes que não sobreviveram à hospitalização; os dados incompletos sobre o uso de outros antagonistas do eixo renina-angiotensina-aldosterona; a dose dos medicamentos não relatados; a duração do tratamento prévio com o IECA e a aderência ao medicamento utilizado e, por último, o pico do marcador não foi estabelecido pelo protocolo do estudo, podendo subestimar sua real magnitude e no diagnóstico de reinfarto, e, deste modo, interferindo nos seus resultados. Em contraposição, nosso estudo foi prospectivo, observacional, não excluiu nenhum paciente no período estabelecido, independente de idade, nível de creatinina ou qualquer outra característica demográfica e contemplava uma população de alto risco cardiovascular (Tabela 2), plenamente medicada, conforme as últimas diretrizes nacionais $^{18}$ e internacionais ${ }^{6}$ (Tabela 3 ). Históricamente, sabe-se, que pacientes com disfunção renal e idosos são, muitas vezes, excluídos dos ensaios clínicos por aumentarem o risco de eventos clínicos graves e dificultarem o manejo terapêutico, interferindo assim em sua otimização, além de não contemplação de um tratamento percutâneo diante de sua indicação. Nesta pesquisa, não foi excluído nenhum paciente durante o período estipulado, e realizou-se a melhor abordagem na internação; sendo ela percutânea ou cirúrgica; sempre em concordância com a equipe médica, paciente e seus familiares. No entanto, nos pacientes com disfunção renal e idosos, observou-se uma mortalidade aumentada em 180 dias de modo significativo $(p<0,001)$ (Tabela D2 Anexo D).

Os pacientes em uso de IECA compõem um grupo de alto risco cardiovascular, em que são incluídos diabéticos, hipertensos, com IAM prévio, com ICC e variados graus de disfunção ventricular, revascularizados, tanto percutânea como 
cirurgicamente, além do emprego de medicações de comprovada eficácia terapêutica com o objetivo de um controle clínico eficaz dessa população.

Nosso estudo foi desenhado na tentativa de demonstrar se haveria redução do marcador de necrose miocárdica relacionada ao uso de IECA, levando-se em consideração outras variáveis que poderiam interferir com a liberação desse marcador.

Analisando as características basais, observou-se que os valores de troponina encontravam-se acima do ponto de corte nos mais idosos $(p<0,001)$; naqueles com procedimentos de RM prévios $(p=0,034)$, nos pacientes com ICC classe funcional $\geq$ II (Killip-Kimball) na admissão $(p=0,002)$, naqueles submetidos a procedimentos percutâneos $(p=0,012)$ ou cirúrgicos $(p=0,003)$ durante a internação, além dos que apresentavam maior depressão do segmento ST ao eletrocardiograma $(p<0,001)($ Tabela 4$)$

Em um dos modelos estatísticos propostos, quando foram comparados os níveis de troponina $->0,5 \mathrm{ng} / \mathrm{dL}$ versus $\leq 0,5 \mathrm{ng} / \mathrm{dL}-$ nos pacientes que utilizaram IECA, observou-se um 'efeito protetor', pois a análise estatística do modelo final apresentou um $\beta$ coeficiente negativo $(-0,520)$ e (OR 0,59;IC 95\% 0,35 a 0,99; $p=0,048)$. Diante desses resultados, ficou explícita a correlação entre o uso de IECA e a menor liberação de troponina em pacientes com SCASSST em nossa casuística, porém, esta correlação não se traduziu em redução de eventos clínicos graves, como morte e re(infarto) em até 180 dias.

No outro modelo, a mortalidade em 180 dias foi significativa em pacientes idosos $(p<0,001)$, considerada uma variável independente de morte em todos os estudos clínicos de SCA; nos usuários de diuréticos $(p<0,001)$, e no grupo composto de pacientes com depressão do segmento ST acima de $0,5 \mathrm{~mm}$ e com níveis elevados de 
troponina $(p=0,005)$. Diante de uma mortalidade intra-hospitalar em nossa casuística de $(2,2 \%)$ e em 180 dias $(6,2 \%)$ serem consideradas baixas, observou-se que o uso de IECA previamente à internação hospitalar não se relacionou com a redução de morte, mas, em comparação ao grupo que não utilizava o medicamento, em 180 dias, a mortalidade nos usuários foi maior nos hipertensos $(p<0,001)$; naqueles com ICC (Classe NYHA $\geq I I)$ na admissão ( $p=0,027)$; com mais IAM prévios $(p=0,002)$; nos que realizaram mais procedimentos percutâneos antes da internação $(p=0,032)$ e utilizavam mais AAS $(p<0,001)$, betabloqueadores $(p=0,008)$, estatinas $(p<0,001)$, diuréticos $(p=0,032)$ e digitálicos $(p=0,053)($ Tabela 5$)$, características essas presentes em um grupo de alto risco cardiovascular.

Outras alterações laboratoriais que estiveram significativamente relacionadas com maior mortalidade em 180 dias, além dos níveis de creatinina, encontraram-se os níveis elevados de potássio $(p=0,025)$, a glicemia de chegada $(p=0,007)$ e os níveis de troponina $(p<0,001)($ Tabela D2 - Anexo D).

Alguns autores observaram que os efeitos clínicos benéficos advindos do uso de IECA tornam-se evidentes somente após cerca de 1 ano $^{117,128}$, e, nesta pesquisa, utilizou-se o período mínimo de 30 dias prévios à internação, como tempo de uso da medicação para critério de inclusão.

Outra questão refere-se às diferenças entre os IECA, pois em nossa pesquisa, esses medicamentos foram considerados como pertencentes a uma "classe". Há um estudo que avaliou as diferentes classes de IECA e correlacionou-as às idades dos pacientes, demonstrando diferenças entre as mesmas ${ }^{129}$. Mas, importantes diferenças farmacológicas existem entre os três grandes grupos de IECA em razão de sua estrutura química, podendo, assim, levar a efeitos clínicos diferenciados ${ }^{130}$. 
Uma última consideração a ser discutida, refere-se à dose terapêutica de IECA empregados previamente à internação hospitalar; pois em estudos clínicos, geralmente a dose é otimizada buscando resultados mais promissores; no entanto, a prática clínica diária ensina que nem sempre se consegue atingir os objetivos em sua plenitude ${ }^{118,128}$.

O estudo de outras populações diferentes da avaliada por esta pesquisa poderia levar a outros resultados, mas, no momento, não há registro na literatura médica de outro estudo, que contemple uma população de risco cardiovascular tão expressivo, em uso de uma terapêutica tão abrangente, amplamente recomendada pelas grandes associações de cardiologia reconhecidas mundialmente e que demonstre uma relação estatisticamente significativa entre o uso de IECA e a presença do marcador de necrose troponina I cardíaca em pacientes com SCASSST.

No entanto, na interpretação deste pesquisador, apesar desta correlação da troponina I cardíaca com o uso de IECA, muitos fatores demográficos, clínicos e laboratoriais estariam implicados nessa população de amplo espectro com SCASSST, para relacioná-la de modo significativo com a redução de eventos clínicos graves como morte e re(infarto), em um período de 180 dias. 


\section{LIMITAÇÕES}

O presente estudo apresentou algumas limitações:

- Trata-se de um estudo observacional, portanto, sem controle das comorbidades e tratamento prévios, incluindo-se aí o grau de risco dos pacientes avaliados;

- O número da amostra pode ter sido insuficiente para avaliar os desfechos clínicos definidos pelo estudo;

- O marcador de necrose miocárdica - troponina I cardíaca - foi avaliado como variável qualitativa, porém, sabe-se que quanto maior a liberação desse marcador, maior será implicação clínica, e, portanto, maiores as chances de eventos clínicos graves;

- Em nosso estudo, om uso de IECA foi considerado por, pelo menos, 30 dias prévios à internação hospitalar, porém, há dois estudos ${ }^{117,128}$, em que os autores observaram que o efeito do uso de IECA foi pleno, após sua utilização pelo período de 1 ano;

- As doses empregadas em estudos clínicos são superiores às da prática clínica diária em nosso meio, podendo com isso alterar alguns resultados do estudo $^{118,128}$

- Há um estudo com idosos demonstrando que a taxa de mortalidade em 1 ano, após IAM, foi diferente a depender do IECA utilizado, e em nossa população, a média de idade era de 62,2 anos ${ }^{129}$;

- O uso de IECA prévio foi avaliado como "classe", portanto, não temos respostas individuais diferenciadas para os três grupos químicos conhecidos. 


\section{CONCLUSÃO}

Pelos dados apresentados nesta pesquisa em um centro terciário de cardiologia, ficou demonstrada a relação entre o uso prévio de IECA e a redução do marcador de necrose tecidual troponina I cardíaca, em pacientes internados por SCASSST. Porém, ainda não há dados disponíveis para se afirmar que esta redução poderia levar a um número menor de eventos clínicos graves, como morte e re(infarto), no período de 180 dias. 


\section{ANEXOS}

\subsection{Anexo A}

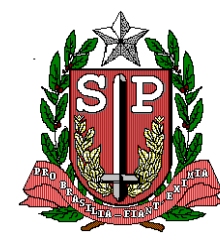

SECRETARIA DE ESTADO DA SAÚDE

COORDENADORIA DE SERVIÇOS DE SAÚDE

INSTITUTO DANTE PAZZANESE DE CARDIOLOGIA

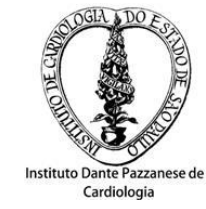

Av. Dr. Dante Pazzanese, 500 - Ibirapuera - 04012-909 - São Paulo

Fone: $5085-6040$

TERMO DE CONSENTIMENTO LIVRE E ESCLARECIDO

CENTRO:

INVESTIGADOR:

NÚMERO DO PACIENTE:

INICIAIS DO PACIENTE:

TíTULO DO ESTUDO: RELAÇÃO ENTRE INIBIÇÃO DO SISTEMA RENINAANGIOTENSINA-ALDOSTERONA E ELEVAÇÃO DE TROPONINA I CARDÍACA EM PACIENTES COM SÍNDROME CORONÁRIA AGUDA SEM SUPRADESNIVELAMENTO DO SEGMENTO ST

\section{OBJETIVO DESTE ESTUDO}

Você está sendo convidado para participar deste estudo porque você veio ao nosso Pronto-Socorro apresentando dor no peito, também conhecida por dor precordial ou angina do peito, entre outras denominações. Pacientes como você devem ser avaliados para diferenciarmos a dor no peito de origem cardíaca de outras de menor gravidade. Assim sendo, nosso objetivo ao fazermos sua avaliação clínica será descartar a maior gravidade da doença cardíaca, e ao mesmo tempo acompanharmos sua evolução clínica ao longo de 1 ano. De outro modo, após ser dispensado do Pronto-Socorro, nós entraremos em contato com você aos 6 meses e 1 ano para sabermos como está sua saúde. Faremos o contato telefônico, e se averiguada qualquer alteração que seja necessária uma avaliação pessoalmente, nós o convidaremos a vir ao Pronto-Socorro. De qualquer modo, se houver qualquer dúvida 
de sua parte, ou, necessidade de procurar nosso hospital, isto poderá ser feito a qualquer momento. Deixamos um telefone para contato direto (11-5085-6186).

\section{PROCEDIMENTOS DO ESTUDO}

Caso você queira participar deste estudo, deverá assinar um Termo de Consentimento Livre e Esclarecido.

Você será examinado por um profissional médico e realizará exames laboratoriais, eletrocardiograma, radiografia do tórax e outros que se fizerem necessários durante a avaliação.

Após a decisão por sua alta hospitalar, você levará uma cópia do Termo de Consentimento Livre e Esclarecido, assinado por você e um profissional médico. Você poderá deixar de participar deste estudo a qualquer momento, sem nenhum prejuízo de seu acompanhamento em nosso hospital.

\section{RISCOS E DESCONFORTOS}

O presente estudo não apresenta nenhum risco aos pacientes, haja vista, que não administraremos nenhum medicamento que possa alterar seu dia a dia. Orientaremos a utilização dos medicamentos que, porventura, você estiver utilizando para seu benefício. Será feita uma coleta de material para determinações genéticas, além de perfil bioquímico e lipídico, por meio de amostra de sangue por punção venosa. Oferece mínimo de risco de complicações, desde que executada por profissional experiente e conforme as normas de coleta de nosso laboratório Central, que segue o padrão internacional de coleta de sangue. Este modo de punção já foi aprovado pela Comissão de Ética de nossa Instituição.

\section{BENEFÍCIOS POTENCIAIS}

O estudo poderá beneficiar outros pacientes que, como você, venham a procurar o Pronto-Socorro apresentando os mesmos sintomas. 


\section{ALTERNATIVAS À PARTICIPAÇÃO}

Caso você não queira participar do estudo, você receberá o tratamento a que estiver realizando em nosso hospital, no setor que for o indicado para seu problema de saúde.

\section{CONFIDENCIALIDADE}

Se você aceitar participar deste estudo, todos os seus registros médicos serão verificados pela equipe de pesquisa em busca de dados para o estudo.

Assinando o Termo de Consentimento Livre e Esclarecido você estará dando permissão para que isso seja feito. Sua identidade será mantida em segredo quando os resultados do estudo forem publicados, pois, você está autorizando seus dados a serem publicados em revistas, artigos e serem tema de debates e aulas. As informações coletadas durante o estudo serão armazenadas em um computador, mas seu nome não. Seu médico será informado de sua participação neste estudo.

\section{NOVOS ACHADOS}

Você será informado sobre quaisquer novos achados importantes que se tornarem disponíveis durante o estudo que possam influenciar seu desejo de continuar ou não a participar do estudo.

\section{PARTICIPAÇÃO VOLUNTÁRIA E CONSENTIMENTO}

Sua participação neste estudo é voluntária. Você poderá se recusar a participar ou poderá desistir, a qualquer momento durante o estudo, sem precisar dar explicações. Isso não mudará a qualidade de atendimento que você estará recebendo muito menos em qualquer tipo de penalidade.

Os membros da equipe de pesquisa podem encerrar sua participação no programa de pesquisa, após a análise das razões pelo Comitê de Ética em Pesquisa da Instituição. O motivo será explicado a você e poderá ser em razão de alguma alteração médica que poderá colocá-lo em risco de outras complicações se continuar a participar, cancelamento do estudo pela coordenação do estudo, por você não cumprir as orientações dadas pela equipe de pesquisa ou outras questões administrativas. Caso isso venha a acontecer seu tratamento continuará sendo feito pelo seu médico. 


\section{SOLICITAÇÃO DE INFORMAÇÕES ADICIONAIS}

O investigador clínico, Dr. Luiz Minuzzo tel (11-5085-6186), irá responder a todas as dúvidas que você possa ter sobre sua participação neste estudo. Em caso de dúvidas ou preocupações, quanto a seus direitos como participante do estudo, você pode entrar em contato com o Comitê de Ética em Pesquisa do Instituto Dante Pazzanese de Cardiologia no tel 5085-6040. Uma cópia deste termo será entregue a você.

Li e compreendi este Termo de Consentimento e todas as minhas dúvidas foram resolvidas. Recebi explicações sobre o objetivo da pesquisa, os procedimentos de estudo a que serei submetido, os possíveis riscos e desconfortos e os benefícios que posso apresentar. As alternativas à minha participação neste estudo também foram discutidas. Portanto, concordo voluntariamente em fornecer meu consentimento para participar deste estudo clínico.

\begin{tabular}{l}
\hline Assinatura do Paciente \\
\hline Assinatura do Paciente \\
\hline Assinatura do Paciente
\end{tabular}

$\begin{array}{ll}\frac{}{\text { Data }} & \frac{}{\text { Hora }}{ }^{\mathrm{h}} \\ \frac{\text { Hora }}{\text { Data }} & \frac{\mathrm{h}}{\text { Hora }}:{ }^{\mathrm{h}}\end{array}$




\subsection{Anexo B}

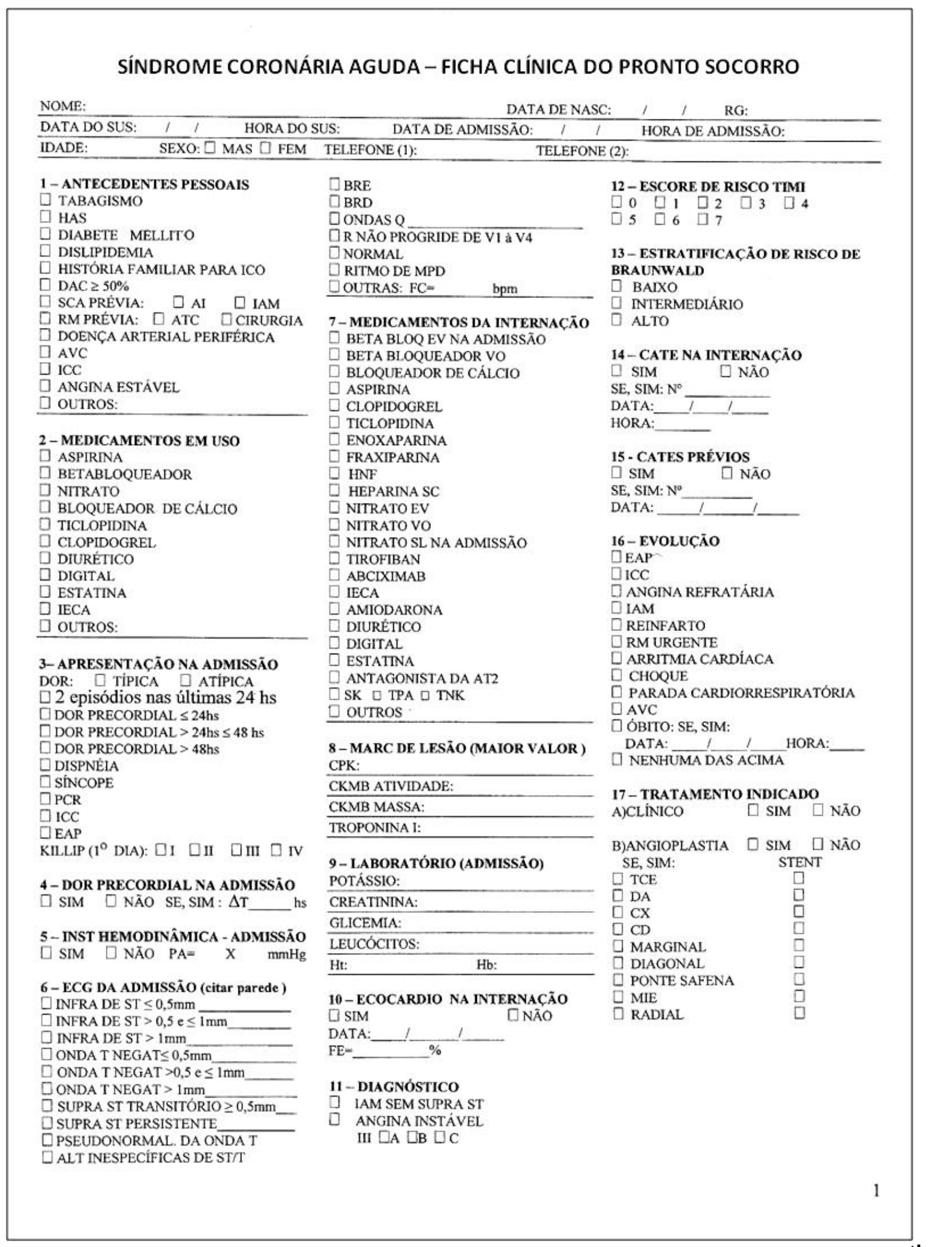




\section{Continuação}
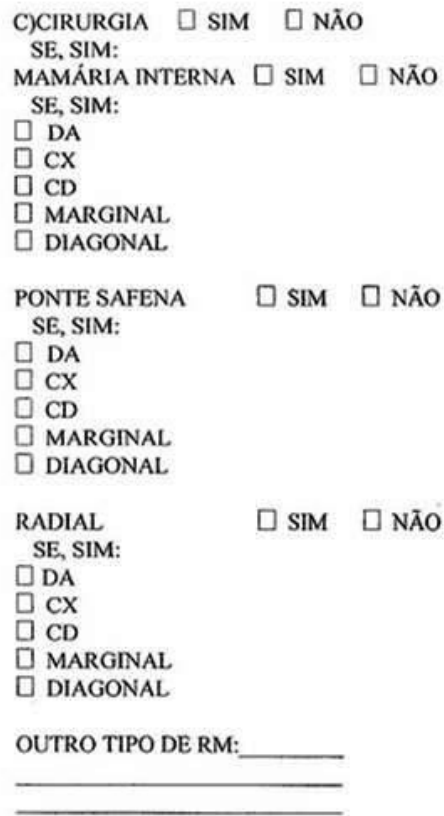

18-REVASC NA INTERNAÇÃo

$\square$ SIM $\square$ NÃO

SE, SIM:

DATA: HORA

19 - ALTA HOSPITALAR

$\square$ SIM $\square$ NÃO

SE, SIM:

DATA: HORA

20-TRANSFERÊNCIA

IIM $\square$ NÃO

SE, SIM:

DATA: HORA

\section{1 - DESTINO DA TRANSFERÊNCIA}

$\square$ UCO

ENFERMARIA CORONÁRIA

$\square$ ENFERMARIA ATC

D OUTROS:

22-MEDICAÇÃO DE ALTA

DASPIRINA

DBETABLOQUEADOR

DNITRATO

DESTATINA

$\square$ IECA

$\square$ CLOPIDOGREL

$\square$ TICLOPIDINA

$\square$ DIURÉTICO

$\square$ BLOQUEADOR DE CÁLCIO

DOUTROS

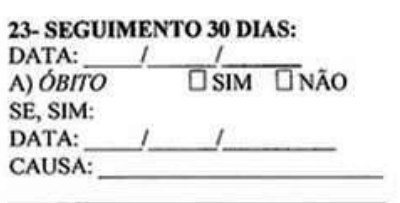
B) $I A M \quad \square$ SIM DNÃO
SE, SIM:
DATA: $\frac{1}{1}$
2) INFRA DE ST
C) (RE)INFARTO $\square \mathrm{SIM} \square \mathrm{NÃO}$ SE, SIM
DATA:
1) SUPRADEST
DE
2) INFRA DE ST

D) ANGINA RECORRENTE

$\square$ SIM \NÃO

E) REVASCULARIZACCÃO URGENTE

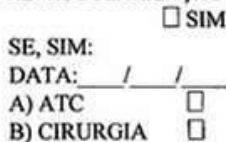

B) CIRURGIA

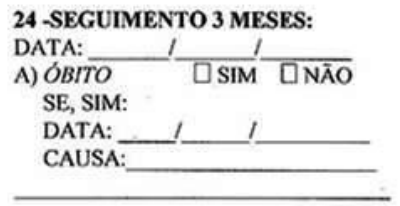

B) $I A M$

$\square \operatorname{SIM} \square \mathrm{NĀO}$

SE, SIM:

DATA:
2) INPRA DE ST

C) (RE)INFARTO $\square$ SIM पNÃO SE, SIM:

DATA:

1) SUPRA DE ST

2) NFRA DE ST

D) ANGINA RECORRENTE

$\square$ SIM $\square$ NÃO

E) REVASCULARIZACÃO URGENTE

SE, SIM:
DATA: ATC
B) CIRURGIA

INDICE

MASSA CORPOREA

TORNOZELO BRAQUIAL:
25-SEGUIMENTO 6 MESES:

DATA: ÓBITO $\frac{1}{\square \text { SIM } \square \text { NÃO }}$

SE, SIM:

DATA:

CAUSA:

B) $I A M \quad \square$ SIM, $\square$ NÃO

SE, SIM:

1) SUPRA DE ST

2) INFRA DE ST

C) (RE)INFARTO $\square \mathrm{SIM} \square$ NÃO SE, SIM:

DATA:

1) SUPRA DE ST

2) INFRA DE ST

D) ANGINA RECORRENTE ¿ SIM DNÃO

E) REVASCULARIZACC̃̃O URGENTE SE, SIM:

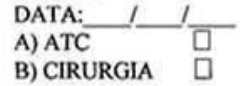

26 -SEGUIMENTO 1 ANO:

DATA:

SE, SIM:

DATA:

CAUSA:

B) $L A M \quad \square \operatorname{SIM} \square \mathrm{NÃO}$

SE, SIM:

DATA: $\frac{1}{1} \frac{1}{-}$

1) SUPRA DE ST

C) (RE)INFARTO \SIM $\square$ NÃO

SE, SIM:

DATA: I SUPRA DE ST

2) INFRA DE ST

D) ANGINA RECORRENTE

口 SIM DNÃO

E) REVASCULARIZACÃOO URGENTE

SE, SIM:

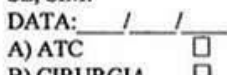

B) CIRURGIA 


\subsection{Anexo C}

SECRETARIA DE ESTADO DA SAÚDE

Coordenadoria de Serviços de Saúde

INSTITUTO DANTE PAZZANESE DE CARDIOLOGIA

PROTOCOLO Dr.Luiz Minuzzo

PACIENTE:

N. ${ }^{\circ}$ DE REGISTRO:

DATA COLETA:

HORÁRIO DE COLETA:

RESPONSÁVEL PELA COLETA/ENTREGA:

Solicito:

\begin{tabular}{|l|l|l|l|}
\hline GLICOSE & POTÁSSIO & HEMOGRAMA & \\
\hline URÉIA & CK - & TROPONINA I & \\
\hline CREATININA & CKMB ATIVIDADE & & \\
\hline SÓDIO & CKMB MASSA & & \\
\hline
\end{tabular}

Colher 01 tubo seco

Colher 02 tubos EDTA

ENTREGAR AMOSTRAS PARA LOURDINHA OU ROBERTO

REALIZAR OS EXAMES - ALÉM DE LIBERAR NO SISTEMA O RESULTADO IMPRIMIR UM RESULTADO E ANEXAR A ESTE PEDIDO.

ALIQUOTAR E IDENTIFICAR AS AMOSTRAS QUE SOBRAREM APÓS DOSAGENS E ENTREGAR PARA PESQUISA ( PLANTÕES - ALIQUOTAR E GUARDAR NO FREEZER A - 20C. ENTREGAR PRÓXIMO DIA ÚTIL PARA LOURDINHA

1. Armazenar freezer $-80^{\circ} \mathrm{C}$ 


\subsection{Anexo D}

Tabela D1. Tratamento realizado de acordo com o uso ou não de IECA

\begin{tabular}{|c|c|c|c|c|c|}
\hline \multirow{2}{*}{ Tratamento realizado } & \multicolumn{2}{|c|}{ Uso de IECA } & \multicolumn{2}{|c|}{ Não uso de IECA } & \multirow{2}{*}{ Valor $p$} \\
\hline & $\begin{array}{l}\text { Pacientes } \\
\text { (total=242) }\end{array}$ & $\%$ & $\begin{array}{c}\text { Pacientes } \\
\text { (total=215) }\end{array}$ & $\%$ & \\
\hline Clínico & 154 & 63,6 & 145 & 67,4 & \multirow{3}{*}{0,225} \\
\hline Intervenção coronária percutânea & 64 & 26,4 & 43 & 20,0 & \\
\hline Revascularização do miocárdio & 24 & 9,9 & 27 & 12,6 & \\
\hline
\end{tabular}

Nota: IECA=inibidor de enzima de conversão da angiotensina 
Tabela D2. Características demográficas e fatores clínicos na apresentação - Óbito versus não óbito em 180 dias -

\begin{tabular}{|c|c|c|c|c|c|c|}
\hline \multirow{2}{*}{ Característica } & \multicolumn{2}{|l|}{ Não óbito } & \multicolumn{2}{|l|}{ Óbito } & \multirow{2}{*}{$\begin{array}{l}\text { Total } \\
(457)\end{array}$} & \multirow{2}{*}{$\begin{array}{c}\text { Valor } \\
\text { p }\end{array}$} \\
\hline & $\begin{array}{l}\text { Pacientes } \\
\text { (total }=429 \text { ) }\end{array}$ & $\%$ & $\begin{array}{l}\text { Pacientes } \\
\text { (total }=28 \text { ) }\end{array}$ & $\%$ & & \\
\hline \multicolumn{7}{|l|}{ Idade } \\
\hline - Média (DP) & $61,5(10,7)$ & - & $72,5(10,8)$ & - & $62,2(11,0)$ & \multirow{2}{*}{$<0,001$} \\
\hline - Mediana (IIQ) & $60,0(53,0 ; 69,0)$ & - & $74,5(65,3 ; 81,3)$ & - & $61,0(54,0 ; 70,0)$ & \\
\hline Gênero masculino & 273 & 63,6 & 18 & 64,3 & 291 & 0,945 \\
\hline \multicolumn{7}{|l|}{ Antecedentes pessoais } \\
\hline - HAS & 364 & 84,8 & 26 & 92,9 & 390 & 0,246 \\
\hline - Dislipidemia & 328 & 76,5 & 19 & 67,9 & 347 & 0,302 \\
\hline - ICC (NYHA $\geq \mathrm{II})$ & 271 & 63,2 & 23 & 82,1 & 294 & 0,042 \\
\hline - SCA prévia & 259 & 60,4 & 16 & 57,1 & 275 & 0,735 \\
\hline - Apenas Al & 87 & 20,3 & 6 & 21,4 & 93 & 0,884 \\
\hline * Apenas IAM & 198 & 46,2 & 12 & 42,9 & 210 & 0,734 \\
\hline - Angina estável prévia & 237 & 55,2 & 13 & 46,4 & 250 & 0,364 \\
\hline - Procedimentos de RM prévios & 216 & 50,3 & 10 & 35,7 & 226 & 0,133 \\
\hline * Apenas ICP & 154 & 35,9 & 5 & 17,9 & 159 & 0,052 \\
\hline * Apenas cirurgia de RM & 101 & 23,5 & 7 & 25,0 & 108 & 0,860 \\
\hline - Diabete melito & 147 & 34,3 & 13 & 46,4 & 160 & 0,191 \\
\hline - História familiar para DAC & 161 & 37,5 & 11 & 39,3 & 172 & 0,853 \\
\hline - Tabagismo & 105 & 24,5 & 5 & 17,9 & 110 & 0,427 \\
\hline - Acidente vascular cerebral & 29 & 6,8 & 1 & 3,6 & 30 & 0,509 \\
\hline - Doença arterial periférica & 11 & 2,6 & 0 & 0,00 & 11 & 0,391 \\
\hline $\begin{array}{l}\text { - Doença arterial coronária } \geq \\
50 \%\end{array}$ & 267 & 62,5 & 20 & 66,7 & 287 & 0,867 \\
\hline \multicolumn{7}{|l|}{ Medicamentos na admissão } \\
\hline - Ácido acetilsalicílico & 314 & 73,4 & 23 & 82,1 & 337 & 0,305 \\
\hline - Betabloqueadores & 273 & 63,8 & 16 & 57,1 & 289 & 0,480 \\
\hline - Estatinas & 264 & 61,7 & 14 & 50,0 & 278 & 0,220 \\
\hline - IECA & 227 & 52,9 & 15 & 53,6 & 242 & 0,946 \\
\hline - Nitratos & 161 & 37,6 & 13 & 46,4 & 174 & 0,352 \\
\hline - Diuréticos & 144 & 33,8 & 20 & 71,4 & 164 & $<0,001$ \\
\hline $\begin{array}{l}\text { - Bloqueadores de canais de } \\
\text { cálcio }\end{array}$ & 83 & 19,4 & 6 & 21,4 & 89 & 0,797 \\
\hline - Clopidogrel & 31 & 7,3 & 1 & 3,6 & 32 & 0,456 \\
\hline - Digitálicos & 10 & 2,3 & 4 & 14,3 & 14 & $<0,001$ \\
\hline \multicolumn{7}{|l|}{ Apresentação na admissão } \\
\hline \multicolumn{7}{|l|}{ - Sintomas } \\
\hline * Dor torácica típica & 372 & 86,7 & 19 & 67,9 & 391 & 0,006 \\
\hline * Edema agudo de pulmão & 1 & 0,2 & 1 & 3,6 & 2 & $0,119 \mathrm{~F}$ \\
\hline * Dispneia* & 11 & 2,6 & 3 & 10,7 & 14 & 0,015 \\
\hline * Síncope* & 4 & 0,9 & 0 & 0,0 & 4 & $1,000 \mathrm{~F}$ \\
\hline $\begin{array}{l}* \text { ICC - Classe de Killip- } \\
\text { Kimball } \geq \text { II }\end{array}$ & 0 & 0,0 & 1 & 3,6 & 1 & $0,061 F$ \\
\hline
\end{tabular}


Continuação...

\section{Característica}

- Número de episódios de dor nas últimas 24 horas

* Dois ou mais episódios

\begin{tabular}{|c|c|c|c|}
\hline \multicolumn{2}{|c|}{ Não óbito } & \multicolumn{2}{|l|}{ Óbito } \\
\hline $\begin{array}{c}\text { Pacientes } \\
\text { (total }=429)\end{array}$ & $\%$ & $\begin{array}{l}\text { Pacientes } \\
\text { (total }=28)\end{array}$ & $\%$ \\
\hline
\end{tabular}

Total

(457)

Valor $p$

- Instabilidade hemodinâmica na admissão**

- Frequência média (DP)

cardíaca (bpm) mediana

- Pressão arterial média (DP) sistólica $(\mathrm{mmHg})$

mediana

- Pressão arterial média (DP) diastólica

$(\mathrm{mmHg})$

mediana

- ICC - Classe de Killip-Kimball

$$
* 1
$$

$* \geq 11$

Diagnóstico

- IAMSSST

- Angina instável III B

Tratamento realizado

- Clínico

- ICP

- RM

Alterações eletrocardiográficas

- Depressão de ST $\geq 0,5 \mathrm{~mm}$ (uma ou mais derivações)

- Inversão de ondas $\mathrm{T} \geq 1,0 \mathrm{~mm}$

\begin{tabular}{|r|r|r|r|r|r|}
\hline 238 & 55,5 & 15 & 53,6 & 253 & 0,844 \\
\hline 8 & 1,9 & 0 & 0,0 & 8 & 0,466 \\
\hline $75,45(16,32)$ & - & $81,93(19,07)$ & - & - & 0,055 \\
\hline 74,00 & - & 80,00 & - & - & \\
\hline $140,07(28,49)$ & - & $132,57(23,36)$ & - & - & 0,128 \\
\hline 140,00 & - & 126,00 & - & - & \\
\hline $82,80(17,20)$ & - & $81,04(15,10)$ & - & - & \\
\hline 80,00 & - & 79,50 & - & - & 0,473 \\
\hline 425 & 99,1 & 26 & 92,9 & 451 & 0,005 \\
\hline 4 & 0,9 & 2 & 7,1 & 6 & \\
\hline 151 & 35,2 & 18 & 64,3 & 169 & 0,002 \\
\hline 278 & 64,8 & 10 & 35,7 & 288 & \\
\hline 277 & 64,6 & 22 & 78,6 & 299 & \\
\hline 104 & 24,2 & 3 & 10,7 & 107 & 0,241 \\
\hline 48 & 11,2 & 3 & 10,7 & 51 & \\
\hline 87 & 20,3 & 12 & 42,9 & 99 & 0,005 \\
\hline 147 & 34,3 & 9 & 32,1 & 156 & 0,818 \\
\hline
\end{tabular}

Notas: *Sintomas associados à dor torácica; **Pressão arterial sistólica < $90 \mathrm{mmHg}$; F: teste exato de Fisher, DP=desvio padrão;

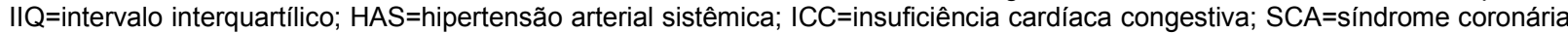
aguda; $\mathrm{Al}=$ =angina instável; $\mathrm{IAM}=$ infarto agudo do miocárdio; $\mathrm{RM}=$ =revascularização do miocárdio; $I C P=$ intervenção coronária percutânea; DAC=doença arterial coronária; IAMSSST=infarto agudo do miocárdio sem elevação do segmento ST; $\mathrm{mm}=$ milímetros. 
Tabela D3. Alterações laboratoriais - Óbito versus não óbito em 180 dias -

\begin{tabular}{|c|c|c|c|c|}
\hline \multirow{2}{*}{\multicolumn{2}{|c|}{ Exame }} & Não óbito & Óbito & \multirow{2}{*}{$\begin{array}{l}\text { Valor } \\
\text { p }\end{array}$} \\
\hline & & $\begin{array}{c}\text { Pacientes=429 } \\
(93,87 \%)\end{array}$ & $\begin{array}{c}\text { Pacientes=28 } \\
(6,13 \%)\end{array}$ & \\
\hline \multicolumn{2}{|c|}{ Troponina $\mathrm{I}>0,5, \mathrm{n}(\%)$} & $151(35,2)$ & $18(64,3)$ & 0,002 \\
\hline \multicolumn{2}{|c|}{ Bioquímica } & & & \multirow{3}{*}{$<0,001$} \\
\hline \multirow{2}{*}{$\begin{array}{c}\text { Troponina I } \\
(\mathrm{ng} / \mathrm{mL})\end{array}$} & média (DP) & $2,89(12,36)$ & $13,78(20,66)$ & \\
\hline & mediana (IIQ) & $0,14(0,04 ; 1,35)$ & $2,87(0,21 ; 23,36)$ & \\
\hline CPK & média (DP) & $172,08(220,11)$ & $599,64(748,04)$ & \multirow{2}{*}{0,008} \\
\hline$(\mathrm{U} / \mathrm{L})$ & mediana (IIQ) & $98,00(64,00 ; 179,50)$ & $196,50(77,25 ; 1091,50)$ & \\
\hline \multirow{2}{*}{$\begin{array}{c}\text { CK-MB atividade } \\
(\mathrm{U} / \mathrm{L})\end{array}$} & média (DP) & $10,29(16,80)$ & $38,15(48,44)$ & \multirow{2}{*}{0,001} \\
\hline & mediana (IIQ) & $6,00(3,00 ; 10,00)$ & $19,00(5,00 ; 54,75)$ & \\
\hline \multirow{2}{*}{$\underset{(\mathrm{ng} / \mathrm{mL})}{\text { CK-MB massa }}$} & média (DP) & $8,26(26,80)$ & $57,43(77,11)$ & \multirow{2}{*}{$<0,001$} \\
\hline & mediana (IIQ) & $1,70(0,80 ; 4,80)$ & $6,50(3,60 ; 164,00)$ & \\
\hline \multirow{2}{*}{$\begin{array}{c}\text { Glicemia } \\
(\mathrm{mg} / \mathrm{dL})\end{array}$} & média (DP) & $126,06(58,57)$ & $185,29(96,23)$ & \multirow{2}{*}{0,007} \\
\hline & mediana (IIQ) & $107,00(91,00 ; 139,00)$ & $152,00(99,00 ; 245,50)$ & \\
\hline \multirow{2}{*}{$\begin{array}{c}\text { Creatinina } \\
(\mathrm{mg} / \mathrm{dL})\end{array}$} & média (DP) & $1,15(0,47)$ & $1,57(0,63)$ & \multirow{2}{*}{$<0,001$} \\
\hline & mediana (IIQ) & $1,00(0,90 ; 1,30)$ & $1,50(1,20 ; 1,80)$ & \\
\hline \multirow{2}{*}{$\begin{array}{l}\text { Potássio } \\
\text { (mmol/L) }\end{array}$} & média (DP) & $4,31(0,57)$ & $4,66(0,85)$ & \multirow{2}{*}{0,025} \\
\hline & mediana (IIQ) & $4,20(4,00 ; 4,60)$ & $4,60(4,00 ; 5,30)$ & \\
\hline \multirow{2}{*}{$\begin{array}{c}\text { Leucócitos } \\
(\mathrm{x} / \mathrm{uL})\end{array}$} & média (DP) & 7955 (2899) & $8852(3143)$ & \multirow{2}{*}{0,086} \\
\hline & mediana (IIQ) & $7600(6225 ; 9175)$ & $8600(5900 ; 10800)$ & \\
\hline \multirow{2}{*}{$\begin{array}{c}\text { Hematócrito } \\
(\%)\end{array}$} & média (DP) & $41,32(5,29)$ & $39,43(7,27)$ & \multirow{2}{*}{0,308} \\
\hline & mediana (IIQ) & $41,55(38,43 ; 44,20)$ & $40,90(35,15 ; 44,55)$ & \\
\hline \multirow{2}{*}{$\begin{array}{l}\text { Hemoglobina } \\
(\mathrm{g} / \mathrm{dL})\end{array}$} & média (DP) & $13,69(1,79)$ & $12,91(2,39)$ & \multirow{2}{*}{0,132} \\
\hline & mediana (IIQ) & $13,70(12,70 ; 14,80)$ & $13,30(11,90 ; 14,70)$ & \\
\hline
\end{tabular}

Notas: $\mathrm{DP}=$ desvio padrão; $\mathrm{IQ}=$ =intervalo interquartílico; $\mathrm{CPK}=$ creatinafosfoquinase; $\mathrm{CK}-\mathrm{MB}=$ fração $\mathrm{MB}$ da creatinafosfoquinase 


\section{REFERÊNCIAS}

1. Laurenti R, Buchalla CM, Caratin CVS. Doença isquêmica do coração. Internações, tempo de permanência e gastos. Brasil, 1993 a 1997. Arq Bras Cardiol. 2000;74:483-7.

2. Schmidt MI, Duncan BB, Silva GA, Menezes AM, Monteiro CA, Barreto SM, et al. Chronic non-communicable diseases in Brazil: burden and current challenges. Lancet. 2011;377:1949-56.

3. World Health Organization. The Global Burden of Disease: 2004 Update. Geneva, World Health Organization, 2008. Available from: http://www.who.int/healthinfo/global_burden_disease/GBD_report_2004update_p art2.pdf.

4. World Health Organization. The Global Burden of Disease: 2004 Update. Geneva, World Health Organization, 2008. Available from: http://www.who.int/healthinfo/global_burden_disease/GBD_report_2004update_p art 3.pdf.

5. Lloyd-Jones D, Adams R, Carnethon M, Simone GD, Ferguson B, Flegal K, et al. Heart disease and stroke statistics-2009 update: A report from the American Heart Association Statistics Committee and Stroke Statistics Subcommittee. Circulation. 2009;119:480-6.

6. Anderson JL, Adams CD, Antman EM, Bridges CR, Califf RM, Casey DE, Jr, et al. American College of Cardiology; American Heart Association Task Force on Practice Guidelines (Writing Committee to Revise the 2002 Guidelines for the Management of Patients With Unstable Angina/Non ST-Elevation Myocardial Infarction); American College of Emergency Physicians; Society for Cardiovascular Angiography and Interventions; Society of Thoracic Surgeons; American Association of Cardiovascular and Pulmonary Rehabilitation; Society for Academic Emergency Medicine. ACC/AHA 2007 guidelines for the management of patients with unstable angina/non ST-elevation myocardial infarction: a report of the American College of Cardiology/American Heart Association Task Force on Practice Guidelines (Writing Committee to Revise the 2002 Guidelines for the Management of Patients With Unstable Angina/Non STElevation Myocardial Infarction): developed in collaboration with the American College of Emergency Physicians, the Society for Cardiovascular Angiography and Interventions, and the Society of Thoracic Surgeons: endorsed by the 
American Association of Cardiovascular and Pulmonary Rehabilitation and the Society for Academic Emergency Medicine. Circulation. 2007;116:e148-304.

7. Yeh RW, Sidney S, Chandra M, Sorel M, Selby JV, Go AS. Population trends in the incidence and outcomes of acute myocardial infarction. $N$ Engl $\mathrm{J}$ Med. 2010;362:2155-65.

8. Rogers WJ, Frederick PD, Stoehr E, Canto JG, Ornato JP, Gibson M, et al. Trends in presenting characteristics and hospital mortality among patients with ST elevation and non-ST elevation myocardial infarction in the National Registry of Myocardial Infarction from 1990 to 2006. Am Heart J. 2008;156:1026-34.

9. White HD. Evolution of the definition of myocardial infarction: what are the implications of a new universal definition? Heart J. 2008;94:679-84.

10. Madala MC, Franklin BA, Chen AY, Berman AD, Roe MT, Peterson ED, et al, for the CRUSADE Investigators obesity and age of first non-ST-segment elevation myocardial infarction. J Am Coll Cardiol. 2008;52:979-85.

11. Pell JP, Haw S, Cobbe S, Newby DE, Pell ACH, Fischbacher C, et al. Smokefree legislation and hospitalizations for acute coronary syndrome. $N$ Engl $J$ Med. 2008;359:482-91.

12. Mansur AP, Favarato D, Souza MFM, Avakian SD, Aldrighi JM, César LAM, et al. Tendência do risco de morte por doenças circulatórias no Brasil de 1979 a 1996. Arq Bras Cardiol. 2001;76:497-503.

13. Braunwald E, Antman EM, Beasley JW, Califf RM, Cheitlin MD, Hochman JS, et al. ACC/AHA Guidelines for the management of patients with unstable angina and non-ST-segment elevation myocardial infarction. A report of the American College of Cardiology/ American Heart Association Task Force on Practice Guidelines (Committee on the Management of patients with Unstable Angina. $J$ Am Coll Cardiol. 2000;36:970-1062.

14. Alpert JS, Antman EM, Apple F, Armstrong PW, Bassand JP, de Luna AB, et al. Myocardial infarction redefined - A consensus document of The Joint European Society of Cardiology/American College of Cardiology Committee for the Redefinition of Myocardial Infarction The Joint European Society of Cardiology/American College of Cardiology Committee. Eur Heart J. 2000;21:1502-13. 
15. Hamm CW, Bertrand M, Braunwald E. Acute coronary syndrome without ST elevation: implementation of new guidelines. Lancet. 2001;358:1533-8.

16. Thygesen K, Alpert JS, White HD. Joint ESC/ACCF/AHA/WHF Task Force for the Redefinition of Myocardial Infarction. Universal definition of myocardial infarction. J Am Coll Cardiol. 2007;50:2173-95.

17. Antman EM, Cohen M, Bernink PJLM, McCabe CH, Horacek T, Papuchis G, et al. The TIMI risk score for unstable angina/non-ST elevation Ml: A method for prognostication and therapeutic decision making. JAMA. 2000;284:835-42.

18. Nicolau JC, Timerman A, Piegas LS, Marin-Neto JA, Rassi A. Jr. Guidelines for unstable angina and non-ST-segment elevation myocardial infarction of the Brazilian Society of Cardiology (II Edition, 2007). Arq Bras Cardiol. 2007;89:e89-131.

19. Budaj A, Yusuf S, Mehta SR, Fox KA, Tognoni G, Zhao F, et al. Benefit of clopidogrel in patients with acute coronary syndromes without ST-segment elevation in various risk groups. Circulation. 2002;106:1622-6.

20. Cannon CP. Evidence-based risk stratification to target therapies in acute coronary syndromes [editorial]. Circulation. 2002;106:1588-91.

21. Libby P. Current concepts of the pathogenesis of the acute coronary syndromes. Circulation. 2001;104:365-72.

22. Yusuf S, Hawken S, Ounpuu S, Dans T, Avezum A, Lanas $F$, et al. INTERHEART study investigators. Effect of potentially modifiable risk factors associated with myocardial infarction in 52 countries (the INTERHEART study): case-control study. Lancet. 2004;364:937-52.

23. Libby P, Ridker PM. Inflammation and atherothrombosis. From population biology and bench research to clinical practice. J Am Coll Cardiol. 2006;48:A33-46.

24. Virmani R, Burke AP, Farb A, Kolodgie FD. Pathology of the vulnerable plaque. $J$ Am Coll Cardiol. 2006;47(8 Suppl):C13-8.

25. Virmani R, Kolodgie FD, Burke AP, Farb A, Schwartz SM. Lessons from sudden coronary death: A comprehensive morphological classification scheme for atherosclerotic lesions. Arterioscler Thromb Vasc Biol. 2000;20:1262-75. 
26. Davies MJ. The pathophysiology of acute coronary syndromes. Heart. 2000;83:361-6.

27. Tigerstedt R, Bergman PG. Niere und kreislauf. Scand Arch Physiol. 1898;8:223-71.

28. Gradman AH. Evolving understanding of the renin-angiotensin-aldosterone system: pathophysiology and targets for therapeutic intervention. Am Heart $\mathrm{J}$. 2009;157(6 Suppl):S1-6.

29. Goodman LS, Gilman AG. As bases farmacológicas da terapêutica. 10.ed. Rio de Janeiro: McGraw-Hill; 2005. Cap. 31.

30. Lindpaintner K, Pfeffer MA, Kreutz R, Stampfer MJ, Grodstein F, LaMotte F, et al. A prospective evaluation of an angiotensin-converting enzyme gene polymorphism and the risk of ischemic heart disease. $N$ Engl $J$ Med. 1995;332:706-11.

31. Ribichini F, Steffenino G, Dellavalle A, Matullo G, Colajanni E, Camila T, et al. Plasma activity and insertion/deletion polymorphism of the angiotensin Iconverting enzyme. A major risk factor and a marker of risk for coronary stent restenosis. Circulation. 1998;97:147-54.

32. Danser AH, Schalekamp MA, Bax WA, van den Brink AM, Saxena PR, Riegger $\mathrm{GA}$, et al. Angiotensin-converting enzyme in the human heart: effect of the deletion/insertion polymorphism. Circulation. 1995;92:1387-8.

33. Pinto YM, van Gilst WH, Kingma, JH, Schunkert $H$. Deletion-type allele of the angiotensin-converting enzyme gene is associated with progressive ventricular dilatation after anterior myocardial infarction. Captopril and Thrombolysis Study Investigators. J Am Coll Cardiol. 1995;25:1622-6.

34. Wagenaar LJ, Voors AA, Buikema H, van Gilst WH. Angiotensin receptors in the cardiovascular system. Can J Cardiol. 2002;18:1331-9.

35. Chrysant SG. Current status of dual renin angiotensin aldosterone system blockade for the treatment of cardiovascular diseases. Am J Cardiol. 2010;105:849-52. 
36. Ferrario CM, Strawn WB. Role of the renin-angiotensin-aldosterone system and proinflammatory mediators in cardiovascular disease. $A m \mathrm{~J}$ Cardiol. 2006;98:121-8.

37. Jacoby DS, Rader DJ. Renin-angiotensin system and atherothrombotic disease. Arch Intern Med. 2003;163:1155-64.

38. Papademetriou V. Inhibition of the renin-angiotensin-aldosterone system to prevent ischemic and atherothrombotic events. Am Heart J. 2009;157:S24-30.

39. Fleming I, Kohlstedt K, Busse R. New fACEs to the renin-angiotensin system. Physiology. 2005;20:91-5.

40. Probstfield JL, O'Brien KD. Progression of cardiovascular damage: The role of renin-angiotensin system blockade. Am J Cardiol. 2010;105(1Suppl):10A-20A.

41. Lonn EM, Yusuf S, Jha P, Montagne TJ, Teo KK, Benedict CR, et al. Emerging role of angiotensin-converting enzyme inhibitors in cardiac and vascular protection. Circulation. 1994;90:2056-69.

42. Asselbergs FW, van Gilst WH. Angiotensin converting enzyme inhibition in cardiovascular risk populations: a practical approach to identify the patient who will benefit most. Curr Opin Cardiol. 2007;22:267-72.

43. Velasquez EJ, Pfeffer MA, McMurray JV, Maggioni AP, Rouleau JL, Van de Werf F, et al. VALIANT Investigators. VALsartan In Acute myocardial iNfarcTion (VALIANT) trial: baseline characteristics in context. Eur J Heart Fail. 2003;5:537-44.

44. Yusuf S, Sleight P, Pogue J, Bosch J, Davies R, Dagenais G. Effects of an angiotensin-converting-enzyme inhibitor, ramipril, on cardiovascular events in high-risk patients. The Heart Outcomes Prevention Evaluation study investigators. N Engl J Med. 2000;342:145-53.

45. Batlouni M, Ramires JAF. Farmacologia e terapêutica cardiovascular. São Paulo: Atheneu; 1999. p.287-303.

46. Solaro RJ, Van Eyk J. Altered interactions among thin filament proteins modulate cardiac function. J Mol Cell Cardiol. 1999;28:217-30. 
47. Cummins B, Auckland ML, Cummins P. Cardiac-specific troponin I radioimmunoassay in the diagnosis of acute myocardial infarction. Am Heart J. 1987;113:1333-44.

48. Antman EM, Tanasijevic MJ, Thompson B, Schactman M, McCabe CH, Cannon $\mathrm{CP}$, et al. Cardiac-specific troponin I levels to predict the risk of mortality in patients with acute coronary syndromes. N Engl J Med. 1996;335:1342-9.

49. Korff S, Katus HA, Giannitsis E. Differential diagnosis of elevated troponins. Heart. 2006;92:987-93.

50. Wallace TW, Abdullah SM, Drazner MH, Das SR, Khera A, McGuire DK, et al. Prevalence and determinants of troponin $T$ elevation in the general population. Circulation. 2006;48:1958-65.

51. MacRae AR, Kavsak PA, Lustig V, Bhargava R, Vandersluis R, Palomaki GE, et al. Assessing the requirement for the 6-hour interval between specimens in the American Heart Association classification of myocardial infarction in epidemiology and clinical research studies. Clin Chem. 2006;52:812-8

52. Mair J, Artner-Dworzak E, Lechleitner P, Smidt J, Wagner I, Dienstl F, et al. Cardiac troponin $\mathrm{T}$ in diagnosis of acute myocardial infarction. Clin Chem. 1991;37:845-52.

53. Sayre MR, Kaufmann KH, Chen I-W, Sperling M, Sidman RD, Diercks DB, et al. Measurement of cardiac troponin $\mathrm{T}$ is an effective method for predicting complications among emergency department patients with chest pain. Ann Emerg Med. 1998;31:539-49.

54. Antman EM, Grudzien C, Sacks DB. Evaluation of a rapid bedside assay for detection of serum cardiac troponin T. JAMA. 1995;273:1279-82.

55. Bakker AJ, Koelemay MJ, Gorges JP, van Viles B, Smits R, Tijssen JG, et al. Failure of new biochemical markers to exclude acute myocardial infarction at admission. Lancet. 1993;342:1220-2.

56. Wu AHB, Valdes R, Apple FS, Gornet T, Stone MA, Mayfield-Stokes S, et al. Cardiac troponin-T immunoassay for diagnosis of acute myocardial infarction. Clin Chem. 1994;40:900-7. 
57. Falahati A, Sharkey SW, Christensen D, McCoy M, Miller EA, Murakami MA, et al. Implementation of serum cardiac troponin I as a marker for detection of acute myocardial infarction. Am Heart J. 1999;137:332-7.

58. Tanasijevic MJ, Antman EM. Diagnostic performance of cardiac troponin I in suspected acute myocardial infarction: Implications for clinicians [editorial]. Am Heart J. 1999;137:203-6.

59. Ohman EM, Armstrong PW, Christenson RH, Granger CB, Katus HA, Hamm $\mathrm{CW}$, et al. Cardiac troponin $\mathrm{T}$ levels for risk stratification in acute myocardial ischemia. GUSTO IIA Investigators. N Engl J Med. 1996;335:1333-41.

60. Karras DJ, Kane DL. Serum markers in the emergency department diagnosis of acute myocardial infarction. Emerg Med Clin North Am. 2001;19:321-7.

61. Hamm CW, Rakilde J, Gerhardt W, Jorgensen P, Peheim E, Ljungdahi L, et al. The prognostic value of serum troponin $\mathrm{T}$ in unstable angina. $N$ Engl $\mathrm{J}$ Med. 1992;327:146-50.

62. Heidenreich PA, Alloggiamento T, Melsop K, McDonald KM, Go AS, Hlatky MA. The prognostic value of troponin in patients with non-ST elevation acute coronary syndromes: a meta-analysis. J Am Coll Cardiol. 2001;38:478-85.

63. Ottani F, Galvani M, Nicolini FA, Ferrini D, Pozzati A, Di Pasquale G, et al. Elevated cardiac troponin levels predict the risk of adverse outcome in patients with acute coronary syndromes. Am Heart J. 2000;140:917-27.

64. Morrow DA, Antman EM, Tanasijevic M, Rifai N, de Lemos JA, McCabe CH, et al. Cardiac troponin I for stratification of early outcomes and the efficacy of enoxaparin in unstable angina: a TIMI-11B substudy. $J$ Am Coll Cardiol. 2000;36:1812-7.

65. Lindahl B, Toss $H$, Siegbahn A, Verge $P$, Wallentin L, for the FRISC study group. Markers of myocardial damage and inflammation in relation to long-term mortality in unstable coronary artery disease. N Engl J Med. 2000;343:1139-47.

66. Newby LK, Goldmann BU, Ohman EM. Troponin: an important prognostic marker and risk-stratification tool in non-ST-segment elevation acute coronary syndromes. J Am Coll Cardiol. 2003;41(4 Suppl S):31S-36S. 
67. Godoy MF, Braile DM, Purini Neto J. A troponina como marcador de injúria celular miocárdica. Arq Bras Cardiol. 1998;71:629-33.

68. Kavsak PA, Newman AM, Lustig V, MacRae AR, Palomaki GE, Ko DT, et al. Long-term health outcomes associated with detectable troponin I concentrations. Clin Chem. 2007;53:220-7.

69. Newby LK, Kaplan AL, Granger BB, Sedor F, Califf RM, Ohman EM. Comparison of cardiac troponin $\mathrm{T}$ versus creatine kinase-MB for risk stratification in a chest pain evaluation unit. Am J Cardiol. 2000;85:801-5.

70. Kontos MC, Shah R, Fritz LM, Anderson P, Tatum JL, Ornato JP, et al. Implication of different cardiac troponin I levels for clinical outcomes and prognosis of acute chest pain patients. J Am Coll Cardiol. 2004;43:958-65.

71. Simoons ML. Effect of glycoprotein Ilb/llla receptor blocker abciximab on outcome in patients with acute coronary syndromes without early coronary revascularization: the GUSTO IV-ACS randomised trial. Lancet. 2001;357:1915-24.

72. Randomized trial of intravenous heparin versus recombinant hirudin for acute coronary syndromes. The Global Use of Strategies to Open Occluded coronary arteries (GUSTO) Ila Investigators. Circulation. 1994;90:1631-7.

73. Lindahl B, Venge $P$, Wallentin $L$. Relation between troponin $T$ and the risk of subsequent cardiac events in unstable coronary artery disease. The FRISC study group. Circulation. 1996; 93:1651-7.

74. Antman, EM. Troponin measurements in ischemic heart disease: more than just a black and white picture. J Am Coll Cardiol. 2001;38:987-90.

75. Roger VL, Killian JM, Weston SA, Jaffe AS, Kors J, Santrach PJ, et al. Redefinition of myocardial infarction: prospective evaluation in the community. Circulation. 2006;114:790-7.

76. Saenger AK, Jaffe AS. Requiem for a heavyweight: the demise of creatine kinase-MB. Circulation. 2008;118:2200-6.

77. Melanson SEF, Tanasijevic MJ, Jarolim P. Cardiac troponin assays. A view from the clinical chemistry laboratory. Circulation. 2007;116:e501-4. 
78. Newby LK, Roe MT, Chen AY, Ohman EM, Christenson RH, Pollack CV, et al. Frequency and clinical implications of discordant creatine kinase-MB and troponin measurements in acute coronary syndromes. $J$ Am Coll Cardiol. 2006;47:312-8.

79. Goodman SG, Steg PG, Eagle KA, Fox KAA, López-Sendon J, Montalescot G, et al. The diagnostic and prognostic impact of the redefinition of acute myocardial infarction: lessons from the Global Registry of Acute Coronary Events (GRACE). Am Heart J. 2006;151:654-60.

80. Rao SV, Ohman EM, Granger CB, Armstrong PW, Gibler B, Christenson RH, et al. Prognostic value of isolated troponin elevation across the spectrum of chest pain syndromes. Am J Cardiol. 2003;91:936-40.

81. Apple FS, Jesse RL, Newby K, Wu AHB, Christenson RH. National Academy of Clinical Biochemistry Laboratory Medicine Practice Guidelines: clinical characteristics and utilization of biochemical markers in acute coronary syndromes. Clin Chem. 2007;53:547-51.

82. Morrow DA, Cannon CP, Jesse RL, Newby LK, Ravkilde J, Storrow AB, et al. National Academy of Clinical Biochemistry Laboratory Medicine Practice Guidelines: clinical characteristics and utilization of biochemical markers in acute coronary syndromes. Circulation. 2007;115:e356-75.

83. Kavsak PA, MacRae AR, Lustig V, Bhargava R, Vandersluis R, Palomaki GE, et al. The impact of the ESC/ACC redefinition of myocardial infarction and new sensitive troponin assays on the frequency of acute myocardial infarction. Am Heart J. 2006;152:118-25.

84. Higgins JP, Higgins JA. Elevation of cardiac troponin I indicates more than myocardial ischemia. Clin Invest Med. 2003;26:133-47.

85. Tate JR, Heathcote D, Koerbin G, Thean G, Andriske D, Bonar J, et al. The harmonization of cardiac troponin I measurement is independent of sample time collection but is dependent on the source of calibrator. Clin Chim Acta. 2002;324:13-23.

86. Hamm CW, Goldmann BU, Heeschen C, Kreymann G, Berger J, Meinertz T. Emergency room triage of patients with acute chest pain by means of rapid testing for cardiac troponin T or troponin I. N Engl J Med. 1997;337:1648-53. 
87. van Domburg RT, Cobbaert C, Kimman GJ, Rainer Zerback, Simoons ML. Longterm prognostic value of serial troponin $\mathrm{T}$ bedside tests in patients with acute coronary syndromes. Am J Cardiol. 2000;86:623-7.

88. Cannon CP, Weintraub WS, Demopoulos LA, Vicari R, Frey MJ, Lakkis N, et al. Comparison of early invasive and conservative strategies in patients with stable coronary syndromes treated with the glycoprotein Ilb/llla inhibitor tirofiban. $N$ Engl J Med. 2001;344:1879-87.

89. Oltrona L, Ottani F, Galvani M, Italian Working Group on Atherosclerosis, Thrombosis, and Vascular Biology and the Associazione Nazionale Medici Cardiologi Ospedalieri (ANMCO). Clinical significance of a single measurement of troponin-I and C-reactive protein at admission in 1773 consecutive patients with acute coronary syndromes. Am Heart J. 2004;148:405-15.

90. James SK, Lindahl B, Armstrong P, Califf R, Simoons ML, Venge P, et al. A rapid troponin I assay is not optimal for determination of troponin status and prediction of subsequent cardiac events at suspicion of unstable coronary syndromes. Intern J Cardiol. 2004;93:113-20.

91. Gale CP, Metcalfe E, West RM, Das R, Kilcullen N, Morrell C, et al. An assessment of the concentration-related prognostic value of cardiac troponin I following acute coronary syndrome. Am J Cardiol. 2011;108:1259-65.

92. Waxman DA, Hecht S, Schappert J, Husk G. A model for troponin I as a quantitative predictor of in-hospital mortality. J Am Coll Cardiol. 2006;48:1755-62.

93. Jaffe AS. How low can you go if you can see the rise? [editorial]. J Am Coll Cardiol. 2006;48:1763-4.

94. Pope JH, Aufderheide TP, Ruthazer R, Woolard RH, Feldman JA, Beshansky $\mathrm{JR}$, et al. Missed diagnoses of acute cardiac ischemia in the emergency department. N Engl J Med. 2000;342:1163-70.

95. Singer AJ, Ardise J, Gulla J, Cangro J. Point-of-care testing reduces length of stay in emergency department chest pain patients. Ann Emerg Med. 2005;45:587-91.

96. Jaffery Z, Nowak R, Khoury N, Tokarski G, Lanfear DE, Jacobsen G, et al. Myoglobin and troponin I elevation predict 5-year mortality in patients with 
undifferenciated chest pain in the emergency department. Am Heart J. 2008;156:939-45.

97. Fox KAA, Birkhead J, Wicolx R, Knight C, Barth J. British Cardiac Society Working Group on the definition of myocardial infarction. Heart. 2004;90:603609.

98. Das R, Kilcullen N, Morrell C, Robinson MB , Barth JH, Hall AS. EMMACE-2 Investigators. The British Cardiac Society Working Group definition of myocardial infarction: implications for practice. Heart. 2006;92:21-6.

99. Mills NL, Churchhouse AMD, Lee KK, Anand A, Gamble D, Shah ASV, et al. Implementation of a sensitive troponin I assay and risk of recurrent myocardial infarction and death in patients with suspected acute coronary syndrome. JAMA. 2011;305:1210-6.

100. Melanson SEF, Morrow DA, Jarolim P. Earlier detection of myocardial injury in a preliminary evaluation using a new troponin I assay with improved sensitivity. Am J Clin Pathol. 2007;128:282-6.

101. White HD. Will new higher-precision troponins lead to clarity or confusion? Curr Opin Cardiol. 2008;23:292-5.

102. Keller T, Zeller T, Peetz D, Tzikas S, Roth A, Czyz E, et al. Sensitive troponin I assay in early diagnosis of acute myocardial infarction. $N$ Engl $J$ Med. 2009;361:868-77.

103. Reichlin T, Hochholzer W, Bassetti S, Steuer S, Stelzig C, Hartwiger S, et al. Early Diagnosis of myocardial infarction with sensitive cardiac troponin assays. $N$ Engl J Med. 2009;361:858-67.

104. Morrow DA, Scirica BM, Karwatowska-Prokopczuk E, Murphy SA, Budaj A, Varshavsky S, et al. Effects of ranolazine on recurrent cardiovascular events in patients with non-ST-elevation acute coronary syndromes. The MERLIN-TIMI 36 Randomized Trial. JAMA. 2007;297:1775-83.

105. Venge $\mathrm{P}$, Johnston $\mathrm{N}$, Lindahl B, James S. Normal plasma levels of cardiac troponin I measured by the high-sensitivity cardiac troponin I access prototype assay and the impact on the diagnosis of myocardial ischemia. J Am Coll Cardiol. 2009;54:1165-72. 
106. Hollander JE. Highly sensitive troponins. The answer or just more questions? J Am Coll Cardiol. 2009:54:1173-5.

107. Eagle KA, Lim MJ, Dabbous OH, Pieper KS, Goldberg RJ, Van de Werf F, et al. A validated prediction model for all forms of acute coronary syndrome: estimating the risk of 6-month postdischarge death in an international registry. JAMA. 2004;291:2727-33.

108. Boersma E, Pieper KS, Steyerberg EW, Wilcox RG, Chang WC, Lee KL, et al. Predictors of outcome in patients with acute coronary syndromes without persistent ST-segment elevation. Results from an international trial of 9461 patients. The PURSUIT Investigators. Circulation. 2000;101:2557-67.

109. Braunwald E, Jones RH, Mark DB, Brown J, Brown L, Cheitlin MD, et al. Diagnosing and managing unstable angina. Agency for Health Care Policy and Research. Circulation. 1994;90:613-22.

110. Killip T, Kimball JT. Treatment of myocardial infarction in a coronary care unit. A two year experience with 250 patients. Am J Cardiol. 1967;20:457-64.

111. Pereira JCR. Bioestatística em outras palavras. São Paulo: EDUSP; 2010.

112. Armitage P, Berry G. Statistical methods in medical research. 3.ed. Oxford: Blackwell Science; 1994.

113. Siegel S, Castellan Jr NJ. Non parametric statistics for the behavioral science. 2.ed. New York: McGraw-Hill; 1988.

114. Zou KH, O'Malley AJ, Mauri L. Receiver-Operating Characteristic Analysis for Evaluating Diagnostic Tests and Predictive Models. Circulation. 2007;115:654-7.

115. Ohman EM, Granger CB, Harrington RA, Lee KL. Risk stratification and therapeutic decision making in acute coronary syndromes. JAMA. 2000;284:876-8.

116. dos Santos ES, Timerman A, Baltar VT, Castillo MTC, Pereira MP, Minuzzo L, Piegas LS. Escore de Risco Dante Pazzanese para Síndrome Coronariana Aguda sem Supradesnivelamento do Segmento ST. Arq Bras Cardiol. 2009;93:43-351. 
117. Fox KM. European Trial on Reduction of Cardiac Events with Perindopril in Stable Coronary Artery Disease Investigators. Efficacy of perindopril in reduction of cardiovascular events among patients with stable coronary artery disease: randomised, double-blind, placebo controlled, multicentre trial (the EUROPA study). Lancet. 2003;362:782-8.

118. Domanski MJ, Fowler SE, Geller NL, Gersh BJ, Hsia J, Pfeffer MA, et al, PEACE Trial Investigators. Angiotensin-converting-enzyme inhibition in stable coronary artery disease. N Engl J Med. 2004;351:2058-68.

119. Dagenais GR, Pogue J, Fox K, Simoons ML, Yusuf S. Angiotensin convertingenzyme inhibitors in stable vascular disease without left ventricular systolic dysfunction or heart failure: a combined analysis of three trials. Lancet. 2006;368:581-8.

120. White HD. Should all patients with coronary disease receive angiotensin converting-enzyme inhibitors? Lancet. 2003;362:755-7.

121. Kennon S, Barakat K, Hitman GA, Price CP, Mills PG, Ranjadayalan K, et al. Angiotensin-converting enzyme inhibition is associated with reduced troponin release in non-ST elevation acute coronary syndromes. J Am Coll Cardiol. 2001;38:724-8.

122. The Acute Infarction Ramipril Efficacy (AIRE) Study Investigators. Effect of ramipril on mortality and morbidity of survivors of acute myocardial infarction with clinical evidence of heart failure. Lancet. 1993;342:821-8.

123. Kober L, Torp-Pedersen C, Carlsen JE, Bagger H, Eliasen $\mathrm{P}$, Lyngborg K, et al. A clinical trial of the angiotensin-converting enzyme inhibitor trandolapril in patients with left ventricular dysfunction after myocardial infarction. Trandolapril Cardiac Evaluation (TRACE) Study Group. N Engl J Med. 1995;333:1670-6.

124. Pfeffer MA, Braunwald E, Moye LA, Basta L, Brown EJ Jr, Cuddy TE, et al. Effect of captopril on mortality and morbidity in patients with left ventricular dysfunction after myocardial infarction: results of the survival and ventricular enlargement trial. The SAVE Investigators. N Engl J Med. 1992;327:669-77.

125. Shariff N, Dumbar C, Matsumura ME. Relation of pre-event use of inhibitors of the renin-angiotensin system with myocardial infarct size in patients presenting with a first ST-segment elevation myocardial infarction. Am J Cardiol. 2010;106:646-9. 
126. Milonas C, Jernberg T, Lindbach J, Agewall S, Wallentin L, Stenestrand U, for the RISK-HIA Group. Effect of angiotensin-converting enzyme inhibition on oneyear mortality and frequency of repeat acute myocardial infarction in patients with acute myocardial infarction. Am J Cardiol. 2010;105:1229-34.

127. Singh SM, Goodman SG, Yan RT, Dery JP, Wong GC, Gallo R, et al, for the Canadian GRACE, GRACE2 and CANRACE Investigators. Relation between previous angiotensin-converting enzyme inhibitor use and in-hospital outcomes in outcomes in acute coronary syndromes. Am J Cardiol. 2012;109:332-6.

128. Hansen ML, Gislason GH, Kober L, Schramm TK, Folke F, Buch P, et al. Different angiotensin-converting enzyme inhibitors have similar clinical efficacy after myocardial infarction. Br J Clin Pharmacol. 2008;65:217-23.

129. Pilote L, Abrahamowicz M, Rodrigues E, Eisenberg MJ, Rahme E. Mortality Rates in Elderly Patients Who Take Different Angiotensin-Converting Enzyme Inhibitors after Acute Myocardial Infarction: A Class Effect? Ann Intern Med. 2004;141:102-12.

130. Shah AD, Arora RR. Tissue angiotensin-converting-enzyme inhibitors: are they more effective than serum angiotensin-converting enzyme inhibitors? Clin Cardiol. 2005;28:551-5. 